RACIAL DISPARITY IN POLICE KILLINGS:

AN ANALYSIS OF 2014 UNITED STATES LETHAL FORCE DATA

\author{
A Dissertation \\ presented to \\ the Faculty of the Graduate School \\ at the University of Missouri-Columbia
}

\author{
In Partial Fulfillment \\ of the Requirements for the Degree \\ Doctor of Philosophy in Public Affairs
}

By Michael Laughlin

PhD Candidate Truman School of Public Affairs, University of Missouri Author Note

I graciously acknowledge and thank the Horowitz Foundation (https://www.horowitzfoundation.org/2017) for their support for this project. The Horowitz Foundation's support and recognition, (including the Donald R. Cressey Award for Most Outstanding Project in Criminal Justice) were paramount to the completion of this project. 
(C) Copyright by Michael Laughlin, 2019

All Rights Reserved 
The undersigned, appointed by the dean of the Graduate School, have examined the dissertation entitled

\section{RACIAL DISPARITY IN POLICE KILLINGS: AN ANALYSIS OF 2014 UNITED STATES LETHAL FORCE DATA}

presented by Michael Laughlin,

a candidate for the degree of doctor of philosophy,

and hereby certify that, in their opinion, it is worthy of acceptance.

Professor Mary Stegmaier

Professor Charles Menifield

Professor Stephanie Potochnick

Professor Corey Webel

Professor Terrell Carter 


\section{Dedication}

I dedicate this project to the families of those who have died from the use of lethal force by law enforcement, and to the officers (https://www.odmp.org/) who have given their lives on duty and their surviving families (https://www.concernsofpolicesurvivors.org/). Any death is a loss. My hope is that this project will provide more answers as to why (and how) these deaths occur to promote a more informed discussion of this topic and lead us to truthful conversations around this topic and more effective policies, which may decrease deaths. 


\section{Acknowledgments}

This project would not have been possible without the love and support of my wife, Kasey, and our sons, Evan and Alex.

Thank you to my parents, Lynne and Harold, for your support, encouragement, and advice throughout my education.

Thank you to my advisers, Charles Menifield and Mary Stegmaier, for your continued support, and your invaluable feedback and advice during this project.

Thank you to Stephanie Potochnick, Corey Webel, and Terrell Carter for your feedback, advice, and willingness to serve with Charles and Mary on my dissertation committee. Thank you to Dr. Rich Beans for your feedback.

Thank you to Samantha Barnhart for your assistance.

Thank you Taryn Aldrich for your feedback and assistance.

Thank you for the work and hours put in by the administrators at KilledByPolice.net and other journalists and citizens who have dutifully tried to fill the governmental gap in information on the use of lethal force by law enforcement.

Thank you to Valentine Lamar, Lacy Peterson, Kendal Lowrey, Amber Letbetter, and Charles Parker, who aided Dr. Charles Menifield and me in the collection and construction of a new database: 2014: Intentional Lethal Force Data. 


\section{TABLE OF CONTENTS}

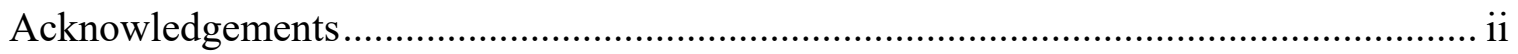

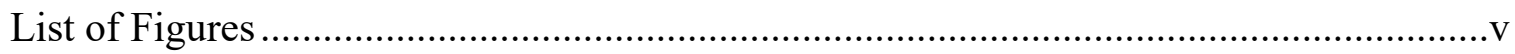

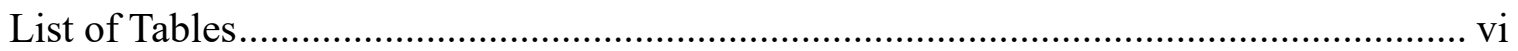

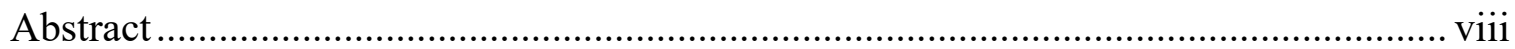

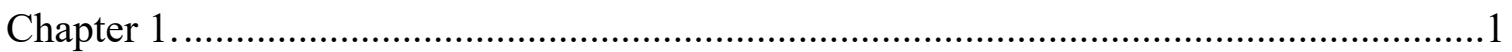

Introducing this Lethal Force Study and the U.S. Criminal Justice Context.......................1

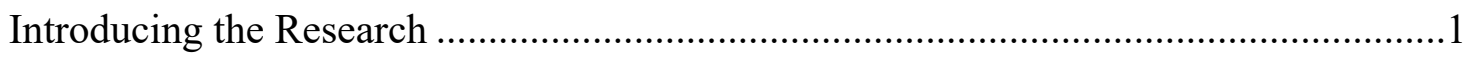

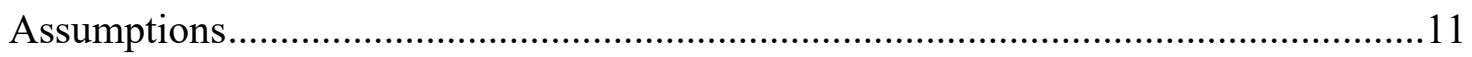

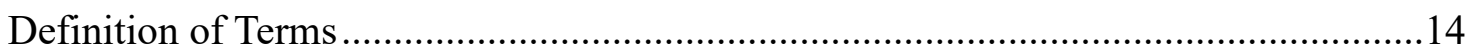

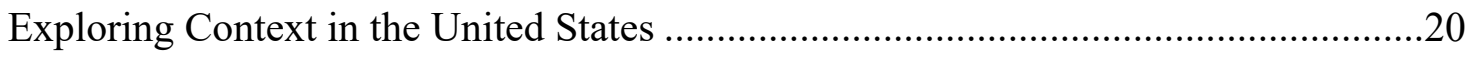

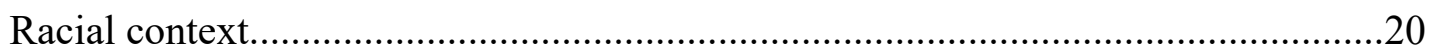

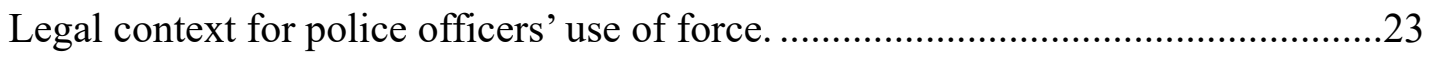

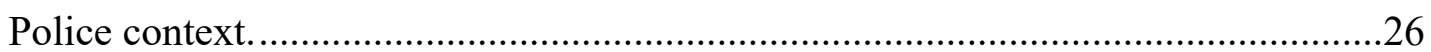

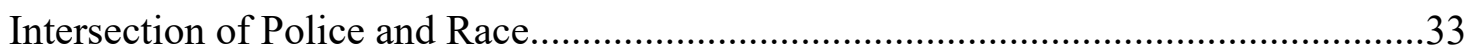

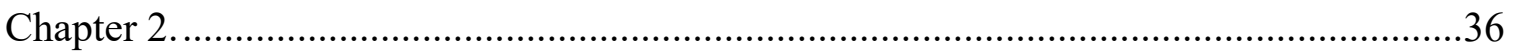

Prior Studies on U.S. Law Enforcement Use of Lethal Force ...........................................36

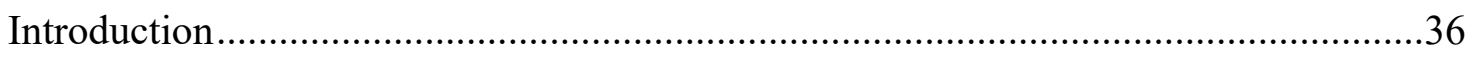

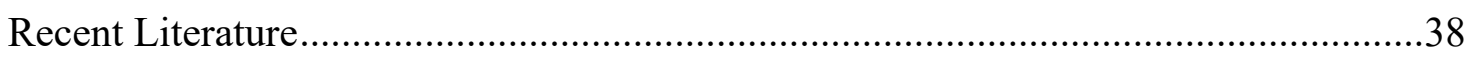

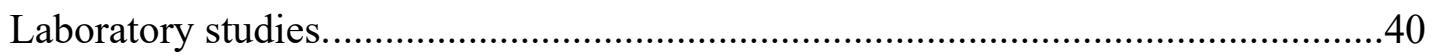

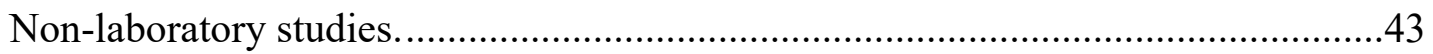

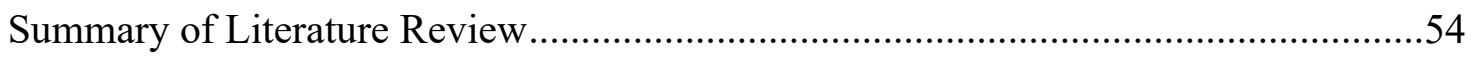

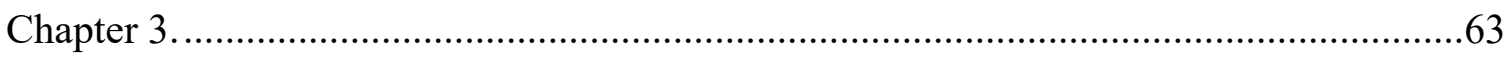

Methods: To create and explore the 2014: Intentional Lethal Force Data.........................63

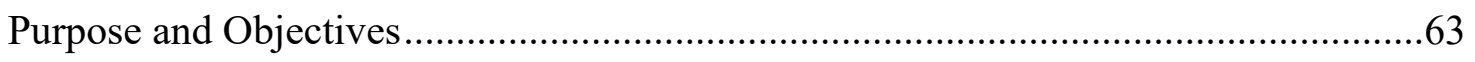

2014 Data: Creation and Description (Objectives 1, 2, and 3) ....................................64

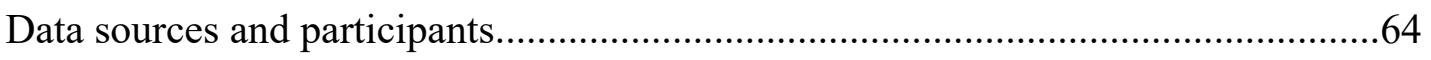

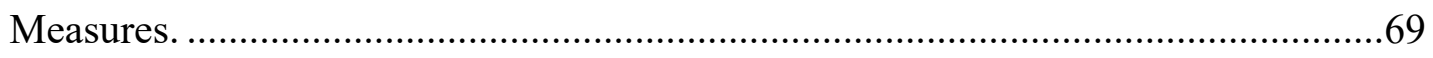

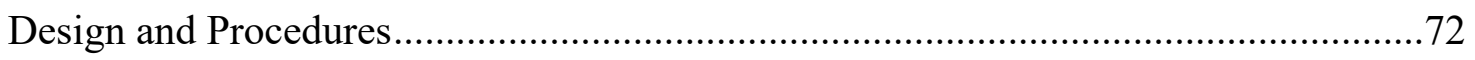

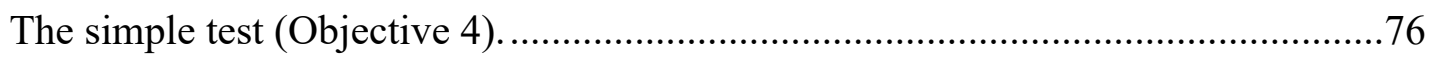

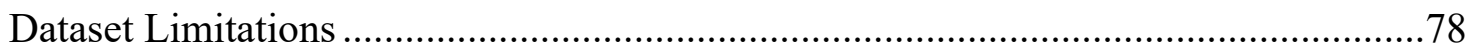

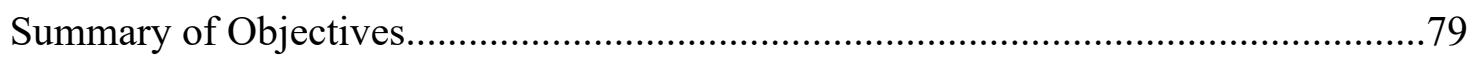

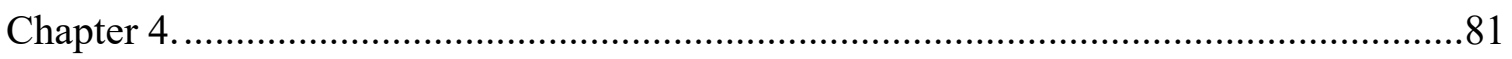

Findings: What Do the 2014: Intentional Lethal Force Data Show?................................81 


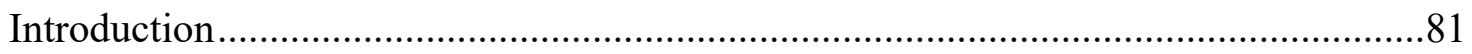

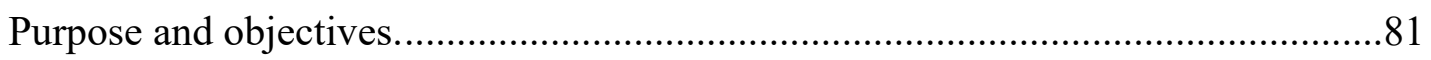

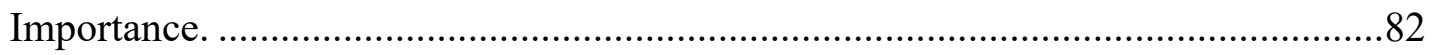

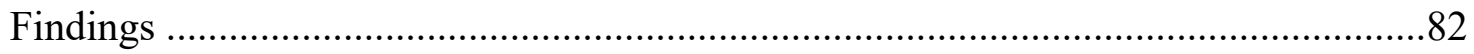

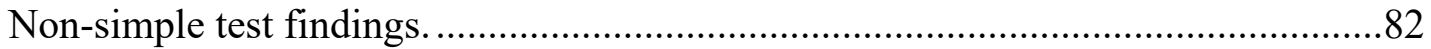

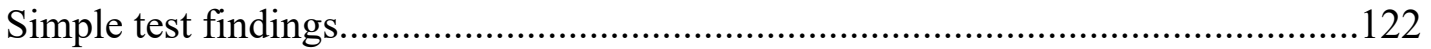

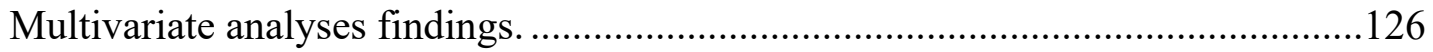

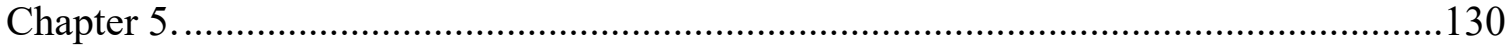

Discussion of Findings and Policy Implications............................................................130

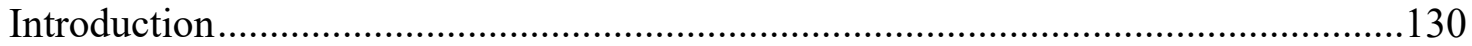

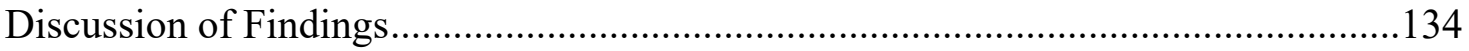

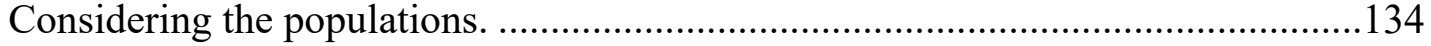

Police officer accountability measures. ..............................................................141

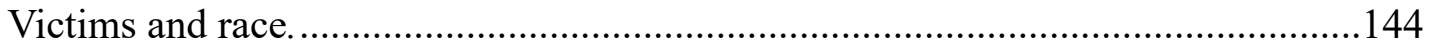

Discussion of findings related to the theoretical perspective....................................150

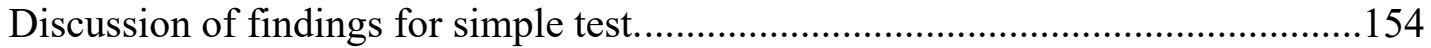

Discussion of findings for belief perspectives...................................................155

Discussion of findings for multivariate regression analyses....................................161

Contribution to Literature …….........................................................................162

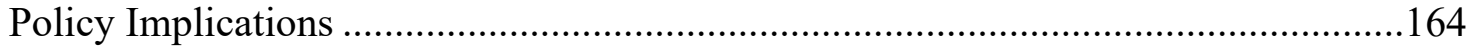

Recommendations from this research.................................................................164

Recommendations based on general literature. ………………............................169

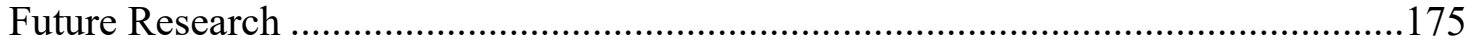

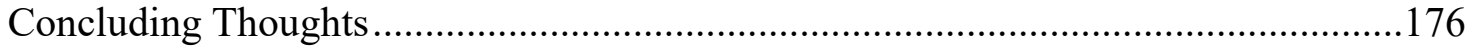

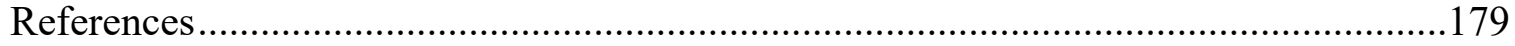

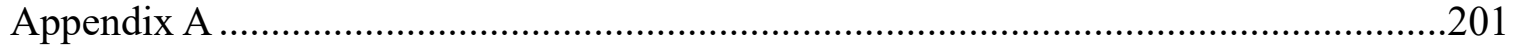

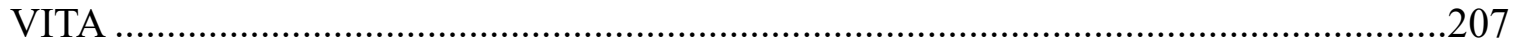




\section{List of Figures}

Figure 1. Lethal Force Incident Location (2014) ......................................................113

Figure 2. Time of Day When Lethal Force Victims Were Killed (2014).......................115

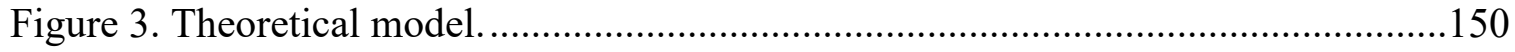




\section{List of Tables}

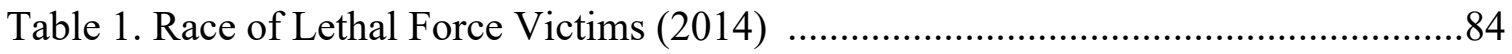

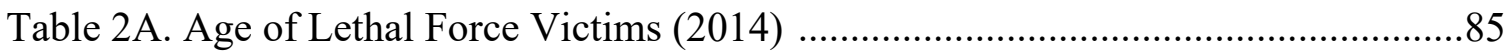

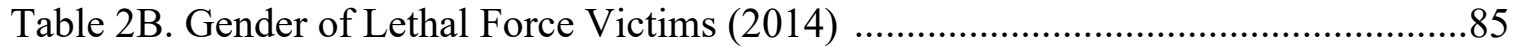

Table 3. Race of Officers Who Deployed Lethal Force (2014) ....................................86

Table 4. Race of Lethal Force Victim $\times$ Race of Officer (2014) ..................................88

Table 5A. Age of All Lethal Force Victims $\times$ Race of Officer $(2014)$...........................91

Table 5B. Age of African American Victims Killed by Lethal Force $\times$ Race of Officer (2014)

Table 5C. Age of Hispanic Victims Killed by Lethal Force $\times$ Race of Officer (2014) ....94

Table 5D. Age of Caucasian Victims Killed by Lethal Force $\times$ Race of Officer (2014)

Table 6. Lethal Force Victim Armed Versus Unarmed $\times$ Race (2014) .........................96

Table 7A. Lethal Force Victim Armed with Gun (or Not) × Race (2014) .....................97

Table 7B. Lethal Force Victim Armed with Gun and Aimed Gun (or Not) $\times$

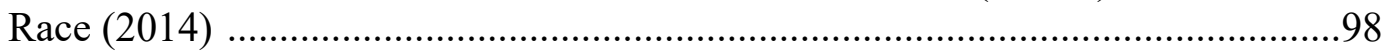

Table 7C. Lethal Force Victim Armed with Gun and Shot Gun (or Not) $\times$ Race (2014)

Table 8. Race of Lethal Force Victim $\times$ Race of Police Chief/Sheriff (2014) ...............101

Table 9. Race of Lethal Force Victim $\times$ Race of Community Mayor (2014) .................102

Table 10. Presence of Non-Police Witness $\times$ Race of Lethal Force Victim (2014) .......103

Table 11. Type of Call: Violence Likely or Not $\times$ Race of Lethal Force Victim (2014) 105

Table 12A. Lethal Force Victims by U.S. Region (2014) ........................................110

Table 12B. Race of Lethal Force Victim by U.S. Region (2014) ................................110

Table 12C. Caucasian v. Non-Caucasian Victims by Region (2014) ...........................111 
Table 13B. Race of Lethal Force Victim $\times$ Location Type (2014)

Table 14B. Race of Lethal Force Victim $\times$ Time of Day (2014) ..................................115

Table 15A. Officer Experience in Years (2014) .........................................................117

Table 15B. Race of Lethal Force Victim $\times$ Officer Experience (2014) …......................117

Table 16A. Zip Code Diversity (2014) .....................................................................118

Table 16B. Race of Lethal Force Victim $\times$ Zip Code Diversity (2014) …....................119

Table 17A. Officers' Use of Lethal Force by Zip Code Income Level (2014) ..............121

Table 17B. Race of Lethal Force Victim $\times$ Zip code Income Level (2014) …................121

Table 18. Simple Test (S.T.): Armed vs. Unarmed $\times$ Race of Lethal Force Victim and Race of Officer (2014) …………………....................................................124

Table 18A. African American Officers (2014) .........................................................124

Table 18B. Caucasian Officers (2014) …………………........................................124

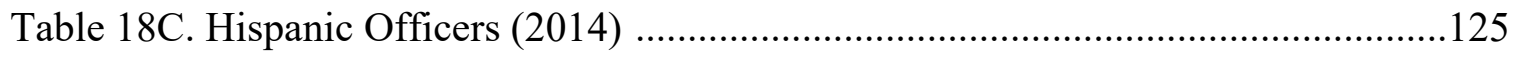

Table 18D. Asian Officers (2014) ……………………….....................................125

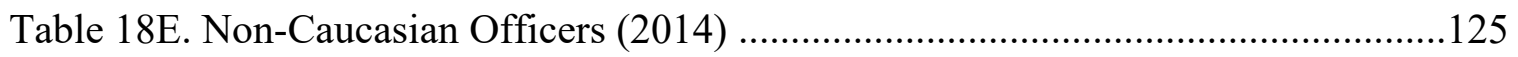

Table 18F. Cau. Officer/Non-Cau. Officer $\times$ Proportion Unarmed Victims by Race ....126

Table 19. Testing the Theories (Belief Perspective 1, Belief Perspective 2, Situational Perspective, and Simple Test (unarmed not included due to missing observations) 


\section{ABSTRACT \\ RACIAL DISPARITY IN POLICE KILLINGS: AN ANALYSIS OF 2014 U.S. \\ LETHAL FORCE DATA.}

Michael Laughlin

The main purpose of this research is to create a reliable database concerning law enforcement use of lethal force and employ this database to evaluate whether evidence exists that the decision to use lethal force is impacted by micro-level (officer) race-based considerations. A new database of all lethal force incidents in the U.S. in 2014 was created using 2014: Killed by Police Data and several other websites: 2014: Intentional Lethal Force Data (Menifield \& Laughlin, 2018). African American victims were overrepresented and Caucasian victims were underrepresented in police officers' use of lethal force.

However, this database and analysis provide no evidence of micro-level discriminatory decision making in the deployment of lethal force by law enforcement. Further, findings do not support the argument that the decision to use lethal force by law enforcement in the U.S. is influenced by race. This research calls into question a number of prevoiusly held assumptions when exploring racially disparate outcomes in lethal force; i.e. these data show greater support for factors external to law enforcement (as opposed to internal) as contributors to disparate outcomes, and questions whether population proportion should be the comparison point for law enforcement use of lethal force.

Keywords: Law Enforcement, Lethal Force, Use of Force, Racial Discrimination, Policing, Criminal Justice Reform, Criminal Justice Policies, Police, Racial Disparity 


\section{Chapter 1.}

\section{Introducing Lethal Force Study and the U.S. Criminal Justice Context}

\section{Introducing the Research}

The primary purpose of this study is to identify causes of the apparent disparity in law enforcement officers' use of lethal force. The study expands available data and analyses used to examine racial disparities in police killings. The results of this study can facilitate a better understanding of the factors contributing to these disparities. Available data were expanded upon by creating a new database from 2014: Killed by Police Data (https://killedbypolice.net/kbp2014/) and several other websites, resulting in the creation of 2014: Intentional Lethal Force Data (Menifield \& Laughlin, 2018). The database presents new characteristics about the people and circumstances surrounding the use of lethal force, offering improved specificity compared to prior databases. Additionally, the final chapters of this dissertation present an analysis of this new database to reveal pertinent information about these lethal force incidents.

The U.S. criminal justice system has long been a target of criticism regarding its mistreatment of African Americans (Potter, 1995). Today, African Americans are overrepresented in incarceration and arrest rates and in use of force compared to their proportion of the U.S. population (Western, 2006). African Americans are also overrepresented as victims of the use of lethal force in law enforcement (Chaney \& Robertson, 2015; DeGue, Fowler, \& Calkins, 2016; Fryer, 2016; Fyfe, 1982, 1988; Goldkamp, 1976; Gross, 2015; Klinger, 2012; Menifield, Shin, \& Strother, 2019; Miller, 2015). One-quarter of African American men can expect to be incarcerated in their 
lifetime (Brazzell, Crayton, Mukamal, Solomon, \& Lindahl, 2009); they are incarcerated at a rate of 2,290 per 100,000 (Mauer \& King, 2007; Western, 2006). Comparatively, the incarceration rate among Caucasian men is merely 412 per 100,000 (Mauer \& King, 2007; Western, 2006). These disparities are particularly evident given that the U.S. is home to the most extensive criminal justice system in the world (Brazzell et al., 2009; Western, 2006).

Research has revealed two primary perspectives regarding causes of discrepant outcomes in policing and officers' use of lethal force (see Appendix A) (Goldkamp, 1976):

- Belief Perspective 1 argues that minority overrepresentation in police killings results from differential police practices. According to this viewpoint, the disparities stem from variations in police organizations, practices, or police officers' beliefs about race. Studies by Chaney and Robertson (2015), Gross (2015), and Moore, Robinson, and Adedoyin (2016) support this perspective.

- Belief Perspective 2 contends that minority overrepresentation in police killings is due to factors external to police organizations. According to this view, police are "utility maximizers" (Fryer, 2016, p. 2). Any disparity reflects the overrepresentation of minorities in violent crimes and violent situations, which may be due, at least in part, to other social inequities (various social inequities and external contributors apply). Work from Fryer (2016), Fyfe (1982), Fyfe (1988), Goldkamp (1976), Klinger (2012), Krapfl (2017), and Miller (2015) supports this perspective. 
These belief perspectives have been applied to explore disparities in policing for over 40 years. However, I do not believe that these perspectives represent a true dichotomy; rather, they have been used to assess disparate outcomes in policing and help researchers and analysts determine which policies to formulate. These two perspectives will be used to look at law enforcement use of lethal force to determine whether there is evidence that racial disparities are more likely due to internal policing decisions and policies, or other external factors within the U.S. Exploring these two perspectives will aide in determining whether there is evidence that racial disparities in law enforcement use of lethal force are a police officers' problem or a societal problem. These broad answers can also help to determine where money and policies should be applied to treat the racial disparate outcomes, which, is an important consideration, because funds and time are limited, and should be devoted to the areas that are most likely to successfully treat the racially disparate outcomes.

Another measure which will be used to consider whether there is evidence that the racially disparate outcomes are a policing problem or a societal problem is the situational perspective. The situational perspective in this paper is based on court decisions concerning law enforcement use of lethal force and will be used to explore whether it looks like lethal force is used in justifiable situations. The assumption is if law enforcement is primarily using lethal force in situations that the courts and public would deem justifiable, then it is less likely that law enforcement is using race as a factor in determining when to deploy lethal force. The Situational perspective is provided below and is also available in Appendix C. 


\section{Weapons}

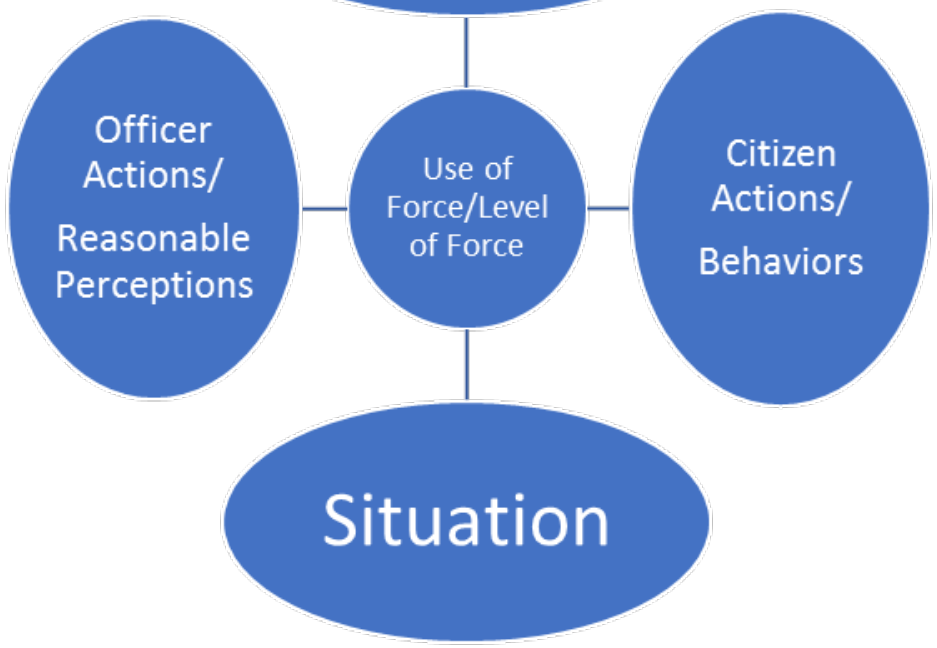

According to the situational perspective proposed in this paper, police officers' interactions can be evaluated on the basis of four components: (1) the officers (and their choices and costs); (2) citizens (and their choices and costs); (3) the nature of the police call (e.g., whether violence is likely); and (4) the presence or absence of weapons. Regarding the fourth point, law enforcement officers in the U.S. will inevitably carry weapons; therefore, the victor in every violent altercation involving a police officer has access to weapons. In other words, if a police officer loses control of a fight, then the officer's weapons become available to his/her adversary. These four components contribute to whether the judicial system justifies an officer's choice to use lethal force.

However, even if the majority of lethal force is deemed justified, in terms of African Americans' overrepresentation as victims of lethal force, Belief Perspectives 1 and 2 require further consideration. Explanations involving Belief Perspective 1 (i.e., disparities are due to internal factors in police departments [Goldkamp, 1976]) suggest that race affects officers' decision to use lethal force. Additionally, media narratives may 
influence beliefs that police officers are using lethal force to target non-Caucasian suspects, particularly young African American men (Menifield et al., 2019).

The media narrative of racial bias in policing is illustrated in articles when performing searches online for police lethal force. Some specific examples of articles highlighting this as a police and African American problem include an article from Reuters entitled "Factbox: U.S. police officers who kill unarmed black men often avoid criminal liability", the article then lists of incidents, in which unarmed black men were killed by police who did not receive criminal liability (Allen, Goldberg, Szekely, 2019). Another example from the Washington Post is entitled "What we've learned about police shootings 5 years after Ferguson", which begins point one with "1. Black Americans are disproportionately killed by police", "2. Black men are more likely to be fatally shot while unarmed", and "3. Most people killed by police are young men" (Fox, Blanco, Jenkins, Tate, Lowery, 2019). A third example is an article from the LA Times which highlights that African Americans are more likely to be killed by police, labels being killed by police a leading cause of death for young African American men, and provides a few specific examples of unarmed African Americans killed by police before moving on to more general information about lethal force, race, and gender (Khan, 2019).

Additional examples of the media narrative include a Journalist's Resource article which is discussing a research study, but the article begins by pointing out that African American men are 2.5 times as likely to be killed by police than Caucasian men; continues by providing more information to show that being killed by police is discrepant between Caucasians and African Americans, and then provides more information about the breadth of the problem and the lack of the data (Merrifield, 2019). Similarly, 
Santhanam's (2019) article is also describing findings from a research study, but the article begins by explaining that African American men still face the highest risk of being killed by police and then provides data on the risk of death from police to African Americans and then discusses other differences between African Americans and Causasians in their contacts with and perceptions of police. Finally, two broader examples are The Washington Post's "Black and unarmed" article and the Huffington Post's "Unarmed Black Man" webpage; both serve as summaries highlighting unarmed African American men who have been killed by police in the last several years (Somashekher, Lowery, Alexander, Kindy, Tate, 2015; Huffington Post, 2019); Menifield et al. (2019) noted that numerous studies have been conducted on police officers' use of lethal force; as of 2018, however, no research has resulted in a complete, yearlong dataset of police killings in the U.S. Even so, many sources have provided data on police killings (e.g., The Guardian (https://www.theguardian.com/usnews/series/counted-us-police-killings), the Washington Post (https://www.washingtonpost.com/graphics/national/police-shootings-2017/), U.S. Police Shooting Database (https://us-police-shootings-database.silk.co/), KilledByPolice.net, and the Lethal Force Database (http://lethaldb.silk.co/). However, many of these data sources rely on crowdsourced data or incomplete data sources. These sites' data and methods are inconsistent and have not necessarily been systematically evaluated (Degue et al., 2016; Fryer, 2016). Increasing the available data on police killings is important (Comey, 2015; DeGue et al., 2016; Fryer, 2016; Fyfe, 1988; Klinger, 2012; Menifield et al., 2019; COPS-USDOJ, 2015). Enhancing the availability and reliability of data on police killings may encourage more informed conversations and policy decisions, including within 
police organizations. Accordingly, a primary purpose of the present study is to leverage reliable empirical research to (a) determine whether race may influence police officers' (micro-level) decisions to use lethal force and (b) evaluate the characteristics related to officers' use of such force.

This study focuses on the use of force in law enforcement during the year 2014. The year 2014 was chosen for two reasons. First, use of lethal force in law enforcement became the focus of polarizing conversation following incidents in several cities, including Ferguson, MO; Baltimore, MD; and New York City. Related to some of these incidents, the year 2014 saw growing national recognition of social movements such as “Black Lives Matter" and "Hands up, don't shoot." Second, information on the use of lethal force in law enforcement is not released immediately. For example, at the onset of this study, data from 2016 or 2017 were not readily available. Law enforcement agencies can take up to a year to complete relevant investigations, which then often require up to an additional year before comprehensive data (e.g., outcomes following use of lethal force) can be released. Because the present project was intended to collect new data and establish a corresponding database, I (and a team of graduate research assistants working under Dr. Charles Menifield) needed substantial time to locate, record, and organize the data.

This study involved a multi-step process to construct an original database. First, data from KilledByPolice.net were examined regarding use of lethal force in law enforcement in the U.S. in 2014. Other scholars have referred to these data and found the information highly reliable (Fischer, Baum, \& Johri, 2014). KilledByPolice.net is a nongovernmental entity that tracks police killings reported in the news and updates its 
database as information becomes available about each incident. According to the site, researchers have spent more than 5 years and donated more than 25,000 hours to assembling the database for years 2013-2018 (recent years in progress). This database served as the foundational source for this study owing to the site's audited reliability (to be discussed further in Chapter 3). Additionally, each use-of-force incident on the site is linked to a news story containing pertinent information.

Data from KilledByPolice.net were cross-checked with the Lethal Force Database and Fatal Encounters (nongovernmental websites that collect data on the use of lethal force in law enforcement) to ensure data accuracy. According to Menifield et al. (2019), researchers studying the use of lethal force in law enforcement have also utilized these three datasets (e.g., Lott \& Moody, 2016; Nicholson-Crotty, Nicholson-Crotty, \& Fernandez, 2017). In many cases, data from KilledByPolice.net consisted of each victim's name and demographic information (race, age, date of birth, and gender); the date and time of the incident; and the city and state where the killing occurred along with a news account of the event. However, not all incidents included every such piece of information. Information from the Lethal Force Database and Fatal Encounters was paired with a content analysis of news accounts and governmental and nongovernmental websites to facilitate in-depth exploration of the use of lethal force in law enforcement in 2014.

These numerous information sources were consulted to establish a novel database in terms of detail, breadth, and depth. This database was then used to accomplish the second research objective: to describe the characteristics of police killings in the U.S. in 2014. The two belief perspectives, the situational perspective, and an exploration of 
micro, meso, and macro level factors will be used to explore the context of law enforcement use of lethal force and better understand how the characteristics in this database can help to better understand the racial disparities in law enforcement use of lethal force. Characteristics of these killings included the presence of a weapon (for the victim); the race of the officer, leadership (e.g., mayor and chief or sheriff), and victim; the victim's age; and a geographic description of the area based on zip code, and other characteristics which help to provide a better view of the context of law enforcement use of lethal force.

The 'presence of a weapon' characteristic was included as a means of determining the truth of the media narrative wherein unarmed African American men are thought to be frequent targets of lethal force (examples include: The Huffington Post's Unarmed Black Man webpage). The 'race of officer' characteristic was incorporated to examine the literature- and media-based narrative suggesting that Caucasian police officers are targeting African American men (examples include: Allen, Goldberg, Szekely, 2019; Fox, Blanco, Jenkins, Tate, Lowery, 2019; Khan, 2019; Merrifield, 2019; Santhanam, 2019; and Somashekher, Lowery, Alexander, Kindy, Tate, 2015, and the Huffington Post's Unarmed Black Man webpage). The 'race of leadership' characteristic reflects the literature concerning passive or active representation (Linn, 2006; Nicholson-Crotty et al, 2017; Wilkens, Williams, 2008; Xiao, Fu, Quinn, Tanaka, Pascalis, Lee, 2014). Characteristics pertaining to economic status and diversity are relevant to studies suggesting that a lack of diversity can lead to increased racial bias or reduced understanding of other races, whether by police or the general public and are helpful for testing whether there is evidence that these external factors are contributors to discrepant 
outcomes in lethal force. Further, the inclusion of zip code diversity may be helpful in evaluating racial threat theory, which hypothesizes that a higher proportion of minority members in a population will result in higher levels of social control by the dominant race (Enos, 2016). The 'race, gender, and age of victim' characteristics were included to investigate the literature- and media-based narrative that young African American men are primary targets in police killings, and as a comparison point for considering whether there is evidence that violent offending is related to lethal force.

The third research objective focuses on whether incident characteristics varied with the victim's race or ethnicity. Racial disparities in law enforcement officers' use of force and lethal force have been well established in the literature; therefore, this objective considers whether apparent differences emerged in the 2014 data on where, when, how, or why people were being killed based on race. The second, third, and fourth objectives will also all be tested using multi-variate analyses to consider if there is evidence that racially disparate outcomes are related to internal law enforcement causes, external societal causes, the factors related to the situational perspective, or micro-level race decisions by the officer.

The fourth research objective is intended to uncover potential evidence of (microlevel) racial discrimination in 2014 police killings data using a simple test. Anwar and Fang (2006), Fryer (2016), and Knowles, Persico, and Todd (2001) used the simple test to explore whether race is a factor in law enforcement actions. Fryer (2016) applied the simple test to explore discrimination in officer-involved shootings; specifically, this method was employed to 
investigate the fraction of Caucasian and African American suspects, separately, who are armed conditional upon being involved in an officer-involved shooting. If the ordinal threshold of shooting at an African American suspect versus a Caucasian suspect is different across officer races, then one could reject the null hypothesis of no discrimination. (p. 6)

In short, the simple test looks for differences by race in proportions of those armed or not between officer races.

\section{Assumptions}

Police interactions with African Americans have been framed negatively for several years, but even more so since 2014 (Ward \& Menifield, 2017). The media narrative surrounding police officers' use of lethal force may cause minorities to feel less safe in general and especially when confronted by police (Intravia, Wolff, Piquero, 2017; Graziano, Schuck, Martin, 2010). Considering the public purpose of police as peacekeepers and protectors, this media narrative may be causing substantial harm, especially if racial bias is not the cause of higher rates of lethal force for African Americans.

Presumably biased police behavior can erode citizens' trust in law enforcement, even in the absence of lethal force (Ward \& Menifield, 2017). If the media narrative that police target minorities is accurate, then such harm (i.e., lower trust and a reduced sense of safety) is understandable. Further, if this narrative is correct, then minorities should feel mistrustful and less safe when encountering police. However, if this narrative is incorrect (i.e., no racial motivation exists and most officers are not committing wrongdoing, even when using lethal force), then such misreporting will likely contribute 
to skewed outcomes. It is therefore necessary to consider how an unreliable narrative may influence disparities in victims killed by police.

A simple traffic stop exemplifies the potential effects of an inaccurate narrative. A traffic stop is the most frequent type of contact officers have with the public, constituting nearly half of all such contact (Bureau of Justice Statistics [BJS], 2018). However, officers are nearly as likely to be killed during a traffic stop as during arrest situations (Federal Bureau of Investigation Uniform Crime Reporting Program [FBI UCR], 2014). Properly trained officers will be highly alert at traffic stops; the individual being stopped could pose no threat or could intend to harm the officer or others. Because of this uncertainty, the police academy trains officers to remain vigilant when interacting with drivers and other vehicle occupants before and during traffic stops. When an officer observes someone behaving erratically, the person may be perceived as a potential threat. The person is not necessarily a threat, but the perceived difference could arouse suspicion from a trained officer. This perception, particularly when combined with a vehicle occupant's perception of fear towards the officer, may escalate fear among all involved.

A vehicle occupant's perception that a police officer may be a potential threat may be the beginning of a dangerous relationship between perceptions and stress at traffic stops. Although people may behave differently than expected when they are planning to attack or flee, they will also do so under high levels of stress. For example, a vehicle occupant who harbors no ill will towards an officer but has learned to distrust police may, out of fear or stress, act similarly to someone considering how best to attack and overcome an officer. Yet an officer may not necessarily ascertain why a vehicle occupant is behaving differently compared to the average person at a traffic stop; the officer will 
only perceive the behavioral discrepancy, regardless of whether the perceived threat is real or a result of stress. The officer may become concerned about safety upon witnessing the potential violator's behavior. The officer's tone of voice may then shift from conversational to confrontational, such as when loudly issuing orders. A vehicle occupant who is already frightened may perceive this tone as threatening, which will increase the occupant's stress and potentially erratic behavior compared to a non-stressed vehicle occupant.

As adrenaline and stress increase, the officer's and vehicle occupant's auditory and visual processing decline (Anderson et al., 2017). These sensory reductions can lead both parties to feel as though the other is not listening. Both parties may then experience a further decline in trust and feelings of safety, which could exacerbate the danger of a traffic stop. This chain of events may be spurred by a vehicle occupant's lack of trust and above-average fear of the officer, which in turn influences the officer's lack of trust and increased fear of the occupant.

The preceding example demonstrates how a vehicle occupant's lack of trust in police can compromise the nature of policing and the safety police are expected and strive to provide. Although this hypothetical consideration is not intended to absolve an officer of blame when killing a person by mistake, it is critical to consider an officer's intent. An officer of any color may kill a citizen of any color in error, without ill intent or willful malice. Further, differing levels of trust towards the police could lead to disparities in policing outcomes without intentional malice from officers.

Just as this hypothetical consideration is not intended to blame or absolve police, nor should it shift the blame to motorists in fear. Further, if an officer possessing implicit 
bias (i.e., assuming certain categories of people to be more dangerous, such as by race) performs a traffic stop, then the escalation of the preceding scenario could occur in reverse. In this case, the impetus for compounding danger would be the officer's implicit bias rather than the motorist's distrust or fear. Likewise, if an officer treats some members of the public more harshly than others, whether due to implicit bias or another reason, then the above scenario could change again. In this case, the impetus might be an officer's differential speech, racial profiling, or unequal treatment of a motorist (Carter, 2015; Voigt et al., 2017). The point being, that media narrative (correct or incorrect) has an effect on people's perception of police (Intravia et al., 2017; Graziano et al., 2010) and that perception (which may induce fear) is one of a number of factors that could affect outcomes between citizens and police.

\section{Definition of Terms}

Prior to progressing too far without a shared understanding of some concepts, it is necessary to first pause, and provide my understanding of some concepts which will be used in this dissertation. To ensure consistent understanding, the following terminology and definitions are applied throughout this dissertation:

Becker's (1974) economic theory of criminal behavior. Becker's theory is a hedonistic cost-benefit analysis related to the choice to commit crime. More specifically, the theory focuses on how differences in wealth and opportunity can alter perceptions of crime among individuals of different socioeconomic standing. For instance, when a person holding a well-paying job considers stealing, the cost-benefit analysis is more likely to prevent them from committing the crime compared with an unemployed or underemployed person whose basic needs are not met. 
Co-contamination. The 'dark side' of co-production (Loeffler \& Bovaird, 2019) in which most police contacts, particularly those related to violent crime, occur when police are sent to contact or check on a person rather than self-selecting who to target or contact. Theoretically, if implicit bias exists within the greater U.S. society, than that bias will bleed into police officer contacts (which are primarily due to citizen complaints), thereby leading to disparate outcomes even if police officers are not acting with explicit or implicit bias.

Discriminatory action. Discriminatory action occurs when a person is aware of their bias and acts differently towards certain groups based on preference. In policing, racial discrimination entails an officer acting differently (e.g., watching, contacting, stopping, ticketing, searching, using force, or arresting) based on suspects' race.

Disparate outcomes. Disparate outcomes are those that differ between groups. In policing, disparate outcomes may arise from various sources: racism or racial profiling, implicit bias among officers or reporters, overt racism, institutional/structural bias, or differences in offending.

Intentional lethal force. Police officers intentionally act in a manner that is likely to and does result in the death or serious physical injury of another person.

Implicit bias. Bias refers to a preference for or aversion to a particular group of people; biases are implicit if the possessor is unaware of them (Godsil \& Johnson, 2013). I believe that all people possess implicit bias, but not all implicit bias is based on race. Implicit bias is of particular concern in this dissertation because if an officer expresses implicit bias based on race, then they are unaware of their preference for or aversion to a group of people. An officer who believes they are treating people fairly may inadvertently 
behave differently towards certain people because of their race. Police officers must regularly participate in implicit bias training and consider their assumptions about, preferences for, and aversions to groups of people. Implicit bias is sometimes referred to as subtle/unconscious discrimination. Implicit bias can manifest from institutional/structural racism, statistical discrimination, or socialization.

Levels of racism. Racism and discriminatory actions exist at multiple levels, which are explored in this dissertation. Micro-level racism (i.e., discrimination/streetlevel racism) is individualized and refers to officers' personal actions. Meso-level racism is organizational and involves departments, precincts, neighborhoods, or zip codes and corresponding organizational policies and procedures. Macro-level racism is systemwide and considers policing as a field along with uniform laws, policies, and procedures.

Media influence. Many individuals obtain information about those who are different from them, policing, and crime from media outlets (Carter, 2019). In today's era of polarized media, where channels tailor their stories to their audience, the "media doesn't teach people anything new, but instead reinforces current prejudices" (Carter, 2019, p. 16).

Passive/active representation. Passive representation occurs when a person represents a group based on demographics (e.g., a higher proportion of African American officers would better represent this ethnicity in policing) (Wilkens, Williams, 2008). Active representation occurs when a person does not reflect a certain demographic, but their policies, laws, or beliefs result in positive outcomes for that group (e.g., an African American officer could support policies that benefit Caucasians or fail to benefit African Americans) (Wilkens, Williams, 2008). 
Police killings. Police intentionally deploy lethal force and it results in the death of the individual towards which the force was deployed.

Police racialization. Using race or racially distinct features (e.g., skin tone) to determine who is subject to police interaction or how those interactions will proceed (Carter, 2019); may also be referred to as police discrimination or racial profiling.

Putnam's (2016) concept of "airbags". The theory that parents with a college degree are more likely to have higher incomes and be able to afford lawyers and other societal 'airbags'; therefore, their children's poor behavior is less likely to result in longterm negative outcomes than for children from less educated families. Important to the context of this dissertation, is the fact that in the U.S., African American and Hispanic families are less likely to be college educated than Caucasian and Asian-American families.

Putnam's (2016) "Goodnight Moon time". The theory that parents with a college degree are more likely to spend time reading to or working on homework with their children compared to parents without a college degree. Putnam (2016) attributed this difference to parents without college degrees potentially working longer hours and more physically demanding jobs that result in greater fatigue. These parents may also be less likely to be able to pay for tutors or other educational support. Putnam (2016) argued that pre-K differences in one-on-one parent-child time elicits differences in children's elementary school educational outcomes.

Race. Racism and other important terms in this dissertation cannot be properly defined without first defining race. Race is a social construct (Clair and Denis, 2015). In different countries and periods, race has been defined using criteria other than skin tone 
(e.g., Hutu, Tutsi, and Ba-Twa). In the U.S., however, racial groups are primarily identified by skin tone. This simplistic categorization often leads to incorrect assumptions of ethnicity (examples include some people from the Dominican Republic being perceived as African American and some people from Cuba being perceived as Caucasian). According to Cornell and Hartman (2006, as cited in Clair \& Denis, 2015), ethnicity encompasses cultural practices, common history, and ancestry, which are more fluid than race. A common distinction between race and ethnicity is that race is often assumed to have a biological basis, which is incorrect (Clair \& Denis, 2015).

Racial bias. Preference for or aversion to a particular group of people based on race (Godsil \& Johnson, 2013). Racial bias can be overt, in which case a person realizes they possess a race-based preference or aversion, does not try to hide their bias, and acts upon it. Overt bias is otherwise known as intentional/explicit discrimination or racial profiling and can manifest from institutional/structural racism, statistical discrimination, or socialization. Covert bias involves awareness with personal attempts to hide the bias or discriminatory actions. Bias can also be implicit (i.e., unacknowledged but consequential).

Socioeconomic disparities. In the context of this dissertation, African Americans and Hispanics have remained in unfavorable positions throughout U.S. history in terms of income, wealth, education, and other factors (when compared to Caucasians and more recently, also Asian Americans).

Structural racism. This form of racism is derived from "nonhuman entities, such as social processes, social forces, and institutions. Rather than explaining racial inequality via individual (micro)-level racism (conscious or otherwise), theories of institutional 
racism give analytic primacy to the taken-for-granted policies, practices, and norms of organizations, systems and structures" (Clair \& Denis, 2015, 3.4). Structural racism is also known as institutional racism or systemic racism. All of these terms recognize that racism can exist in consequential ways outside of micro-level decision makers and individual actions. Evidence that structural racism is likely still impactful includes: The U.S. forced African Americans into slavery and later forced them to live in a separate and unequal society under Jim Crow laws based on skin tone. African Americans were also overrepresented in the War on Drugs, which targeted the poor. African Americans have thus been overrepresented among incarcerated individuals, and they continue to have lower educational and economic outcomes then Caucasians. Ongoing disparities in incarceration rates have exacerbated these poor outcomes. African Americans have also been inaccurately depicted as violent criminals and as being involved in violent situations (Oliver, 2003; Gilliam, Iyengar, Simon, \& Wright, 1996) or have been 'invisible' and underrepresented (Dixon \& Williams, 2014).

Utility maximizers. This perspective assumes that police do not deploy officers equally to all areas; for example, officers may be overrepresented in neighborhoods believed to have higher crime rates.

The preceding list summarizes pertinent terms in this dissertation, but there are additional assumptions that I hold, which influence my interpretation of the interactions between police and African Americans, which include the following:

- Overrepresentation of African Americans and other minorities among persons killed by police compared to the overall U.S. population. 
- Overrepresentation of African Americans and other minorities who are unarmed and killed by police based on media coverage of high-profile police killings.

- Overrepresentation of African Americans and other minorities among persons contacted, arrested, and incarcerated compared to the overall U.S. population. Assuming that African Americans are overrepresented among those killed by police, several important questions warrant exploration in an effort to clarify why this disparity exists. This study thus aims to construct and use reliable empirical research to shed light on such questions; Chapter 4 and 5 will discuss these questions and relevant findings in detail. However, before analyzing the data or considering the literature, the relationship between race and police officers' use of lethal force in the U.S. should be addressed further.

To understand the use of lethal force in the U.S., several factors must be considered. The first is race, including socioeconomic characteristics related to race, crime, and police officers' interactions with citizens. The second factor concerns the legality of officers' use of lethal force according to the U.S. Supreme Court's legal standards, and the third is police culture.

\section{Exploring Context in the United States}

Racial context. This dissertation focuses primarily on the relationship between African American men and police officers; the media's primary narrative surrounding the use of lethal force in law enforcement often highlights officers killing young African American men.

Mistreatment of African Americans has persisted throughout U.S. history (Potter, 1995). African Americans endured slavery followed by segregation (Fryer, 2016); today, 
they experience inequitable outcomes in an array of socioeconomic areas. Compared to other races in the U.S., a higher proportion of African Americans are born into lowincome families, and a higher proportion of low-income African American families are poor, earning incomes $200 \%$ below the poverty line (Simms, 2009). Further, African American families are more likely than families of other races to have no income earners in their household (Simms, 2009). The socioeconomic status of a child's parents at the child's birth can substantially shape his or her future (Alexander et al., 2014; Reeves \& Sawhill, 2014). In addition to suffering historical mistreatment in the U.S., one could assume based on research (Alexander et al., 2014; Putnam, 2016; Reeves \& Sawhill, 2014; Simms, 2009) that a higher percentage of African American children have a lower likelihood of future success compared to other races due to racial disparities in socioeconomic status at birth.

The criminal justice system has not been faultless in treatment of African Americans, particularly in the South, where disparate treatment of African Americans can be traced to police officers enforcing Jim Crow segregation laws and even to early slave patrols (Potter, 1995). With the passage of the U.S. Slave Act of 1850 and related state and local laws, police officers were legally required to return slaves from free states to the slave owners from whom they had fled—even in areas of the U.S. where slavery was not permitted (Rennison \& Dodge, 2018).

Disparate outcomes for African Americans in the criminal justice system have yet to be eradicated, and the consequences associated with these disparities have permeated societal outcomes for past offenders. The higher incarceration rate of African Americans in the U.S. has been particularly detrimental to African American men (Western, 2006). 
Incarceration has been shown to hinder past offenders' employment rates, income, and likelihood of avoiding future incarceration (Freeman, 2003; Mauer \& King, 2007; Western, 2006). Because the U.S. has the most extensive criminal justice system worldwide, a disparity within this system affects a greater number of people than the same disparity would in any other country. As of 2008 , for the first time in U.S. history, more than one in every 100 adults were incarcerated in either jail or prison (The Pew Charitable Trusts, 2008), and the prison population has remained comparably high since that year (Appendix A). Moreover, the incarcerated population only accounts for a portion of those who are "serving time" (Freeman, 2003). When including all persons in jail, or prison, or on probation or parole, an estimated 6.9 million persons of all races were supervised by the criminal justice system in 2013 (Federal Bureau of Prisons, 2013; Glaze \& Kaeble, 2014).

A large and increasing share of Americans are directly affected by incarceration due to the high incarceration rate and dramatic increase in the length of sentences in the U.S. over the last 20 years (Kling, 2006; Western, 2006). This shift is partially attributable to laws such as the 3 -strike system (Gilliard, 2018). The prison population has grown by nearly $500 \%$ since the 1970 s (Mauer \& King, 2007), yet incarceration is only one of many possible adverse outcomes of the criminal justice system for convicted offenders; options for offender punishments include fines, supervision, community service, incarceration, and loss of rights (Western, 2006). In the U.S., African American men continue to be much more susceptible to these adverse outcomes within the criminal justice system. 
Legal context for police officers' use of force. Adverse outcomes in the criminal justice system are not limited to those who are convicted. When confronted by the police, individuals who are suspected of crimes but who may not have committed an offense may experience adverse outcomes as severe as any court judgment, including death. A police officer's job requires use of force to control an unstable situation, detain suspects, or stop individuals in the midst of committing a crime (Klinger, 2012). Police officers can also use force to detain a person given reasonable suspicion that the individual has previously or is about to commit a crime (Klinger, 2012; Terry v. Ohio, 1968; U.S. Courts, 2017). Use of force is also necessary when placing persons into custody, most of whom would prefer not to be arrested. Officers can exert force through various means: verbal persuasion; manual techniques including strikes (hits or kicks); use of intermediate weapons (e.g., tasers, batons, pepper spray, or beanbag rounds); and lethal force (e.g., shooting, neck restraints, and vehicle collisions).

Just as the use of force is necessary for police officers to perform certain duties, deadly force is occasionally required (Klinger, 2012; Miller, 2015). The U.S. Supreme Court has ruled on how courts should evaluate the constitutionality and legality of police officers' use of force; for example, the Fourth Amendment requires all searches and seizures to be reasonable (U.S. Courts, 2017). The case of Graham v. Connor (1989) discussed how courts should evaluate individual instances of use of force (see Appendix B for further information on courts' evaluations of individual officers' use of force). In Tennessee v. Garner (1985), the U.S. Supreme Court ruled that officers could use deadly force to defend themselves or others and to arrest or detain a person who had committed or threatened to commit a crime that could have resulted in severe physical injury or 
death (Gross, 2015). Officers can only use deadly force (i.e., lethal force) to stop a person they reasonably believe to be an immediate or imminent threat (if not detained instantly) to the officer or another person. In this context, the U.S. Supreme Court defines 'reasonable' as what would be acceptable to a reasonable police officer of equal training with the same information as the officer in question at the time lethal force was deployed (see Appendix B for additional information). An immediate threat requires the threat of serious bodily injury or death; per the FBI, “'serious bodily injury' refers to an injury that carries a substantial risk of death, unconsciousness, protracted and obvious disfigurement, or protracted loss or impairment of the function of a bodily member, organ, or mental faculty" (FBI, n.d.).

Recent court decisions have allowed for mistaken officer perceptions that a suspect possesses a gun because officers must often make instantaneous decisions. In one case, a suspect had an audio player in his back pocket. When confronted by police with their weapons drawn, the man reached for the bulge in his back pocket, which police mistook for a firearm (Ross, 2013). They then fired at the unarmed suspect. The court decided the shooting was justified on the grounds that police need to make split-second choices. The court further ruled that officers do not need to wait until a firearm is pointed at them before they are entitled to shoot (Ross, 2013). In another case, police believed a cell phone was a gun because of the way the suspect presented the phone. The court again ruled in favor of the officers, noting that they were required to make

[a] split-second judgement in a circumstance which was tense, uncertain, and rapidly evolving. The court noted that the officers had articulable basis to believe that, based on [the victim] Hudspeth's behaviors, suddenly turning toward the 
officers and extending his arms with a cell phone as if to point a weapon. (Ross, 2013, pp. 93-94)

The court decided that officers had acted reasonably in perceiving Hudspeth as a threat; hence, the shooting was justified (Ross, 2013).

These officer misperceptions may be more likely in certain incidents. Honig and Lewinski provided the example of a suspect making "furtive movements as the officer perceives the suspect's motion; sees a dark-colored object of unidentified shape; and, based on the officer's prior experiences, expectations, and contextual cues, perceives a handgun and responds based on that perception" (as cited in Ross, 2013, p. 94). The courts have been clear that when these decisions must be made in seconds or milliseconds, the Constitution does not require officers to be absolutely certain of the need to act in self-defense, the perceived threat, or the suspect's intent in order to justify reasonable force (Ross, 2013). Essentially, due to the immediacy of the required response, grave accidents are allowable when based on reasonable perceptions. Yet the public tends not to view these misperceptions favorably, even if such decisions have been made in a split second.

Although the public recognizes deadly force as a necessary means for police officers to maintain public order, citizens may also fear such immense power and potential misuse thereof (Klinger, 2012). Police officers' use of deadly force has evoked social unrest many times over the past 50 years (Klinger, 2012). Recent examples include events in St. Louis, MO; New York; Baltimore, MD; and Cleveland and Cincinnati, $\mathrm{OH}$. Fortunately, however, officers' use of force is rare, and deadly force is even rarer (Fryer, 2016; Klinger, 2012; Miller, 2015). 
Despite the low frequency of use of force, some members of the public believe that police discriminately use force and deadly force depending on the suspect's race (Chaney \& Robertson, 2015; DeGue et al., 2016; Fryer, 2016; Fyfe, 1982, 1988; Goldkamp, 1976; Gross, 2015; Klinger, 2012; Miller, 2015; Moore et al., 2016). Two factors contributing to this belief are the media and available raw numbers concerning lethal force, namely the use of statistics without considering context. A cursory examination of media coverage of high-profile police killings had led many to believe that Caucasian police officers may target non-Caucasian suspects when exercising lethal force (Menifield et al., 2019). Additionally, compared to the overall population by race, data show that African Americans and Hispanics are overrepresented among those killed by police (Chaney \& Robertson, 2015; DeGue et al., 2016; Fryer, 2016; Fyfe, 1982, 1988; Gross, 2015; Goldkamp, 1976; Klinger, 2012; Menifield et al., 2019; Miller, 2015).

Police context. The raw numbers and media narrative of police killings often focus on two aspects - the race of those involved and whether the victim was armedwhile ignoring additional context. Along with examining the context of incidents more closely, the context of policing within the U.S. also warrants attention. It is first necessary to consider who is policing in the U.S. and how they are policing. The literature suggests that racial disparities are to be expected in police officers' deployment of lethal force (Chaney \& Robertson, 2015; DeGue et al., 2016; Fryer, 2016; Fyfe, 1982, 1988; Gross, 2015, Goldkamp, 1976; Klinger, 2012; Menifield et al., 2019; Miller, 2015; Moore et al., 2016); however, why such disparities exist is less clear. Micro-level (i.e., individual officer) racism or racial profiling (as described in Carter, 2015) was not found to be a cause of racial disparities in most studies according to my literature review. If micro-level 
(i.e., individual officer) racism is not the driving force behind racial disparities in officers' use of lethal force, then a combination of macro-level (i.e., systemwide or national) public policies and meso-level (i.e., organizational) police policies and practices could shape these disparities (Menifield et al., 2019).

Macro-level factors in criminal policy and policing have likely contributed to racial disparities in policing and the use of lethal force in law enforcement (Alexander, 2012; Menifield et al., 2019; Miller, 2015; Weaver, 2007). The "War on Drugs" is an example of Congress enacting laws that impose harsher punishments for drug offenders using substances most often abused by impoverished and minority populations (Gilliard, 2018; Provine, 2007); such regulations can lead to increased police contact, arrest, and incarceration of these populations. The disproportionate effects of these policies on races, together with the high rate of incarceration for African American men in the U.S. (Brazzell et al., 2009; Freeman, 2003; Mauer \& King, 2007; Western, 2006) and the U.S. police's history of being deployed to enforce racist laws and policies, yields greater African American mistrust of police, particularly among men (Carter; 2019; COPSUSDOJ, 2015; Enns, 2016; Menifield et al., 2019).

Research has also revealed meso-level contributors to racial disparities in outcomes from policing along with meso-level contributors to racial disparities in outcomes related to use of lethal force. Meso-level contributors include organizational use-of-force policies (formal and informal), including various methods to engage the population (i.e., suspects), and discrepancies in the extent and type of training police forces receive (Menifield et al., 2019). Examples include New York's stop-and-frisk implementation (Fryer, 2017; Menifield et al., 2019; Rennison \& Dodge, 2018) and 
investigative stops (Epp, Maynard-Moody, \& Hairder-Markel, 2017). Historical implicit bias and the stories told by the dominant U.S. population (i.e., Caucasian Americans) around policing also revolve around long-held fear and suspicion of African American men (Carter, 2019).

Additional examples of meso-level contributors from recent U.S. studies include the Department of Justice's investigation into the Ferguson Police Department following the killing of Michael Brown, which found "a pattern or practice of unlawful conduct": the department was targeting black residents for fees and fines, thus treating them as a source of "alternative revenue for the city" (DOJ, 2015, as cited in Menifield et al., 2019). Another study of traffic stops in the San Francisco Police Department revealed racial disparities in the department's stops, searches, and arrests of African Americans (Eterno et al., 2017, as cited in Menifield et al., 2019, p. 10; San Francisco Blue Ribbon Panel, 2016). Another unwritten meso-level contributor within law enforcement may be the police's "Code of Silence" (Carter, 2015).

Exploring police behavior. Overrepresentation of minorities in the use of lethal force and other disparities in policing may not require changing micro-level prejudice but may instead necessitate modifying the behaviors and policies derived from prejudice. When left unchecked, these macro- (i.e., system-level) and meso-policies could continue to have a cumulative effect of disproportionate policing of minorities that is passed down through generations. After all, the most significant predictor of a child offending is the incarceration of his/her parent (Siegel \& Welsh, 2017). When considering this problem, one cannot ignore the influence of existing policies and structures, as organizational rules and culture shape organizational members' job duties (Adams \& Balfour, 2015; Argyris, 
1999; Diamond \& Allcorn, 2009; Menifield et al., 2019; Schein, 2010; Wilkins \& Keiser, 2004). In law enforcement, organizational members' actions and behaviors can exert direct, long-term impacts on citizens (including citizens' children) and the public's overall perceptions of law enforcement.

Additionally, the type of training officers receive, regarding how to respond to perceived threats and how to interact with citizens and suspects, affects officers' likelihood of using force (Balko, 2014; Eterno et al., 2017; Lersch \& Mieczkowki, 2005; Menifield et al., 2019; Prenzler, Porter, \& Alpert, 2013). According to empirical studies, 0.01 seconds can be the difference between life and death for police officers, as evidenced by the reactionary gap. The reactionary gap describes the time it takes an officer to perceive an armed suspect's movement, interpret the action, decide on a response, and execute that response; this process typically takes longer than the armed suspect's shooting action (Blair et al., 2011). More specifically, highly trained police officers (S.W.A.T. personnel) encountered situations in which a suspect was visibly armed with a firearm (not pointed at officers) and would then sometimes, but not always, point the firearm and shoot at the officers (Blair et al., 2011. In these lab-like situations (without other officer distractions), police officers fired at the same time or later than the suspect $61 \%$ of the time. When the officer fired before the suspect, there was a less than 0.2-second difference between when the officer and suspect each fired (Blair et al., 2011). The authors noted that their findings were consistent with those of similar studies (e.g., Brebner \& Welford, 1980; Grossman \& Christensen, 2004; Honig \& Lewinski, 2008; Luce; 1986; Welchman et al., 2010). 
Notably, not all deaths at the hands of police officers are due to firearms. Some instances may not be considered intentional use of lethal force by police; rather, an officer's intentional use of lower force resulted in death. Conversely, any shooting by a police officer could be considered lethal force irrespective of whether death results; when police train, they train to stop the threat rather than kill the perpetrator. However, when police use firearms as force, their weapons are nearly always deployed in a manner consistent with lethal force: officers are trained to shoot center mass (typically at the target's chest) to stop a threat, which could easily result in death.

Accuracy is another important officer consideration when shooting, particularly in high-stress situations. Numerous studies have shown that officers hit their targets at a low percentage in perceived life-or-death situations. In a study of NYPD officers between 1998 and 2006, in circumstances where police shot at suspects, the officers hit their targets only $18 \%$ of the time; that percentage increased to $30 \%$ when the suspect did not return fire (Rostker, Hanser, Hix, Jensen, \& Morral, 2008). These hit rates are likely not due to poor training but to the effects of high stress on the human body. However, these low proportions highlight the importance of ensuring police officers are highly trained. Although training is a proven asset for officer safety (Ross, 2013), an unintended outcome of safe-operations training is potentially diminished officer trust of the public, which may increase the likelihood of officers feeling isolated from the public (Carter, 2019; COPS-USDOJ, 2015; Johnson, 2010).

Such isolation has been found to affect officers in several ways. Isolation and hypervigilance each contribute to officer suicide, a leading cause of death among police officers in the U.S. (Gilmartin, 2002). American police officers are about 2.5 times more 
likely to die from suicide than from homicide (COPS-USDOJ, 2015) and 5 times more likely to use their gun on themselves than in the line of duty (Campbell, Cataldi, McIntosh, \& Millet, 2004; Johnson, 2011). Dr. Dean Angelo, President of the Chicago Fraternal Order of Police, stated that "Police officers are constantly surrounded by misery, heartache, frustration, and disrespect" (Rufo, 2015, p. 57), yet most officers receive no training in hypervigilance or how to manage it or PTSD in their personal lives (Gilmartin, 2002). Hypervigilance refers to a physiological change in a person's body, namely indicated by an elevated stress level or elevated level of awareness (Gilmartin, 2002). Essentially, police training prepares on-duty officers to remain hypervigilant. Yet when officers leave the police department and enter the world, they may find themselves in the "law enforcement fishbowl" (original concept from Laughlin). In the fishbowl, officers' actions are scrutinized and can affect other officers; many people observe one officer's actions and apply them to all members of the police force. In Ferguson, MO and New York City in 2014, one officer's actions- and the public's perceptions thereof - contaminated the water in the fishbowl for all officers. Despite being trained to operate at a heightened level of awareness, officers might not realize how public perceptions of their actions may influence various aspects of their work (e.g., the reputation of all officers and how an officer feels about his/her work) or personal life. Apparently unfavorable public perceptions of police could increase the likelihood of officers isolating themselves from non-police in their personal lives.

Such heightened awareness coupled with cognizance of public perceptions of one's profession (leading to isolation) can contribute to what Gilmartin (2002) labeled the "hypervigilance roller coaster" (p. 47). Gilmartin describes the hypervigilance roller 
coaster in the following manner. Many police officers experience this roller coaster. When an officer is subjected to elevated stress for 8-12 hours a day, the officer's body spends that time operating outside its normal state. Rather than returning to homeostasis, the body responds by shifting to a low level of awareness and activity to compensate for the excess energy burned while on duty, hence the 'rollercoaster'. Off-duty officers may return home after a day at work to find a comfortable seat and cease all emotional and relational engagement, even to the point of being unable to make simple decisions about what to eat or do. Withdrawing into a state of hypovigilance (i.e., reduced awareness) can have detrimental effects on officers' relationships.

According to Gilmartin (2002), the human body takes 18-24 hours to recover from hypervigilance. However, within that period, officers generally return to work to restart the rollercoaster before achieving a state of normalcy. Gilmartin (2002) argues that over time, this cycle can have severe physical, emotional, psychological, and personal consequences. These effects apply regardless of role. For example, although a patrol officer may not bring work home as a detective would, that officer may still struggle to take advantage of time away from work; Weber (2013) suggested that officers may remain in the 'iron cage' even when at home. When police departments fail to address hypervigilance and self-imposed isolation among officers, these departments cannot effectively control work-imposed stressors and are presumably committing moral violence against officers (Diamond \& Allcorn, 2009). These emotional wounds can result in atypically high rates of divorce, alcohol abuse, cardiac arrest, and suicide among police (COPS-USDOJ, 2015; Gilmartin, 2002). 
The aggregate effects of ongoing stress can also influence officers' likelihood of using force (Bergland, 2013; Carter, 2019; COPS-USDOJ, 2015). Training and conditioning enhance individuals' ability to stay calm in high-stress situations (Bergland, 2013), but law enforcement training does not provide adequate stress management skills (Carter, 2019; COPS-USDOJ, 2015; Rufo, 2015). An officer who has not received ample training in stress management may experience negative effects related to citizenry, the organization, and his/her personal and family life (Gilmartin, 2002).

Some officers also have difficulty separating themselves from their organization or group (Diamond \& Allcorn, 2009), partially due to hypervigilance and isolation (Gilmartin, 2002). According to Gilmartin, this form of regression may explain why many officers describe themselves first as police officers and only identify with other officers. Their lives are distinct from those of non-police officers, and officers may find it difficult to separate themselves from their on-duty work. Police officers' training, hypervigilance, pointed media narratives, and negative interactions with the public lead many officers to assume an "us versus them" mentality, where "them" comprises all nonpolice officers (Gilmartin, 2002).

\section{Intersection of Police and Race}

The U.S. policing profession is not diverse; $89 \%$ of officers are men, $79 \%$ are Caucasian (Deloitte, 2017), and approximately $75 \%$ are Caucasian men (Ashkenas \& Park, 2015; Reaves, 2015). This racial and gender-based overrepresentation inherently influences use of lethal force; if African Americans are disproportionately killed by police, then they would presumably be disproportionately killed by Caucasian male officers simply because police departments have a higher proportion of such officers 
compared to the U.S. population. If less than $75 \%$ of officers using lethal force are Caucasian men, then these individuals should be considered as underrepresented in killing based on the proportion of police officers despite being overrepresented compared to the overall U.S. population.

This overrepresentation may also imply that the media narrative of Caucasian male police officers killing African Americans holds some truth; however, one cannot assume that this overrepresentation is racially motivated. The context in the U.S. is a double-edged sword. First, African American men are more likely to grow up in lowincome areas (Alexander et al., 2014; Reeves \& Sawhill, 2014; Simms, 2009) with high crime rates (Blau \& Blau, 1982; Harrell, Langton, Berzofsky, Couzens, \& SmileyMcDonald, 2014; USDOJ, 2015). Second, police departments and the criminal justice system have a history of policies that disproportionately target low-income and highcrime populations (Carter, 2019; COPS-USDOJ, 2015; Gilliard, 2018), and these factors would lead to greater police contact with African American men. One could argue that having a disproportionate number of police officers in high-crime areas is not a racial issue but a logical distribution of the police force based on crime rates. Even so, this unequal distribution suggests that African American men are more likely to encounter, be apprehended by, or feel targeted by police in high-crime areas. These outcomes could lead to lower trust among individuals living in heavily policed areas.

National conversations have also focused on the ages and genders of victims of officers' lethal force. In the criminology field, consistent evidence has shown that criminal activity is associated with gender and age. Men are more likely to commit violent crimes than women, and criminal activity tends to peak in the late adolescent or 
early adult years (Cornelius, Lynch, \& Gore, 2017; Ulmer \& Steffensmeier, 2014). In every crime (except gambling) reported by the FBI UCR, people under age 25 are the most frequent offenders (Ulmer \& Steffensmeier, 2014). These disparities in offending rates by gender and age show that these demographic characteristics should be considered when studying police killings.

Demographics, especially race and gender, deserve close attention in the context of officers' use of lethal force. When considering lethal force in law enforcement, one might assume that most officers using lethal force are Caucasian men simply because they comprise most of the police force (Ashkenas \& Park, 2015; Reaves, 2015). However, many studies and data on lethal force ignore population size. The demographics of population samples, including officers and the individuals they confront, are important to consider when examining officers' use of lethal force and will be further explored in Chapters 3, 4, and 5.

The remainder of this dissertation is organized as follows: Chapter 2 will provide a summary of the literature; Chapter 3 presents a description of the methodologies employed in this project; findings drawn from the 2014: Intentional Lethal Force Data appear in Chapter 4; and Chapter 5 presents a concluding discussion about the results from Chapter 4 and the overall findings of this dissertation. 


\section{Chapter 2.}

\section{Prior Studies on U.S. Law Enforcement Use of Lethal Force}

\section{Introduction}

This chapter opens by describing two explanatory perspectives on African Americans' overrepresentation among individuals killed by law enforcement. Then, I present a survey of recent literature pertaining to the use of lethal force in law enforcement. Relevant research includes laboratory studies evaluating the factors contributing to "shoot or don't" decisions, descriptive analyses of regional data, incomplete national data, and untested national data on officers' use of lethal force. By summarizing the major studies, this chapter highlights the need for the compilation and analysis of a national dataset on officers' use of lethal force.

Given that African Americans are grossly overrepresented among those killed by officers' (Chaney \& Robertson, 2015; DeGue et al., 2016; Fryer, 2016; Fyfe, 1982, 1988; Gross, 2015; Goldkamp, 1976; Klinger, 2012; Miller, 2015), it is necessary to evaluate why this is the case. A review of the literature reveals two widely accepted perspectives regarding racial disparities in use of force and lethal force by law enforcement (Goldkamp, 1976). Arguments related to Belief Perspective 1 (internal causes) contend that racial disparities in policing outcomes are caused by differential police practices or policies, these may be micro-level officer decisions, meso-level organizational policies and practices, or macro-level nationwide policies. Arguments related to Belief Perspective 2 (external causes) contend that racial disparities result from factors external to police organizations (e.g., external social inequities or societal problems). 
It is important to consider whether these disparate outcomes follow from problems within policing organizations or if societal factors are at play, in which case police are merely serving as "utility maximizers" (Fryer, 2016, p. 2). If disparities in deaths by lethal force is due to internal factors, then law enforcement should aim to address the problems within law enforcement that are driving such disparities. However, if these disparities are due to external factors, then these outcomes may merely reflect how U.S. society promotes disparate outcomes for people by race. It would then be necessary to advocate for equitable social outcomes (e.g., equal access to education and income), which could presumably diminish discrepant rates of arrest and police encounters. In this case, changes in policy and practice must occur outside of law enforcement agencies to lead to more equitable law enforcement contact based on race.

The objective, regardless of whether the causes of these disparities are internal or external, should be to minimize the use of lethal force by law enforcement agencies and reduce or eliminate mistaken, illegal, or unjustified use of deadly force. Police officers will need to apply lethal force in certain circumstances to fulfill their job duties; however, law enforcement should aim to minimize the number of people killed by officers. This goal requires an analysis that extends beyond simple statistics, as overall numbers are insufficient in uncovering the nature of law enforcement agencies' use of lethal force (Fryer, 2016). For example, consider a small city where $90 \%$ of the population represents Race A and 10\% of the population represents Race B. Police kill nine people from Race B and one person from Race A. Using only the raw numbers to compare the population sample to the lethal force sample (a standard method of exploring racial discrimination in policing), then this disparity is cause for concern. However, if the nine persons from Race 
B shot at police before being killed, but the single person from Race A was unarmed and misidentified when killed, then the focus of concern shifts. Although most studies and media outlets monitor law enforcement's use of lethal force and then report these data to the public, even if a wide disparity exists in the representation of individuals killed by police, a simple count of death tolls by races reveals little about policing or discrimination. To understand whether lethal force is justified, one must consider context (e.g., the type of call), the actions of law enforcement, the actions of others at the scene, and the presence of weapons.

\section{Recent Literature}

Regarding Belief Perspectives 1 and 2, many studies have considered internal causes of the overrepresentation of African Americans in law enforcement's use of deadly force. Relevant theories include closed systems/para-military policing, lack of passive representation (Linn, 2006; Nicholson-Crotty et al, 2017; Wilkens, Williams, 2008; Xiao et al, 2014), critical race theory/intentional/explicit discrimination (Chaney \& Robertson 2015; Gotanda, N., \& Peller, G., 1995), subtle/unconscious discrimination (Chaney \& Robertson 2015; Godsil \& Johnson, 2013), statistical discrimination/racial profiling (Western, 2006), organizational/structural discrimination (Epp, Maynard-Moody, Hairder-Markel, 2017; Fryer, 2017; Menifield et al., 2019; Rennison \& Dodge, 2018), organizational culture/stress (Anderson et al., 2017; Gilmartin, 2002), training (Anderson et al., 2016; Menifield et al, 2019; Ross, 2013), and utility maximization (i.e., the density of police presence based on crime) (Fryer, 2017).

Research has also unveiled possible external causes of overrepresentation: cocontamination (Loeffler \& Bovaird, 2019); socioeconomic disparities (e.g., in education 
or income) (Alexander et al., 2014; Simms, 2009; Reeves \& Sawhill, 2014); opportunity/cost differences (Becker, 1974); Putnam's (2016)“Goodnight Moon time” and "airbags"; violent crime rate/Becker's (1974) economic theory of criminal behavior; neighborhood crime (Lee et al., 2014); and disparities in police trust (Carter, 2019; COPS-USDOJ, 2015; Enns, 2016; Menifield et al., 2019). Whether racial disparities in use of lethal force are due to internal or external factors, most studies on officers' use of lethal force have revealed no evidence of discriminatory or biased policing (Becker, 1974; Fryer, 2016; Fyfe, 1982, 1988; Goldkamp, 1976; Gross, 2015; Klinger, 2012; Krapfl, 2017; Miller, 2015; Newport, 2014; Putnam, 2016). Yet other studies (Chaney \& Robertson, 2015; Gross, 2015; Moore et al., 2016) have presented conflicting evidence of racial discrimination or bias in officers' decisions to use lethal force. The causes of racial disparities in law enforcement's use of lethal force thus remain ambiguous, hence the need for ongoing research and improvements to available data.

Due to inconsistent methods of data collection, inconsistent database figures, and a lack of systematically tested data sources (Degue et al., 2016; Fryer, 2016), researchers must often employ various methods to investigate the potential of racial bias in the decision to use lethal force. Some studies have included lab experiments, others have involved small or incomplete samples, and still others have referred to non-systematically tested data to investigate bias in police use of lethal force. The following sections summarize recent research examining racial bias in the lethal force decision-making process for law enforcement officers (and others) in high-stress encounters. The literature is separated into lab studies and non-lab studies. 
Laboratory studies. Many lab studies have focused on racial bias in the use of lethal force in law enforcement, using video and pictures to evaluate whether officers or other participants exhibited racial bias in their decisions to deploy lethal force (or not). Taking the situational context and the race of the suspect as primary characteristics, the following studies evaluated the time participants or officers took to shoot. Other studies discussed in this chapter used eye tracking (e.g., to evaluate participants' perceived importance of a suspect's style of dress) or other methods to ascertain bias in participants' decision-making processes. The following literature review is not exhaustive but presents work relevant to the use of lethal force in law enforcement along with broader themes of research in this area. Among chosen lab studies, six revealed no evidence of bias and one indicated bias in participants' decisions.

No evidence of bias. Several studies have found that participants 'shoot/don't shoot' decisions were determined by the dangerousness of the situation more than the suspect's race. Additionally, participants' mistakes tended to counter the media narrative of police officers targeting African Americans. In two studies, Ma and Correll (2011) used first-person shooter simulation software to test the role of target prototypicality in participants' 'shoot/don't shoot' decisions. Target prototypicality determines how well targets fit stereotypical norms of their category. In this case, the category was racial stereotypes. Ma and Correll (2011) found no evidence of racial bias in participants' 'shoot/don't shoot' decisions in both studies. Additionally, they found that participants' decisions in both studies were shaped by Caucasian targets' prototypicality but not by African American targets' prototypicality. 
In another study, Correll, Wittenbrink, Park, Judd, and Goyle (2011) sought to determine whether race influenced participants' 'shoot/don't shoot' decisions. Their work was based on previous research suggesting that participants in simulated shooting tests tended to shoot armed African American men faster and more frequently than armed Caucasian men. Correll et al. (2011) used first-person shooter simulation software to place participants in simulated lethal force situations and timed participants' responses to videos featuring suspects of different races who were armed or not. The authors found that participants' perceptions of the danger of a situation drove shooting decisions and that race was not a factor in participants' decisions to shoot at suspects (Correll et al., 2011). Participants were more likely to shoot, regardless of race, in situations where they perceived greater danger.

A third study involved participants with varying degrees of training: police- and military-trained officers were placed along with civilians in a first-person shooter simulator to simulate real-life deadly force encounters (James, Vila, \& Daratha, 2013). Participants were found to display a strong bias in favor of African American suspects when deciding to shoot: participants took longer to shoot armed African American suspects than Caucasian or Hispanic suspects, and participants were more likely to shoot unarmed Caucasian suspects than African American or Hispanic suspects.

In similar studies, James, Klinger, and Vila (2014) and James, James, and Vila (2016) both used simulated real-life deadly-force encounters to test whether participants were more likely to mistakenly shoot minorities than Caucasian suspects when no deadly threat was present. In James et al. (2014), participants demonstrated significantly greater threat responses to African American suspects than to Caucasian or Hispanic suspects, 
suggesting a subconscious bias towards African Americans as more threatening. However, participants took longer to shoot armed African American suspects compared to Caucasian or Hispanic suspects and hesitated significantly longer before shooting African American suspects than Caucasians or Hispanics in more challenging simulated scenarios (James et al., 2014). The authors thus argued that their study demonstrated a lack of affected shooting behavior from subconscious bias, even in participants with subconscious bias.

One difference between James et al. (2014) and James et al. (2016) was that the Implicit Association Test (IAT) was used in the latter study to identify subconscious implicit bias among police officers. Officers were exposed to realistic simulated situations in a controlled laboratory setting and demonstrated no evidence of racial discrimination in their shooting decisions (James et al., 2016). The authors found that officers took longer to shoot armed African American suspects than Caucasian suspects and were less likely to shoot unarmed African American men than Caucasian men. Although findings revealed clear evidence of implicit bias against African American suspects on the IAT, such bias was not reflected in participants' 'shoot/don't shoot' decisions. This discrepancy is perhaps unsurprising; Azar (2008) contended that IAT results may indicate implicit bias that does not manifest in participants' decision making because the IAT may or may not reveal bias related to the studied characteristic.

Cox, Devine, Plant, and Schwartz (2014) used photographs and videos to investigate the influences of suspect race, officer race, and neighborhood characteristics on officers' shooting mistakes. By presenting officers with a realistic plastic gun and targets in still-photo and video formats, the authors found that officers spent longer 
considering their shoot decisions when viewing videos rather than photos. Cox et al. (2014) posited that differences in officers' performance in videos compared to photos indicates that 'shoot/don't shoot' tests should include the complexity officers may face in real-life situations. Results showed no evidence of racial bias; although officers correctly shot armed African American suspects faster than armed Caucasian suspects, the officers were less likely to erroneously shoot unarmed African American suspects than unarmed Caucasians.

Evidence of bias. In a study of 25 Caucasian undergraduate students at the University of Chicago, Donders, Correll, and Wittenbrink (2008) evaluated whether or not participants (14 men and 11 women) associated African American faces with danger more than Caucasian faces. The authors tracked how quickly participants glanced at faces and how long participants held their gaze. Donders et al. (2008) concluded that exposure to societal stereotypes linking African Americans with danger socialized participants to consider African Americans as fear-conditioning stimuli, resulting in participant bias as indicated by paying more attention to African American faces. This implicit bias of African Americans being more dangerous could contribute to disparities in the deployment of lethal force.

Non-laboratory studies. Non-laboratory studies on use of lethal force have incorporated available data to examine incomplete national, regional, or untested data to identify bias in officers' use of lethal force. The following sections present six studies revealing no evidence of bias, two with mixed results, and four pointing to evidence of bias. I explain data sources in these non-lab studies as needed and identify potential drawbacks of these sources in this chapter's conclusion. 
No evidence of bias. Lee, Vaughn, and Lim (2014) examined whether violent neighborhood crime affected police officers' use of force by using geographic information systems mapping to evaluate 2 years of self-reported use-of-force incidents from the Austin, Texas Police Department. Neither citizen race nor officer race significantly altered officers' probability of using force (Lee et al., 2014). Instead, use of force was primarily attributed to higher citizen resistance in police encounters. Results also indicated a positive relationship between use of force and violent crime within small geographic areas (500-3000-foot buffer zones), but no relationship manifested at the precinct level or in larger areas. Given these findings, the authors recommended higher levels of training and supervision for officers working in high-crime neighborhoods. Such neighborhoods may evoke higher degrees of officer fear, particularly among officers who have not received adequate training in stress management or realistic use-of-force decision making in stressful situations.

Officers' decision making in highly stressful situations is paramount when considering lethal force. Miller (2015) examined psychological factors associated with officers' application of deadly force in citizen encounters and found that officers used deadly force only when they believed they had no other choice (i.e., to preserve their own life or the lives of others). Certain attitudes, personalities, and job experiences could enhance officers' tendencies to use force in citizen encounters. Relatedly, specific emotional and behavioral features could serve as a 'tipping point' in officers' deployment of force. Miller (2015) found no evidence that race alone influenced officers' use of force; he argued that paying attention to certain features in officer selection like 
education, training, discipline, and supervision could lead to improved officer-civilian interactions.

To further contextualize police shootings, Selby, Singleton, and Flosi (2016) tested the hypothesis that most use of lethal force is clearly justifiable and that a false media narrative implies a larger proportion of questionable police shootings than occur in reality. Selby et al. (2016) pointed out that in most research on police killings, investigators simply count the numbers without considering context. Referring to cases identified in the Washington Post's "Police Shooting Investigation" (Kindy \& Elliott, $2015)$, they attempted to provide context in the 153 cases $(9 \%)$ in which unarmed persons (as identified by Kindy \& Elliott, 2015) were killed by police in the U.S. in 2015. Many of their findings countered popular media narratives about police killings; unarmed was not analogous to non-dangerous, as most unarmed persons were actual threats due to their conduct. Selby et al. (2016) also found that over half of unarmed persons killed were either suffering from mental illness, a physical disability, a drug overdose, or a combination thereof. Nearly $90 \%$ of persons killed by police died in incidents where someone had called the police to request help; that is, community members had identified the suspect and called police, leading to police contact that ultimately resulted in the person's death. Additionally, of the 153 persons killed by police, slightly more than half were shot. Only 10 cases $(6.5 \%)$ were deemed unjustified, revealing no evidence that police are targeting African Americans in lethal force encounters.

In a similar study, Shane and Swenson (2018) investigated the same 2 years of incidents (153 cases) in which the Washington Post identified victims as unarmed. Of the original 153 cases, Shane and Swenson (2018) discovered that in 112 of those incidents, 
the subject had been initially identified as unarmed by the Washington Post but had in fact held a real or improvised weapon (e.g., a metal-tipped broomstick, tree branches, bear spray, knife, rocks, or vehicles). Thus, there were 41 actual cases of unarmed persons killed by police. Shane and Swenson (2018) also found that when police deployed lethal force towards (actually) unarmed civilians, the police or a third person faced an imminent threat nearly $90 \%$ of the time; the remaining $10 \%$ of incidents were accidents resulting in the subject's death (including accidental deployment of lethal force). Unarmed persons shot by police were identified as attempting one of the following: disarming an officer, drowning an officer, throwing an officer off a roof, throwing an officer off a bridge, strangling an officer, gesturing as if they had a weapon, keeping their hands concealed despite commands to show their hands, or charging towards an officer in a way that could be perceived as a threat of assault (as summarized by Remsberg, 2018). Shane and Swenson (2018) thus emphasized that unarmed does not mean not dangerous. Additionally, they argued that when the media focus solely on a citizen being unarmed (when killed by lethal force), most members of the public then assume that the shooting was unjustified. This study provided important context regarding the reality of what 'unarmed suspects' may represent for police in actual situations.

Rather than focusing on whether unarmed persons killed by police should typically be considered non-dangerous, another study questioned the most common means of testing racial disparities in officers' use of lethal force by comparing Caucasian and African American persons shot by police to each group's proportion of the U.S. population (Cesario, Johnson, \& Terrill, 2019). The authors argued that this comparison 
method is problematic because it assumes the likelihood of the event to be equal for every person per group. Specifically, Caucasian and African American individuals are equally as likely to be in a situation that results in their being shot by police. Cesario et al. (2019) pointed out that in order to be shot by police, one must experience "police exposure" (p. 587); differences in exposure will affect whether a person is likely to be shot by police. Differences in crime rates are also tied to differences in police exposure, hence why crime rate is a more appropriate measure of officers' use of lethal force. Cesario et al. (2019) used odds ratios to calculate the odds of being fatally shot by police for African Americans and Caucasians based on their respective crime rates, arguing that population proportions are misleading and less accurate than crime rates. Whereas population proportions indicate that African Americans are 2.5 times more likely than Caucasians to be shot by police, crime rates present a more precise picture. According to estimates, the likelihood of Caucasians being shot by police is 2.7 times higher (U.C.R.'s S.R.S. homicide reports), 2.6 times higher (U.C.R.'s S.R.S. homicide arrests), 2.9 times higher (U.C.R.'s NIBRS homicide reports), 3.9 times higher (U.C.R.'s NIBRS homicide arrests), and 2.5 times higher (Center for Disease Control and Prevention's [CCD] death by assault data) compared to African Americans. These results show that the most common metric for comparison, the U.S. Census population proportion, may not be ideal when considering Caucasians' and African Americans' odds of being killed by police (Cesario et al., 2019).

Fryer (2016) also focused on disparities in Caucasians' and African Americans' odds of being killed by police. Specifically, he investigated lethal force and use of force in general, but the following overview focuses on his findings regarding lethal force. He 
evaluated 1,332 shootings occurring in 10 major metropolitan police departments in Texas, Florida, and California between 2000 and 2015. Fryer (2016) reviewed secondary sources (police narratives) and coded the data by each suspect's age and race, number of officers at the scene, officers' race, content of the dispatch call, presence of violence, time of day, whether the suspect attacked, and whether the officer shot before or after an attack. Fryer (2016) aimed to determine whether officers shot at African American suspects more quickly compared to other suspects. He found no evidence of racial bias. Results revealed that officers tended to shoot before an attack when suspects were Caucasian, and African American and Caucasian citizens were equally likely to be carrying a weapon when officers shot at them. Notably, Fryer's (2016) study included shootings in which the suspect died and those in which the suspect survived. This study, along with that by Klinger et al. (2016) (summarized in the Mixed Results section), may be more relevant than those including only situations in which a suspect was killed by police; that is, officers make lethal force decisions whenever they intentionally shoot a firearm regardless of whether the suspect lives.

Mixed results. Similar to Fryer's (2016) study, Klinger, Rosenfeld, Isom, and Deckard (2016) examined incidents where police shot at citizens irrespective of whether such shootings resulted in civilian death. Using a micro-spatial analysis of 230 police shootings in St. Louis, MO between 2003 and 2012, they investigated social determinants behind the use of deadly force by police, potential racial disparities in police shootings, and to what degree such disparities may reflect biased police behavior. Police officers hit suspects in less than half of the selected shootings and killed approximately one out of six suspects (Klinger et al., 2016). Demographically, two-thirds of officers were non- 
Hispanic Caucasians, one-third were non-Hispanic African Americans, and the vast majority (96\%) were men and African American (93\%). Klinger et al. (2016) found that neither racial composition nor neighborhood socioeconomics affected the frequency of police shootings, but the level of violent crime in a neighborhood did: surprisingly, shootings were less frequent in areas with the highest level of violent crime compared to moderately violent areas.

To study actual incidents involving the use of lethal force in law enforcement, Menifield et al. (2019) studied the original dataset 2014: Intentional Lethal Force Data (Menifield \& Laughlin, 2018) to explore whether Caucasian police officers were more likely to use lethal force on minority suspects or persons of a specific race. They found that minorities were disproportionately killed by police, but Caucasian officers were no more likely to kill minority suspects compared with non-Caucasian officers. Further, no evidence emerged to suggest that disproportionate killing of African Americans was driven by micro-level racism. Menifield et al. (2019) also found no indications within the data of macro- or meso-level policies contributing to the disproportionate killing of African Americans. However, they suspected that such policies may target minorities and lead to disproportionate police killings of African Americans. They further argued that the disproportionate killing of African Americans is not a problem exclusive to Caucasian police officers but concerns all officers.

Evidence of bias. Similar to Menifield et al. (2019), the following three studies explored racial disparities in officers' use of lethal force at the national or near-national level. Using data from the CDC's National Violent Death Reporting System (NVDRS) (https://www.cdc.gov/violenceprevention/nvdrs/index.html), DeGue et al. (2016) reported 
that most victims of lethal force by law enforcement were Caucasian (52\%). They also found that African Americans were overrepresented as victims (32\%), with a fatality rate nearly 3 times higher than Caucasian victims compared to their U.S. Census population proportion. At the time of this study, the NVDRS contained data for violent deaths from 17 states for the years 2009-2012. DeGue et al. (2016) considered 812 incidents of lethal force by law enforcement and corresponding information about each incident based on case narratives in the NCDRS database. They reported that most victims (83\%) were armed, but African American victims were more likely to be unarmed (14.8\%) than Caucasian (9.4\%) or Hispanic (5.8\%) victims. Additionally, their research highlighted the importance of exploring the actions during each incident; in nearly $88 \%$ of cases, the victims posed an actual or perceived immediate threat to law enforcement officers (DeGue et al., 2016).

Further, the findings of DeGue et al. (2016) highlight the importance of considering the context of a police call. Their results indicated that law enforcement personnel in lethal force incidents were responding to reports of alleged criminal activity over $80 \%$ of the time, and more than $50 \%$ of those cases involved reported violent criminal activity. Additionally, military veterans were 1.4 times more likely to be victims than other civilians; $22 \%$ of all victims exhibited mental health concerns; $18 \%$ of all victims included potential suicide by cop; and $14 \%$ of all victims were involved in intimate partner violence.

Buehler (2017) referred to another CDC source to investigate officers' use of lethal force over several years. He examined vital statistics and census data from the CDC's Wide-Ranging Online Database for Epidemiologic Research (WONDER) from 
2010-2014 and found that the number of persons killed by lethal force was underreported by nearly $40 \%$ compared to NVDRS data. WONDER included all reported deaths due to "injuries inflicted by the police or other law enforcing agencies, including military on duty, in the course of arresting or attempting to arrest lawbreakers, suppressing disturbances, maintaining order, and other legal actions" (International Classification of Diseases, 10th Revision as cited in Buehler, 2017). He also considered information about the cause of death, age at death, and race and ethnicity of the deceased as reported on death certificates. Results showed that from 2010 to 2014, 2,285 legal intervention deaths occurred, of which $96 \%$ involved death by firearm and $96 \%$ were men. Additionally, Buehler (2017) reported that non-Hispanic Caucasians accounted for slightly more than half of those killed (over the age of 10). However, the number of deaths per million were 2.8 and 1.7 times higher among non-Hispanic African American men and Hispanic men, respectively, than among Caucasian men. In all racial categories, a higher proportion of younger men died by law enforcement compared to older men. About a third (35\%) of those killed lived in large central metropolitan areas (i.e., home to more than 1 million people), $52 \%$ resided in other metropolitan areas, and 13\% resided in non-metropolitan areas. Buehler (2017) did not find evidence of discrimination in officers' use of lethal force, but he noted racial disparities in levels of police contact: a higher likelihood of contact increased the probability of African Americans being contacted, stopped, or arrested by police. He also concluded that these figures (lower-level disparities), together with other factors, led to overrepresentation of African Americans among those killed by law enforcement. 
Ross (2015) also set out to evaluate racial bias in lethal force at the national level. He referred to the U.S. Police-Shooting Database (USPSD), to evaluate police shootings on a national level. He estimated county-level risk ratios of being shot by police as a function of the suspect's race and whether the suspect was armed. Of suspects who were shot, Caucasian suspects were more likely to be armed than African American or Hispanic suspects. Ross (2015) identified significant bias in the killing of unarmed African Americans relative to unarmed Caucasians: the median probability of police shooting an unarmed African American man was 3 times greater than that of police shooting an unarmed Caucasian man. The propensity for police to shoot unarmed African American men compared with armed Caucasian men remained the same across counties. Notably, however, the reliability of the dataset was questionable; USPSD is a crowdsourced website, and its main page warns (a) that the accuracy of data is not guaranteed and (b) data collection and verification are ongoing (Wagner, 2014).

Similar to Ross (2015), other studies revealing evidence of biased policing (Chaney \& Robertson 2015; Gross, 2015; Moore et al., 2016) did not consider many important factors and limited their exploration primarily to "a simple count of the number of police shootings that occur" (Fryer, 2016, p. 2). For example, Chaney and Robertson (2015) reported that only 13 officers were indicted from 78 police killings of unarmed African Americans between 1999 and 2015. They argued that the number of unarmed African Americans shot, combined with the small number of police officers indicted, suggests police bias and a devaluation of African American persons' lives. They used critical race theory to explain these police killings. This theory assumes that Caucasian racial domination is at the center of today's legal and social decision making and that its 
prevalence is routine, embedded, and accepted as legally and morally legitimate (Inderbitzin, Bates, \& Gainey, 2014). Per this theory, an excessive number of African Americans killed and few officers indicted are because the system is set up to protect officers who are predominately Caucasian. Furthermore, the system does not place appropriate value on African American lives.

Just as Chaney and Robertson (2015) viewed these disparities as a partially macro-level problem, Carbado (2016) argued that disparities in police violence towards African American men should not be considered an issue with individual officers. He instead proposed a theoretical model to explain persistent police violence against African Americans. He outlined the following six features as contributors:

(1) A variety of social forces converge to make African Americans vulnerable to ongoing police surveillance and contact. (2) The frequency of this surveillance and contact exposes African Americans to the possibility of police violence. (3) Police culture and training encourage that violence (mostly implicitly). (4) When violence occurs, a range of legal actors in the civil and criminal process translates that violence into justifiable force. (5) The doctrine of qualified immunity makes it difficult for plaintiffs to win cases against police officers, and when plaintiffs win such cases, police officers rarely suffer financial consequences because their local government indemnifies them. (6) The conversion of violence into justifiable force, the qualified immunity barrier to suing police officers, and the frequency with which cities and municipalities indemnify police officers reduce the risk of legal sanction police officers assume when they employ excessive force. (p. 1479) 
Carbado (2016) further argued that violence against African Americans transcends the conduct of particular police officers; instead, such violence should be addressed from a structural perspective. Structural violence occurs when a social structure or institution (e.g., policy, law, or practice) interferes with individuals' or groups' abilities to meet their basic needs (Galtung, 1969). Essentially, racial disparities in police violence are more likely to emerge at the meso (organizational) or macro (system) levels than the micro level (individual officers) (Carbado, 2016).

\section{Summary of Literature Review}

The U.S. Supreme Court has emphasized the importance of context in evaluating police officers' use of force (Graham, 1989; Klinger, 2012). According to Fryer (2016), "a simple count of the number of police shootings that occur does little to explore whether racial differences in the frequency of officer-involved shootings are due to police malfeasance or differences in suspect behavior" (p. 2). As summarized in the preceding sections, some studies have described systemic racial bias at the meso and macro levels. Yet other studies considering the actions of individuals killed by police, the actions and perceptions of police, and other essential criteria identified by the U.S.S.C. (e.g., presence of weapons or type of call) revealed no evidence of micro-level bias among Caucasian police officers or officers/actors in general (Fryer, 2016; Fyfe, 1982, 1988; Goldkamp, 1976; Klinger, 2012; Krapfl, 2017; Miller, 2015).

When police kill, the action should be scrutinized without assumptions that the death was inherently justified or not. The debate on whether police killings are discriminatory persists because insufficient reliable data are available regarding these deaths. Fryer (2016) pointed out that "a primary obstacle to the study of police use of 
force has been the lack of readily available data" (p. 2). Additionally, police departments in the U.S. are not required to submit data on police killings or use of lethal force to a governing body (Klinger, 2012). One could argue that each instance of lethal force, regardless of whether death results, should be reported to facilitate appropriate scrutiny of lethal force in law enforcement.

According to former FBI Director James Comey (2015), it is impossible to have an informed discussion regarding the use of lethal force in law enforcement due to insufficient data. The lack of an official government database on the use of lethal force in law enforcement is particularly concerning given the Death in Custody Reporting Act of 2013, which requires the head of each law enforcement agency to report to the Attorney General annually regarding the death of any person detained or arrested by an officer (Congressional Research Service [CRS], 2014). The following information must be included in the report:

- Name, gender, race, ethnicity, and age of the deceased;

- Date, time, and location of death;

- Law enforcement agency that detained, arrested, or was in the process of arresting the deceased; and

- Brief description of circumstances surrounding the death (CRS, 2014).

No such database was available at the end of 2018; however, the National Use of Force Data Collection was scheduled to begin January 1, 2019. Per the National Use of Force Data Collection (2019), a nationwide data collection pilot was conducted from July 1, 2017 to December 31, 2017. On "September 5, 2018 the O.M.B. [White House Office of Management and Budget] gave final approval to begin collecting the data starting 
January 1, 2019"; however, agencies are only encouraged (not mandated) to participate (National Use of Force Data Collection, 2019). The National Use of Force Data Collection (2019) dataset will include the following incident information:

- Date and time of the incident

- Total number of officers who applied actual force during the incident

- Number of officers from the reporting agency who applied actual force

- Location of the incident (address or latitude/longitude)

- Location type of the incident (street, business, residence, restaurant, school, etc.)

- Did the officer(s) approach the subject(s)?

- Was it an ambush incident?

- Was a supervisor or a senior officer acting in a supervisory capacity present or consulted at any point during the incident?

- What was the reason for initial contact between the subject and the officer (response to unlawful or suspicious activity, routine patrol, traffic stop, etc.)?

- If the initial contact was due to "unlawful or criminal activity," what were the most serious reported offenses committed by the subject prior to or at the time of the incident?

- If applicable, the reporting agency will enter the National Incident-Based Reporting System or local incident number of the report detailing criminal incident information on the subject and/or assault or homicide of a law enforcement officer

- If the incident involved multiple law enforcement agencies, the agency will include case numbers for the local use-of-force reports at the other agencies 
- Subject information

- Age, sex, race, ethnicity, height, and weight

- Injury/death of subject(s) (gunshot wound, apparent broken bones, unconsciousness, etc.)

- Type(s) of force used connected to serious bodily injury or death (firearm, electronic control weapon, explosive device, blunt instrument, etc.)

○ Did the subject(s) resist?

- Was the threat by the subject(s) directed to the officer or to another party?

- Type(s) of subject resistance/weapon involvement (threatened officer, threatened others, threatened self, active aggression, firearm, attempt to flee, etc.)

- Was there an apparent or known impairment in the physical condition of subject? If yes, indicate which (mental health/alcohol/drugs/unknown)

- At any time during the incident, was the subject(s) armed or believed to be armed with a weapon?

- Officer information

- Age, sex, race, ethnicity, height, and weight

- Years of service as a law enforcement officer (total tenure, number of years)

- At the time of the incident, was the officer a full-time employee?

- Was the officer readily identifiable?

- Was the officer on duty at the time of the incident?

○ Did the officer discharge a firearm? 
Was the officer injured?

- What was the officer's injury type? (gunshot wound, apparent broken bones, severe laceration, unconsciousness, etc.)

However, none of the above information is currently available, nor is there any indication that the National Use of Force Data Collection (2019) will gather historical information about officers' use of lethal force. Therefore, the above information may only enhance data on the use of lethal force in law enforcement beginning on January 1, 2019. Excluding the release of the National Use of Force Data Collection (2019) data, four governmental data reporting systems have been used to collect information on nationwide lethal force in law enforcement: (1) the FBI's Uniform Crime Reporting Program (UCR), which gathers data from more than 18,000 law enforcement agencies (https://ucr.fbi.gov/); (2) the National Vital Statistics System (NVSS) (https://www.cdc.gov/nchs/nvss/index.htm), which is operated by the CDC's National Center for Health Statistics and obtains information regarding use of lethal force from death certificates for all U.S. states and territories; (3) the CDC's NVDRS (https://www.cdc.gov/violenceprevention/datasources/nvdrs/index.html), which collects information from death certificates, coroner or medical examiner reports, and law enforcement reports (DeGue et al.); and (4) the CDC'S WONDER database (https://healthdata.gov/dataset/wide-ranging-online-data-epidemiologic-research-wonder) (Buehler, 2017).

Although UCR, NVSS, NVDRS, and WONDER appear to be the most robust government-run databases at this time, UCR and NVSS are widely thought to undercount the number of persons killed by police (DeGue et al., 2016). UCR's major problem is 
data omission due to many jurisdictions' failure to provide data on officers' use of lethal force; participation in UCR data submission remains voluntary. NVSS misclassifies the use of lethal force in law enforcement as homicide when death certifiers do not mention police involvement. Comparatively, NDVRS is much more effective in summarizing use of lethal force in law enforcement, identifying twice as many lethal force incidents as UCR and 71\% more than NVSS (DeGue et al., 2016). Despite this advantage, NDVRS cannot provide national data regarding use of lethal force; it only includes information on 17 states. Finally, WONDER underreports the use of lethal force in law enforcement by nearly $40 \%$ when compared to the 17 states included in NDVRS (Buehler, 2017).

Data on police officers' use of lethal force are clearly lacking (DeGue et al., 2016; Fyfe, 1988; Fryer, 2016; Klinger, 2012; Menifield et al., 2019). The abovementioned databases and others should thus continue to be developed. Research revealing bias in the use of lethal force by law enforcement is similarly troublesome. Researchers such as Ross (2015), Degue et al. (2016), and Buehler (2017) sought to leverage available resources and do their best with less reliable crowdsourced information or partial governmental information. No official national database is available, and not all databases have been systematically tested. Being armed is an important component in determining whether a killing was justified, but the suspect's behavior and the nature of the call should also be considered when assessing lethal force decisions. Ample evidence from Shane and Swenson (2018) and Selby, Singleton, and Flosi (2016) indicates that being unarmed is not the same as being non-dangerous.

The overrepresentation of African American men among those killed by police is alarming and warrants further investigation. Even so, simple counts of the number and 
races of those killing and being killed are unlikely to produce valuable information that could lead to solutions and improvements in policies and practices. For example, Chaney and Robertson (2015) argued that the number of unarmed African Americans shot and the small number of police indicted convey a lack of value of African American lives within a racially biased system. However, such data do not consider additional context surrounding the actions of killed unarmed African Americans, officers' behavior, or details about the incidents in which deaths occurred. By ignoring these factors, all lives taken by police are presumed to be equally as appalling or justified. The unfortunate reality is that some actors' actions demand a response from police (to avoid loss of life), and that response can lead to actors' deaths. In these cases, death counts provide no information apart from the reality of policing. Equally weighing all lives taken by police does a disservice to those who have been killed by police in situations where force was unjustified. This misperceived equality also does little to promote conversations around necessary policy implementation.

As noted in Lee et al. (2014), when evaluating racial bias in the use of lethal force, most studies referred to precinct-level or larger-area data. Lee et al. (2014) provided support for ecological contamination theory and social disorganization when examining smaller areas (500-3000-foot buffer zones). Ecological contamination theory and social disorganization theory argue that ecological factors in certain areas influence whether deviant behavior flourishes in some spaces but not others (Inderbitzen et al., 2014). Social disorganization theory explains why certain neighborhoods control deviance and why others are unable to minimize or eliminate it; this theory also points to structural (ecological) neighborhood factors to explain crime clusters (e.g., high poverty 
prevents residents from owning property, landlords do not live locally or are disinterested in improving their property, population turnover, and racial/ethnic heterogeneity) (Inderbitzen et al., 2014). Lee et al. (2014) also found partial support for socioeconomic disadvantages as a contributor in these smaller areas regarding the association between violent crime and officers' use of force; however, this relationship did not apply to larger areas. This study suggests that area size (i.e., smaller areas) is thus important to consider in future law enforcement racial bias studies. Although DeGue et al. (2016) argued that their findings offer evidence of bias, their work also indicated that law enforcement officers were deploying lethal force in a high percentage of situations (94\%). Contrary to the prevailing media narrative, most incidents were in response to an immediate threat $(88 \%)$ or accident $(6 \%)$.

The literature on the use of lethal force in law enforcement described above helps to provide a picture of the lack of clarity in the overall amount of those killed by police and the circumstances of those killed by police. The literature also provides valuable information on some important data points that would be important to collect, if possible. Even before reviewing the literature, it is important to note from previous U.S. Supreme Court rulings that the nature of the dispatched call (i.e., potential for violence), whether weapons are present, and the actions of individuals at the incident are critical to determining whether the use of force was justified.

It is evident that more data and a better database on lethal force is needed. Such a database should include the race of the leader of the responding law enforcement agency and the race of the community leader to identify potential evidence of structural racism within the law enforcement agency or local government. Collecting data on whether the 
person killed was armed can inform the media narrative that law enforcement officers target unarmed African American men. Studies (Xiao et al, 2014; Linn, 2006) regarding how a lack of diversity can lead to increased racial bias or less understanding of people from other races necessitates the inclusion of the economic status and diversity characteristics; these two characteristics are also noteworthy given research (Lee et al, 2014) regarding the importance of considering the demographics of a given neighborhood and the surrounding population. 


\section{Chapter 3.}

Methods: To create and explore the 2014: Intentional Lethal Force Data

\section{Purpose and Objectives}

The primary purpose of this study was to evaluate whether evidence exists that the decision to use lethal force is influenced at the micro-level by officers using race as a factor in their deployment decisions. This primary purpose was addressed by accomplishing four objectives: (1) creating a reliable dataset; (2) describing the breadth of information in this new dataset; (3) evaluating whether pertinent characteristics varied by race; and (4) conducting empirical research to determine whether race influenced police officers' decisions to use lethal force.

The first objective was to improve the availability and reliability of data regarding officers' use of lethal force by constructing an original dataset on intentional use of lethal force in law enforcement in 2014. The second objective was to describe the characteristics of police killings in the U.S. in 2014. The third objective focused on the extent to which incident characteristics varied by the victim's race or ethnicity. The second and third objectives also include considerations about whether there is evidence supporting either of the two belief perspectives (internal or external), whether officers are using force in justified situations based on the theoretical perspective, and exploring whether there is evidence that the disparities in law enforcement use of lethal force exist within law enforcement but not at the micro-level of officers' decision to deploy lethal force.

The fourth objective examined potential evidence of racial discrimination in data on police killings (micro-level officer decision to deploy lethal force) using a simple test. 
According to Anwar and Fang (2006), Fryer (2016), and Knowles et al. (2001), a simple test is a way to test for discrimination in police actions. When applied to discrimination in officer-involved shootings, a simple test can be useful for

[investigating] the fraction of Caucasian and African American suspects, separately, who are armed conditional upon being involved in an officer-involved shooting. If the ordinal threshold of shooting at an African American suspect versus a Caucasian suspect is different across officer races, then one could reject the null hypothesis of no discrimination (Fryer, 2016, p. 6).

The final test employs a multivariate analysis considering whether characteristics related to law enforcement (Belief Perspective 1), characteristics from the community (Belief Perspective 2), the victim's actions and the situational context of the encounter (situational perspective), or criteria from the simple test influence the likelihood that a Caucasian officer will kill an African American or Hispanic victim (as compared to a Caucasian victim).

\section{Data: Creation and Description (Objectives 1, 2, and 3)}

Data sources and participants. This study was intended to increase available data on officers' use of lethal force by incorporating characteristics into existing databases and providing descriptive analysis of data on important features of officers' use of lethal force. This analysis produced means, standard deviations, and ranges of scores for some characteristics; for others, the analysis was used to compare the figures in this study to the expected figures based on the overall U.S. population. Additionally, we used cross-tabulations to evaluate certain relationships between characteristics. 
The term "we" appears often in this chapter because a team of graduate students at the University of Missouri (MU) completed data collection. Charles Menifield led the team in collecting the initial data and I did the final preparation steps to prepare the data in this database (2014: Intentional Lethal Force Data). The following students assisted Dr. Menifield and I with data collection: Valentine Lamar (MU), Lacy Peterson (MU), Kendal Lowrey (MU), Amber Letbetter (MU), and Charles Parker (MU).

Data sources (creation of dataset). To construct an original database of lethal force encounters among U.S. law enforcement in 2014, we employed a multi-step process. We began by reviewing data from KilledByPolice.net, which was audited previously and deemed highly reliable (Fischer et al., 2014). KilledByPolice.net is a nongovernmental entity that tracks police killings reported in the news and updates the database as more information becomes available about each incident. Researchers have spent more than 5 years and donated more than 25,000 hours to assembling this database. We selected the Killed by Police database as our initial resource for two reasons: (1) the proven reliability of the dataset; and (2) each incident is linked directly to a news story. KilledByPolice.net data contained each victim's name, race, age, date of birth, and gender; city, state, and date and time of the killing; and a news account describing the incident.

To conduct a more in-depth exploration of the use of lethal force in law enforcement in 2014, we also incorporated material from lethaldb.silk.co and fatalencounters.org, two nongovernmental websites that collect data on police officers' use of lethal force. While studying the use of lethal force, Lott and Moody (2016) and Nicholson-Crotty et al. (2017) both used these three databases and audited them for 
reliability (Menifield et al., 2019). Additionally, we performed a content analysis of other news accounts and websites, including governmental (U.S. Census) and nongovernmental sites to check for accuracy and incorporate more characteristics into these data. We added the following characteristics to the 2014: Intentional Lethal Force Data: population demographics, cause of death, presence (and type) of weapon, geographic location of the killing, type of reported offense, presence of a non-police witness, whether the suspect had an active warrant, and the race of the city's mayor. When possible, we performed content analysis to code for numerous officer characteristics: race, gender, age, years of service, officer type, and race of the law enforcement leader (i.e., police sheriff or chief).

Participants. The 2014: Intentional Lethal Force Data sample included all persons intentionally killed by police in $2014(N=860)$. In total, 860 persons were ultimately identified from the Killed by Police database, which included 1,114 incidents. To assemble the final sample, we performed a series of content analyses and examined how and why officers killed each victim. We first looked at online newspapers, online television reports, and available government databases to gather information about each of the 1,114 incidents from KilledByPolice.net. Content analysis of KilledByPolice.net, lethaldb.silk.co, fatalencounters.org, and several other nongovernmental and governmental sources resulted in an initial dataset of 1,104 persons killed by police in 2014; 10 deaths were omitted because they did not occur when police officers were acting in an official capacity (e.g., an off-duty police officer who committed a murdersuicide of his estranged wife; an off-duty police officer who collided with a vehicle while driving his personal car, killing the other vehicle's occupant). We did not exclude killings by officers who were off-duty but acting in a law enforcement capacity. 
An additional 109 incidents were omitted for various reasons (e.g., erroneous inclusion in the original database, such as incidents with no indicated police involvement; incidents in which police officers were present but did not kill the individual), reducing the original sample to 995 persons killed by police. We then performed content analysis to verify that police had intentionally killed each victim listed on KilledByPolice.net. We coded those killed by whether police had intentionally killed (1) or accidentally killed (0) the victims. Of the 995 persons killed by police, 135 killings were accidental (e.g., car accident), hence our final sample of 860 persons intentionally killed by police in 2014 . In this sample, 232 victims were African American (26.9\%), 420 were Caucasian (48.8\%), 159 were Hispanic (18.5\%), 14 were Asian American (1.6\%), and 35 identified as other $(4.1 \%)$.

The sample was then further divided into police officers who had deployed lethal force. Due to the lack of an official database containing such information and missing data in our primary sources, we analyzed news stories, official police department websites, and governmental and nongovernmental websites for incidents involving use of lethal force. Several news stories included the officer's race, which we confirmed as accurate through secondary sources when possible. In some cases, we deduced the officer's race based on his/her photograph accompanying a news story. For example, in an article detailing the death of Dino Smith, Jr. in Nashville, TN, officers Michael Gooch and Josh Reece were identified as having used lethal force (Menifield et al., 2019). We then checked the Metro Nashville Police Department and located department photographs of both officers to deduce their race (Metro Nashville Police Department 2014 as cited in Menifield et al., 2019). When neither news articles nor police department websites 
provided pictures of the officer(s), we employed other methods such as locating an officer's Facebook profile or finding other news stories where an officer received an award or went to court for a different offense.

We were unable to determine an officer's race in many cases, which highlights the need for a more concerted effort from the government in collecting information related to officers' use of lethal force (see Chapter 5 for discussion of this and other recommendations). Ultimately, we identified the officer's race in only around 36\% (309 of our 860) of our selected incidents. Of the 309 officers who deployed lethal force, 11 were African American (3.6\%), 263 were Caucasian (85.1\%), 33 were Hispanic (10.7\%), and 2 were Asian American (0.6\%).

Lack of information regarding officer race should not be taken as evidence of malpractice or of departments or officers intentionally hiding such information for nefarious purposes. Rather, police officers' social media profiles are often private, as is many officers' information overall. Officers are trained to remain vigilant of arrestees seeking information about where officers live and if the officers have family members. It may also be easier to find information about Caucasian officers who have killed minorities, partially because the media and public are not equally interested in all law enforcement incidents involving use of lethal force. Cases in which the officer is Caucasian and the victim is a minority are more likely to receive widespread media coverage, particularly if the victim was unarmed. It therefore is likely that it is also much simpler to identify an officer's race in these instances. 


\section{Measures.}

Primary characteristic. The primary unit of analysis in this paper is the victim (i.e., the person killed by police). We determined victims' races through content analysis of governmental and nongovernmental sources. Only in a few cases were we unable to identify a victim's race.

This study's situational perspective. The U.S. Supreme Court has decided that context matters in law enforcement officers' use of lethal force, and the first two chapters provided several possible explanations for the overrepresentation of African Americans as recipients of officers' use of lethal force. The present study includes additional characteristics to more effectively capture the context in which law enforcement officers used lethal force in 2014. The situational perspective underpinning this study requires additional characteristics because every officer interaction involves an officer (with choices and costs), a victim (with choices and costs), a situation (e.g., robbery, assault, theft, or area check), weapons the officer is carrying, and the potential of the victim carrying weapons.

In Graham v. Connor, the U.S. Supreme Court ordered lower courts to consider three questions when contemplating the lawfulness of use of force: (1) severity of the crime reported to police; (2) presence or absence of an immediate threat to the officer or the public from the suspect; and (3) presence or absence of the suspect actively resisting arrest or attempting to escape (Graham, 1989). Therefore, when considering whether race may be a factor in lethal force decisions, it is imperative to include as many aspects of the situational perspective as possible (see Appendices C and D). 
Other characteristics. To gather all characteristics, we deployed methods described in the Participants section. After comparing the original database on KilledByPolice.net to other selected databases, we sought to address gaps when possible via content analysis of online newspapers, online television broadcasts, or government sources (i.e., police department websites or databases on state-level use of force/lethal force in law enforcement). We included each victim's age and sex to understand the descriptive characteristics of individuals killed by police in 2014 and to explore the relationship between a victim's age or sex and race.

Additionally, criminology has long connected differences in violent offending rates to age, sex, and time of day (Rennison \& Dodge, 2018; Siegel \& Welsh, 2017). To more fully address the situational perspective (Appendix C) our research also included the type of call the police officer received and whether law enforcement considered the call violent. We incorporated the victim's possession (or not) of a weapon, the weapon type (if applicable), and whether the victim was aiming or shooting the weapon (if applicable) to address aspects of the situational perspective as well as the narrative that Caucasian officers discriminately kill unarmed African Americans.

Other characteristics included the time of day, location (inside or outside), and whether there was a non-law enforcement witness present. The time of day (particularly at night) and the location (particularly inside) could affect the likelihood for an officer to feel fear and could affect the likelihood that the officer and the suspect are isolated. The presence of witnesses, which should decrease the likelihood that an officer will deploy lethal force in a non-justified manner; assuming that officers know the force is unjustified at the time and do not want to face legal ramifications. However, the presence of a 
witness could also increase the likelihood that an officer will feel fear (officer outnumbered and more likely to be overcome by numbers) depending on the number of witnesses and the other contextual factors of the call (testing situational perspective).

We assessed the race of the officer(s) who deployed lethal force because it is a necessary component of the simple test for racial discrimination. We also incorporated the gender of officer(s), officer type (e.g., deputy or trooper), and officer(s)' years of experience to more thoroughly evaluate the descriptive characteristics of officers who used lethal force in 2014.

We also considered the location of the killing (e.g., neighborhood or business district; outside or inside), the time of the killing, the median income in the zip code, and the racial diversity of the zip code to better understand the descriptive characteristics of officers' use of lethal force, and to explore for evidence that external factors to law enforcement are causal for discrepant outcomes in lethal force. We also included the race of the mayor and the race of the law enforcement leader to determine whether the race of governmental leaders was associated with the race of persons killed by police and to explore whether there is evidence that racial disparities could be due to meso or macro level factors, or internal passive representation in law enforcement leadership or external to law enforcement passive representation in leadership.

Many of the characteristics we pursued for inclusion in our database were related to understanding the context of the important context of each situation, including characteristics that could shed light on whether racial disparate outcomes are more likely to be due to internal law enforcement factors or external societal factors. Most of our chosen characteristics were selected on the basis of recent studies or national debates on 
these or related topics. For example, we considered the presence of a weapon due to the literature and ongoing debate around police targeting unarmed African Americans. We considered the officer's race in light of recent literature and the national debate that Caucasian police officers are discriminately killing African American men. The race and age of victims were included based on research and the narrative that young African American men are the primary targets of police killings. Race of leadership was chosen to align with the literature on the importance of passive representation and diversity within public agencies (Linn, 2006; Nicholson-Crotty et al, 2017; Wilkens, Williams, 2008). Socioeconomic characteristics by zip code were included given research in public administration and sociology regarding how lack of community diversity can increase racial bias or inhibit empathy toward other races (Xiao et al, 2014) and to explore for evidence that external factors may be contributing to disparate outcomes by race.

\section{Design and Procedures}

The data collected in this study are retrospective and present accurate information regarding individuals killed by police, the police officers who used lethal force, and the situational context of those incidents in 2014. We described our retrospective data in terms of characteristics rather than variables. We chose to deviate from normative language because this is a descriptive and cross-tabulation analysis of characteristics related to persons killed by police. These characteristics cannot be manipulated; they are actual characteristics tied to the persons and situations where lethal force was deployed. In this study, I discuss information and the relationships between characteristics following retrospective evaluation to provide an array information rather than a narrow, causal investigation into this topic. 
The Results section will show that we used descriptive analysis and crosstabulation analysis to describe and evaluate associations between important characteristics. The Results section opens with an overview of descriptive analysis of individuals intentionally killed by police $(N=860)$ and police officers who we definitively identified as having intentionally killed a person $(N=309)$. Most of the Results consists of cross-tabulation analysis presented in contingency tables, which we used to analyze relationships between important characteristics. Each contingency table also displays Pearson's Chi-square statistic to show the relative significance of the relationship between characteristics along with the Cramer's V test to reveal the strength of the association between two characteristics. Regarding Pearson's Chi-square results, we referred to Table G.4 in Wooldridge (2013, p. 837) to determine the $.01, .05$, and .1 significance levels based on the degrees of freedom for each contingency table. For the purposes of this paper, when the contingency tables have the greatest level of significance in their relationships, or when the contingency table's level of significance has a critical value of .01 or lower, the table will have three asterisks. When the contingency table's level of significance has a critical value greater than .01 but equal to or less than .05 , the table will have two asterisks. When the contingency table's level of significance has a critical value greater than .05 but equal to or less than .1, the table will have one asterisk. Contingency tables whose level of significance's critical value is greater than .1 will still be reported but will have no asterisks, and the lack of significance will be noted and further explained as needed. Similarly, for the Cramer's V test, in the description of the tables, it will be noted if the characteristics in the contingency table had a weak relationship (Cramer's V below 0.1), a moderate relationship (Cramer's V of 0.1 or 
greater but less than 0.3), or a strong relationship (Cramer's V greater than or equal to $0.3)$.

Results also provide descriptive analysis of the race, sex, and age of victims; the race of officers; the U.S. region where killings occurred; location type (outside, residential, business, or vehicle); and the time of day in which killings occurred. In Chapter 4, contingency tables evaluate the following relationships:

Belief Perspective 1 or 2 (internal or external):

- Race of Lethal Force Victim $\times$ Race of Officer

- Age of Lethal Force Victim $\times$ Race of Officer

- Race of Lethal Force Victim $\times$ Officer Experience

- $\quad$ Race of Lethal Force Victim $\times$ Armed vs. Unarmed

- Race of Lethal Force Victim $\times$ Violent Call or Not

- Race of Lethal Force Victim $\times$ Race of Community Leader (i.e., Mayor)

- Race of Lethal Force Victim $\times$ Race of Law Enforcement Leader (Chief or Sheriff)

- Race of Lethal Force Victim $\times$ Presence of a Non-Police Witness

- Race of Lethal Force Victim $\times$ Region of the U.S.

- Race of Lethal Force Victim $\times$ Location Type (outside, residential, business, vehicle)

- Race of Lethal Force Victim $\times$ Time of Day

- Race of Lethal Force Victim $\times$ Zip Code Income

- Race of Lethal Force Victim $\times$ Zip Code Diversity

Force justified (the situational perspective): 
- Race of Lethal Force Victim $\times$ Armed vs. Unarmed

- Race of Lethal Force Victim $\times$ Armed with Gun vs. Not

- Race of Lethal Force Victim $\times$ Aiming Gun vs. Not

- Race of Lethal Force Victim (armed or not) x Race of Officer

- Race of Lethal Force Victim $\times$ Presence of a Non-Police Witness

- Race of Lethal Force Victim $\times$ Violent Call or Not

- Race of Lethal Force Victim $\times$ Time of Day

Micro-level, meso-level, or macro-level:

- Race of Lethal Force Victim $\times$ Race of Officer

- Age of Lethal Force Victim $\times$ Race of Officer

- Race of Lethal Force Victim $\times$ Officer Experience

- Race of Lethal Force Victim $\times$ Race of Community Leader (i.e., Mayor)

- Race of Lethal Force Victim $\times$ Race of Law Enforcement Leader (Chief or Sheriff)

- Race of Lethal Force Victim $\times$ Armed vs. Unarmed

- Race of Lethal Force Victim $\times$ Armed with Gun vs. Not

- Race of Lethal Force Victim $\times$ Aiming Gun vs. Not

- Race of Lethal Force Victim $\times$ Presence of a Non-Police Witness

- Race of Lethal Force Victim $\times$ Violent Call or Not

- Race of Lethal Force Victim $\times$ Region of the U.S.

Simple test to determine if race is a factor in micro-level officer decision to deploy lethal force: 
- Simple Test: Proportion of Victims Armed vs. Unarmed ( $\times$ Race of Victim) $\times$ Race of Officer

The simple test (Objective 4). The fourth objective considers potential evidence of racial discrimination in police killings data using a simple test. I argued that, based on the data, race may influence police officers' decisions to use lethal force; the null hypothesis is that there is no evidence that race may affect the decision to use lethal force.

According to Anwar and Fang (2006), Fryer (2016), and Knowles et al. (2001), the simple test can be used to test for discrimination in officers' actions. Fryer (2016) also explained that the simple test is an acceptable approach to testing for discrimination in officer-involved use of lethal force. In this case, the simple test compares the fraction of Caucasian and African American suspects who were armed, respectively, and considers the race of officers who deployed lethal force (Fryer, 2016). As part of the present study, we constructed a simple contingency table to apply the simple test to the 2014: Intentional Lethal Force Data. The table depicts the percentage of persons killed by police (and those who were unarmed) by the victim's race, separated by those who were killed by Caucasian or non-Caucasian officers. According to Fryer (2016), if the proportion of killing an unarmed victim by race differs based on officer race, then one can reject the null hypothesis of no discrimination.

Reliability of simple test. Fryer (2016) used the simple test to consider racial discrimination in police killings. Knowles et al. (2001) and Anwar and Fang (2006) employed the test when considering racial discrimination related to traffic stop searches. Even so, the test has limitations; it does not evaluate all elements of the chosen situational perspective (Appendix C); the elements courts use to evaluate whether use of force is 
justified; or the type of call (danger/situation), suspect's actions, the presence of a weapon, and reasonableness of the officer's decision. A complete analysis would include whether the suspect was armed and whether he/she was attacking or violently resisting an officer, the latter of which is important to consider regardless of whether a suspect was armed. Violently resisting is of prime importance because, in the U.S., any fight in which an officer is involved will include the firearm the officer carries; if the officer loses a fight with an armed or unarmed person, then the firearm becomes readily available. If the officer's firearm falls into the hands of a violently resisting person, then one may assume an immediate threat to the officer and others in the surrounding area. Therefore, unarmed persons who are violently resisting an officer could warrant lethal force.

As another drawback of the simple test, the method does not consider the likelihood of violence in the call to which an officer was responding. The U.S. Supreme Court recommended this consideration to lower courts in Graham v. Connor (Graham, 1989). Thus, the simple test does not capture all critical components of the situational perspective regarding a law enforcement lethal force encounter, but it does provide a tested and accepted model for evaluating evidence of racial discrimination in officers' use of lethal force.

Multivariate analysis (Objectives 2, 3, 4). I employ 4 separate models to test the aforementioned theories (Belief Perspectives 1 and 2, the situational perspective, the simple test). The first two models examine whether there is greater evidence that internal law enforcement factors (Belief Perspective 1) or external, societal, factors are related to racial disparities in lethal force. The third model examines whether there is evidence that the danger of a situation (victim armed, violence likely in initial call, call at night, 
witnesses present) are related to disparities in lethal force. The fourth model is a test of the simple test to see if a regression model shows anything different than the simple test, related to whether there is evidence that race is a factor used in the micro-level officer decision to deploy lethal force. and considering the above findings I turn to a multivariate analysis in Table 19.

\section{Dataset Limitations}

Considering the Graham v. Connor recommendations to lower courts along with the theoretical model in Figure 1, the characteristics of this dataset capture lethal force usage in the context of (1) the severity of the crime to which officers were responding; (2) the presence of weapons; and (3) citizen actions or behaviors, such as resisting, escaping, or posing a threat. One limitation of this dataset is that no characteristic captures officers' behavior apart from use of lethal force; that is, there is no measure of an officer's actions or words prior to using force.

Shane and Swenson (2018) and Selby, Singleton, and Flosi (2016) also highlighted another crucial characteristic: whether the suspect was violently resisting the officer. Establishing whether a suspect is violently resisting is highly controversial; essentially, the officer who deployed lethal force would need to describe whether the other person's actions led to the killing. The Killed by Police: 2014 Dataset did not include this characteristic. However, most studies on the use of lethal force in law enforcement (e.g., Fryer, 2016; Selby et al., 2016; Shane \& Swenson, 2018) have reported that nearly all individuals killed by police were armed and/or violently resisting.

The only aspect of the theoretical perspective that this dataset did not capture is officer actions. Although our data reflected an officer's action of deploying lethal force, 
we do not know whether officers issued verbal commands or attempted other force techniques prior to applying lethal force. Additionally, this dataset did not capture whether the officer perceived a threat when deploying lethal force. Future research should seek to identify officers' actions prior to use of lethal force.

Although our analysis revealed that 860 persons were intentionally killed by police in the line of duty in 2014, the population size varied based on other characteristics; the sample size declined when a characteristic included missing data. Another dataset limitation is that all observations involved situations in which officers killed the victim. Our dataset does not capture situations where officers were authorized to use lethal force and chose not to. It also does not reflect situations where officers employed force that would descriptively qualify as lethal force but the suspect survived. Both of these situations are of theoretical and practical importance when evaluating officers' use of lethal force but are inherently more difficult to ascertain than the data captured in this dataset. However, our descriptive data are generally inclusive, accurate, and reliable, thereby facilitating an informed discussion on the use of lethal force in law enforcement.

\section{Summary of Objectives}

As described, the main purpose of this research was to perform and employ empirical research to explore whether there is evidence that race is a factor at the microlevel officer decision to use lethal force. The first objective was to enhance the availability and reliability of data and information on use of lethal force to promote more informed conversations and policy decisions in police organizations and among policymakers. The second objective was to describe the characteristics of police killings 
in the U.S. in 2014. Accordingly, we described available information about all chosen characteristics and consider those characteristics according to the two belief perspectives (internal and external), the theoretical perspective (justified force or not), and varying levels where race could be a factor (micro, meso, macro). Characteristics collected in 2014 included the victim's possession of a weapon, officer race, leadership race (e.g., race of the mayor or chief), victim's demographic characteristics, officer's demographic characteristics, and contextual details (e.g., location and time of killing; reported incident/call type). The third objective considers the extent to which incident characteristics varied by the victim's race or ethnicity, which enabled us to identify unique situational factors correlated with the victims (collectively and respectively) by race. The fourth objective considers whether evidence exists of racial discrimination in police killings data using a simple test. This test involved a comparative analysis of proportions (i.e., of persons killed by police and unarmed by race, separated by officer race). The final test uses multivariate analyses to test assumptions within the two belief perspectives, the situational perspective, and the simple test. 


\section{Chapter 4.}

\section{Findings: What Do the 2014: Intentional Lethal Force Data Show?}

\section{Introduction}

Purpose and objectives. The main purpose of this research was to conduct and apply reliable empirical research to determine whether there is evidence that race (or other characteristics) were influences in police officers' decisions to use lethal force. Chapter 3 described the data creation, and this chapter provides a description and evaluation of the 2014: Intentional Lethal Force Data (Menifield \& Laughlin, 2018). The overarching objective of this dissertation is to extend the availability and reliability of data and information on police killings to promote informed conversations and policy decisions among police organizations, the public, and policymakers. The second objective is to describe police killings in the U.S. in 2014. The third objective considers to what extent incident characteristics varied by a victim's race or ethnicity. The fourth objective examines whether evidence exists of racial discrimination in police killings data by using a simple test ("the fraction of Caucasian and African American suspects, separately, who are armed conditional upon being involved in an officer-involved shooting" [Fryer, 2016, p. 6], compared across officer races). The final test uses multivariate analysis to measure the influence of community/societal factors, internal law enforcement factors, factors related to the danger of the incidents, and the simple test (whether victims are armed by victim race against officer race).

This study provides a descriptive analysis, cross-tabulations, a simple test, and multivariate analyses to evaluate potential evidence of racial bias in officers' deployment 
of lethal force in 2014. This analysis offers valuable information about the state of the use of lethal force in law enforcement in the U.S. in 2014 to enrich the body of knowledge around the use of lethal force in law enforcement and provide a foundation for collecting additional years of data. This chapter concludes by presenting the results of the simple test along with potential evidence of discrimination in officers' use of lethal force.

Importance. This study is important because available data on police officers' use of lethal force are lacking and should be expanded (DeGue et al., 2016; Fyfe, 1998; Fryer, 2016; Klinger, 2012; Menifield et al., 2019). The constructed database offers reliable information about persons killed by police along with characteristics of the victims, the offending officers, and the context of each incident. I refer to these data in evaluating the relationships between race and several critical characteristics of incidents involving lethal force to determine whether there is evidence of racial bias in officers' use of lethal force. Given that Caucasian officers may be perceived as targeting unarmed nonCaucasian suspects, this database may be helpful in clarifying the narrative around lethal force in law enforcement. Despite previous findings discussed in Chapters 1 and 2, there is an ongoing national debate concerning law enforcement officers' use of lethal force, and some individuals believe that Caucasian officers are targeting unarmed nonCaucasian suspects. Adding data to an area of policy that is data-poor and adding pertinent information to this ongoing national debate are strong reasons to explore the use of lethal force in law enforcement in more detail.

\section{Findings}

Non-simple test findings. In 2014, officers used lethal force to intentionally kill 860 persons. Table 1 provides an overall picture of the race of victims compared to the 
U.S. population (population data derived from U.S. Census Bureau Quick Facts, 2017). These data show that African Americans (AA) represented 26.9\% of those killed by police, twice their representation in the U.S. population (13.2\%). Hispanic persons represented $18.5 \%$ of those killed by police, similar to their representation in the U.S. population (17.8\%). Asian Americans (1.6\%), Native Americans, (0.5\%), and Caucasians (48.8\%) were each less represented among those killed by police than in the U.S. population $(5.3 \%, 1.9 \%$, and $61.8 \%$, respectively). In accordance with the literature, Table 1 reveals that African Americans were overrepresented among those killed by police in 2014.

Differences between overall population estimates by race and violent offender estimates by race are substantial and provide additional context into officers' use of lethal force. Table 1 presents a comparison of the race of those killed by police to a proxy for the race of violent offenders. Violent offender race was identified based on victim reports from the National Crime Victimization Surveys (NCVS) between years 2012 and 2015 (Morgan, 2017). NCVS estimates are not assumed to be perfect but are considered preferable to UCR arrest numbers. However, both forms of data may be subject to misrepresentation: NCVS reports should be interpreted cautiously due to potential cocontamination by self-reported victims; UCR data could be inaccurate due to reporter cocontamination, police misreports, or discriminatory policing.

The Violent Offender Race estimate in Table 1 is only equal to $83.1 \%$ because NCVS includes "Two or more races", "Multiple offenders of various races", "Unknown offender race", and "unknown number of offenders" as qualifiers. If Violent Offender Race is an accurate estimate of violent offending rates in the U.S., then racial disparities 
in officers' use of lethal force shift accordingly. African Americans (26.9\%) and Hispanics (18.5\%) remain overrepresented as victims than as violent offenders (by 4.2 percentage points and 4.1 percentage points, respectively). Likewise, there is still an underrepresentation of 5.0 percentage points of Caucasian victims when compared to the Violent Offender Race. As Violent Offender Race is a more controversial proxy than the U.S. Census' population estimates based on race (which is also a proxy of the actual U.S. population) and because the U.S. Census estimates are more commonly used as a basis for comparison, the remainder of this chapter will focus on U.S. Census Population estimates, but that does not mean the reader should ignore disparities in victim reported Violent Offender Race and U.S. population estimates by race.

Table 1

Race of Lethal Force Victims (2014)

\begin{tabular}{lllll}
\hline $\begin{array}{l}\text { Race of } \\
\text { Victims }\end{array}$ & $\begin{array}{l}\text { Number } \\
\text { of } \\
\text { Victims }\end{array}$ & $\begin{array}{l}\text { Total } \\
\text { Victims } \\
\text { (Percentage) }\end{array}$ & $\begin{array}{l}\text { U.S. } \\
\text { Population* } \\
\text { (Percentage) }\end{array}$ & $\begin{array}{l}\text { Violent } \\
\text { Offender } \\
\text { Race** } \\
\text { (Percentage) }\end{array}$ \\
\hline A.A. & 232 & 26.9 & 13.2 & 22.7 \\
Cau. & 420 & 48.8 & 61.8 & 43.8 \\
H.A. & 159 & 18.5 & 17.8 & 14.4 \\
A.S.A.M. & 14 & 1.6 & 5.3 & 1.3 \\
N.A. & 5 & 0.5 & 1.9 & 0.4 \\
Other & 30 & 3.5 & N/A & $2.2^{* * *}$ \\
Total & 860 & 100 & 100 & 83.1 \\
\hline
\end{tabular}

Note. Data taken from 2014: Intentional Lethal Force Data (Menifield \& Laughlin, 2018). [Copyright: Michael Laughlin]. A.A. = African American; Cau. = Caucasian; H.A $=$ Hispanic; A.S.A.M. $=$ Asian American; N.A. $=$ Native American.

* 2017 estimates

** 2012-2015 estimates

*** $2.2 \%$ includes $1.3 \%$ A.S.A.M. and $0.4 \%$ N.A.

National conversations continue regarding the age and gender of victims of lethal force. As noted, in the field of criminology, consistent evidence has shown that criminal 
activity is associated with age. More specifically, in every crime (except gambling) reported by the FBI UCR, people under 25 have the highest offending rates (Ulmer \& Steffensmeier, 2014). In 2014 and thereafter, the media has highlighted police officers killing young African American men in several instances; therefore, it is reasonable to assume that some individuals may believe that Caucasian police officers are not merely targeting minorities, but more specifically young African American men. Tables 2A and 2B show that age and gender warrant consideration in police killings. Each table includes a robust sample size (2A $n=847,2 \mathrm{~B} n=860)$, although Table $2 \mathrm{~A}$ is missing 13 victims' ages; all victims' genders appear in Table 2B. As expected based on prior lethal force studies, most victims (95\%) in 2014 were men. Over 80\% were younger than 51 years of age, and over $75 \%$ were younger than 45 .

Table 2A

Age of Lethal Force Victims (2014)

\begin{tabular}{lcl}
\hline Age & $n$ & Percentage \\
\hline$<26$ & 190 & 22.4 \\
$26-33$ & 208 & 24.6 \\
$34-45$ & 243 & 28.7 \\
$>45$ & 206 & 24.3 \\
Total & 847 & 100 \\
\hline
\end{tabular}

Table 2B

Gender of Lethal Force Victims (2014)

\begin{tabular}{lll}
\hline Gender & $n$ & Percentage \\
\hline Male & 817 & 95 \\
Female & 43 & 5 \\
Total & 860 & 100 \\
\hline
\end{tabular}

Note. Data taken from 2014: Intentional Lethal Force Data (Menifield \& Laughlin, 2018). [Copyright: Michael Laughlin]. 
Table 3 outlines the race of officers who intentionally deployed lethal force in 2014 compared to total officer race population estimates for U.S. law enforcement (DataUSA, 2014). The officer's race was missing in 122 instances and unknown in 427 instances, hence the sample size of 309 . Caucasian officers comprised $85.1 \%$ of those using lethal force. By contrast, 10.7\% of officers using lethal force were Hispanic; roughly 3.6\% were African American. Caucasian officers were slightly overrepresented (85.1\%) compared to U.S. police officer diversity estimates (79.6\%). African American officers were underrepresented (3.6\%) compared to national estimates $(12.3 \%)$, as were Asian American officers ( $0.6 \%$ used lethal force compared to $2.2 \%$ of the overall officer population). Native American officers only deployed lethal force twice. Hispanic officer estimates were not available via the DataUSA website; these estimates were based on the Department of Justice's 2013 estimates and the Bureau of Labor Statistics' 2016 estimates.

Table 3

Race of Officers Who Deployed Lethal Force (2014)

\begin{tabular}{lllll}
\hline $\begin{array}{l}\text { Officer } \\
\text { Race }\end{array}$ & $n$ & $\begin{array}{l}\text { Sample } \\
\text { (Percentage) }\end{array}$ & $\begin{array}{l}\text { Total U.S. } \\
\text { Police } \\
\text { Officer } \\
\text { Population } \\
\text { (Percentage) }\end{array}$ & $\begin{array}{l}\text { Total U.S. } \\
\text { Workforce } \\
\text { (Percentage) }\end{array}$ \\
\hline A.A. & 11 & 3.6 & 12.3 & 11.6 \\
Cau. & 263 & 85.1 & 79.6 & 75.2 \\
H.A. & 33 & 10.7 & $12^{*}$ & $16.8^{* *}$ \\
A.S.A.M. & 2 & 0.6 & 2.2 & 5.6 \\
N.A. & 2 & 0.6 & 0.6 & 0.5 \\
Total & 311 & 100 & $94.7^{* * *}$ & $92.9^{* * *}$ \\
\hline
\end{tabular}

Note. Data taken from 2014: Intentional Lethal Force Data (Menifield \& Laughlin, 2018). [Copyright: Michael Laughlin]

*Hispanic Police Officer estimate from Department of Justice (year 2013).

**Hispanic Workforce estimate from Bureau of Labor Statistics (year 2016). 
***Total percentage does not include Hispanics.

As noted in Chapter 3, each contingency table provides the Pearson's Chi-square statistic to show the relative significance of relationships between characteristics; Cramer's V test indicates the strength of a relationship between two characteristics. A high level of significance in Pearson's Chi-square test suggest low probability of the data distribution having occurred by chance. A strong association in Cramer's V test implies that the independent variable (i.e., victim's race in Table 4) is a strong predictor of the dependent variable (i.e., officer's race in Table 4).

Table 4 further considers the race of officer(s) who deployed lethal force along with the race of the victim, which had a moderately strong relationship according to Cramer's V. Table 4 includes officer race and the specific victim's race rather than separating victim race dichotomously. Officer race was considered based on the literature and media narrative that Caucasian police officers are discriminately killing African American men. The relationship between officer race and victim race is an essential consideration for evaluating the belief perspectives (internal or external) and the simple test. In Table 4 (and all tables including officer race, organizational leader race, or community leader race), column and row totals are reported (column totals are third from the top row for each characteristic).

Table 4 shows that officer race may matter when considering officers' use of lethal force, yet a passive representation of race may not lead to a more equitable representation of victims in officers' use of lethal force. The data indicate that each officer was more likely to kill members of his/her own race than to kill members of other races. Although African American officers killed less than 4\% of all victims, nearly $73 \%$ 
of their victims were African American. Whereas Hispanic officers killed less than 11\% of victims, approximately $75 \%$ were non-Caucasian, and nearly half were Hispanic. Caucasian officers killed around $85 \%$ of all victims and were responsible for the deaths of more than $91 \%$ of Caucasian victims.

The discussion in Chapter 5 will address how the relationship between officer race and victim race is believed to be related to officers' deployment decisions and employment tendencies rather than micro-level use of lethal force. Briefly, cities with higher percentages of any race may be more likely to employ officers of that race; when police departments work in areas with differential race distribution, those departments may seek to deploy officers into neighborhoods by matching officer race with neighborhood racial disparities.

Table 4

Race of Lethal Force Victim $\times$ Race of Officer (2014)***

Race of Officer

\begin{tabular}{llllll}
\hline $\begin{array}{l}\text { Race of } \\
\text { Victim }\end{array}$ & $\begin{array}{l}\text { African } \\
\text { American }\end{array}$ & $\begin{array}{l}\text { Asian } \\
\text { American }\end{array}$ & $\begin{array}{l}\text { Hispanic } \\
\text { American }\end{array}$ & Caucasian & $\begin{array}{l}\text { Total } \\
\text { Percentage } \\
\text { (Number) }\end{array}$ \\
\hline African & $8.4 \%$ & $0 \%$ & $10.5 \%$ & $81.1 \%$ & $100 \%$ \\
American & $(8)$ & $(0)$ & $(10)$ & $(77)$ & $(95)$ \\
& $72 \% *$ & 0 & $31.3 \%$ & $29.8 \%$ & $31.4 \%$ \\
Asian & 0 & 0 & 0 & $100 \%(6)$ & $100 \%$ \\
American & $(0)$ & $(0)$ & $(0)$ & $2.3 \%$ & $(6)$ \\
& 0 & 0 & 0 & & $2.0 \%$ \\
Hispanic & 0 & 0 & $31.1 \%$ & $68.9 \%$ & $100 \%$ \\
American & $(0)$ & $(0)$ & $(14)$ & $(31)$ & $(45)$ \\
& 0 & 0 & $43.8 \%$ & $12 \%$ & $14.9 \%$ \\
Caucasian & $1.9 \%$ & $1.3 \%$ & $5.1 \%(8)$ & $91.7 \%$ & $100 \%$ \\
& $(3)$ & $(2)$ & $25 \%$ & $(144)$ & $(157)$ \\
& $18 \%$ & $100 \%$ & & $55.8 \%$ & $51.8 \%$ \\
Total & $3.6 \%$ & $0.6 \%$ & $10.6 \%$ & $85.1 \%$ & \\
& $(11)$ & $(2)$ & $(32)$ & $(258)$ & $N=303$ \\
& $100 \%$ & $100 \%$ & $100 \%$ & $100 \%$ & \\
\hline
\end{tabular}


Note. Data taken from 2014: Intentional Lethal Force Data (Menifield \& Laughlin, 2018). [Copyright: Michael Laughlin]. $p<.05$.

*Column totals listed third.

Regarding victim age, Table 5 lists victims' ages in relation to the race of the officer(s) who deployed lethal force (Table 5A). Because young persons (i.e., under age 25) are overrepresented offenders in all UCR crime categories except gambling (Ulmer \& Steffensmeier, 2014), one could assume that younger persons will be contacted by police more frequently, increasing the likelihood of younger persons being killed by police. Exploring the age and race of the victims who were killed by police provides additional information about those who were killed by police.

The Chi-square tests in Tables 5A-D demonstrate insignificant relationships because some columns contain too few incidents. Table 5A shows the relationship between the victim's age and officer's race, which exhibited a weak relationship according to the Cramer's V test. The relationship was also not significant based on Pearson's Chi-square test. The sample contained 308 incidents due to missing data, but victims' ages appeared representative. Approximately $24 \%$ of victims were older than age 45 in Table $2 \mathrm{~A}$ compared with roughly $23 \%$ in Table $5 \mathrm{~A}$. Victims were overrepresented in the two youngest age categories and underrepresented in the 34-45 age category when comparing Tables $2 \mathrm{~A}$ and $5 \mathrm{~A}$.

The most people killed by Caucasian police officers were either younger than 26 (26.7\%) or between 34 and 45 years old (26.3\%). The most people killed by African American officers were younger than 26 years old (45.5\%). Data in Table 5A help refute the perspective that Caucasian police officers kill younger people more often than officers of other races. When comparing the three largest race categories among police 
officers, Caucasian officers (26.7\%) killed fewer victims under age 26 than African American officers (45.5\%) but more than Hispanic officers (21.2\%). The age-crime relationship noted in the field of criminology would lead one to expect that police would kill more young people. The data in Table 5 of those killed by police are reflective of the FBI's UCR (2017) estimates of offenders under age 50.

Tables 5B-5D indicate that the race of the officer and victim may matter when considering age. The 'under 26' age category included more African American (31.9\%) and Hispanic (37.3\%) victims than Caucasian victims (20\%). In Table 5B, the race of the officer deploying force and the age of African American victims had a moderately strong but non-significant relationship. African American officers killed African American victims under age 26 more often (57\%) than the other three age categories combined (43\%). Caucasian and Hispanic officers killed higher proportions of African American victims between the ages of 26 and 33 and 34-45 compared to victims younger than 26 .

Table $5 \mathrm{C}$ reveals that the race of the officer deploying force and the age of Hispanic victims had a moderately strong but non-significant relationship. Only Hispanic and Caucasian officers appeared to use lethal force against Hispanic victims. Hispanic and Caucasian officers deployed the highest proportion of lethal force against the youngest Hispanic victims (36\% of Caucasian and Hispanic officers on average) and the second highest proportion against Hispanic victims between 34 and 45 years old (33\% of Caucasian and Hispanic officers on average).

Table 5D reveals the relationship between the age of Caucasian victims and officer race. The race of the officer who deployed force and the age of Caucasian victims had a moderately strong relationship as evidenced by Cramer's V; however, this 
relationship was not significant according to Pearson's Chi-square test. Caucasian victims were killed most often among victims over age 45 (32\%), with comparatively low proportions of Hispanic (12\%) and African American victims (11\%) according to Tables $5 \mathrm{~B}$ and $5 \mathrm{C}$.

Although the overall numbers do not suggest Caucasian officers were targeting young African American men in 2014, the data indicate higher proportions of African American and Hispanic victims killed at younger ages. Tables 5A-5D also reveal a higher proportion of Caucasian victims older than age 45. Taken together, these results imply that age should be considered when evaluating police officers' use of lethal force. Interestingly, victims' ages do not support the established age-crime relationship for younger offenders; however, the age distribution does echo the estimated proportion of offenders younger than age 50. Therefore, offenders who do not 'age out' early as expected (Ulmer \& Steffensmeier, 2014) may go on to engage in more severe or violent crimes. Higher proportions of older-young offenders (26-45 years old) may thus be killed by police despite not engaging in crime (or being caught engaging in crime) as often as younger offenders (under 26).

Table 5A

Age of All Lethal Force Victims $\times$ Race of Officer (2014)

Officer's Race (all victims)

\begin{tabular}{llllll}
\hline $\begin{array}{l}\text { Victim } \\
\text { Age }\end{array}$ & A.A. & Cau. & H.A. & A.S.A.M. & $\begin{array}{l}\text { Total by } \\
\text { Age } \\
\text { Percentage } \\
\text { (Number) }\end{array}$ \\
\hline$<26$ & $6.1 \%$ & $85.4 \%$ & $8.5 \%$ & $0 \%$ & $100 \%$ \\
& $(5)$ & $(70)$ & $(7)$ & $(0)$ & $(82)$ \\
& $45.5 \% *$ & $26.7 \%$ & $21.2 \%$ & 0 & $26.6 \%$ \\
$26-33$ & $40 \%$ & $82.7 \%$ & $10.7 \%$ & $2.7 \%$ & $100 \%$ \\
& $(3)$ & $(62)$ & $(8)$ & $(2)$ & $(75)$ \\
\hline
\end{tabular}




\begin{tabular}{|c|c|c|c|c|c|}
\hline $\begin{array}{l}\text { Victim } \\
\text { Age }\end{array}$ & A.A. & Cau. & H.A. & A.S.A.M. & $\begin{array}{l}\text { Total by } \\
\text { Age } \\
\text { Percentage } \\
\text { (Number) }\end{array}$ \\
\hline & $27.3 \%$ & $23.7 \%$ & $24.2 \%$ & $100 \%$ & $24.4 \%$ \\
\hline $34-45$ & $\begin{array}{l}1.3 \% \\
\text { (1) }\end{array}$ & $\begin{array}{l}87.3 \% \\
(69)\end{array}$ & $\begin{array}{l}11.4 \% \\
(9)\end{array}$ & $\begin{array}{l}0 \% \\
(0)\end{array}$ & $\begin{array}{l}100 \% \\
(79)\end{array}$ \\
\hline & $9.1 \%$ & $26.3 \%$ & $27.3 \%$ & 0 & $25.6 \%$ \\
\hline$>45$ & $\begin{array}{l}2.8 \% \\
(2) \\
18.2 \%\end{array}$ & $\begin{array}{l}84.7 \% \\
(61) \\
23.3 \%\end{array}$ & $\begin{array}{l}12.5 \% \\
(9) \\
27.3 \%\end{array}$ & $\begin{array}{l}0 \% \\
(0) \\
0\end{array}$ & $\begin{array}{l}100 \% \\
(72) \\
23.4 \%\end{array}$ \\
\hline $\begin{array}{l}\text { Total } \\
\text { by } \\
\text { Officer } \\
\text { Race }\end{array}$ & $\begin{array}{l}3.6 \% \\
(11) \\
100 \%\end{array}$ & $\begin{array}{l}85.1 \% \\
(262) \\
100 \%\end{array}$ & $\begin{array}{l}10.7 \% \\
(33) \\
100 \%\end{array}$ & $\begin{array}{l}0.6 \% \\
(2) \\
100 \%\end{array}$ & $N=308$ \\
\hline
\end{tabular}


Table 5B

Age of African American Victims Killed by Lethal Force $\times$ Race of Officer (2014)

Officer's Race (African American Victims)

\begin{tabular}{|c|c|c|c|c|c|}
\hline $\begin{array}{l}\text { Victim } \\
\text { Age }\end{array}$ & A.A. & Cau. & H.A. & A.S.A.M. & $\begin{array}{l}\text { Total } \\
\text { by } \\
\text { Age }\end{array}$ \\
\hline \multirow[t]{3}{*}{$<26$} & $13.3 \%$ & $80 \%$ & $6.7 \%$ & $0 \%$ & $100 \%$ \\
\hline & (4) & (24) & (2) & $(0)$ & $(30)$ \\
\hline & $57 \% *$ & $31.2 \%$ & $20 \%$ & 0 & $31.9 \%$ \\
\hline \multirow[t]{3}{*}{$26-33$} & $3.8 \%$ & $84.6 \%$ & $11.5 \%$ & $0 \%$ & $100 \%$ \\
\hline & (1) & $(22)$ & (3) & $(0)$ & (26) \\
\hline & $14.3 \%$ & $28.6 \%$ & $30 \%$ & 0 & $27.7 \%$ \\
\hline \multirow[t]{3}{*}{$34-45$} & $3.8 \%$ & $88.5 \%$ & 7.7 & $0 \%$ & $100 \%$ \\
\hline & (1) & $(23)$ & (2) & $(0)$ & (26) \\
\hline & $14.3 \%$ & $29.9 \%$ & $20 \%$ & 0 & $27.7 \%$ \\
\hline \multirow[t]{3}{*}{$>45$} & $3.8 \%$ & $66.7 \%$ & $25 \%$ & $0 \%$ & $100 \%$ \\
\hline & (1) & (8) & (3) & $(0)$ & (12) \\
\hline & $14.3 \%$ & $10.4 \%$ & $30 \%$ & 0 & $12.8 \%$ \\
\hline Total & $7.4 \%$ & $81.9 \%$ & $10.6 \%$ & $0 \%$ & \\
\hline & (7) & $(77)$ & $(10)$ & $(0)$ & $N=$ \\
\hline $\begin{array}{l}\text { Officer } \\
\text { Race }\end{array}$ & $100 \%$ & $100 \%$ & $100 \%$ & 0 & 94 \\
\hline
\end{tabular}


Table 5C

Age of Hispanic Victims Killed by Lethal Force $\times$ Race of Officer (2014)

Officer's Race (Hispanic Victims)

\begin{tabular}{|c|c|c|c|c|c|}
\hline $\begin{array}{l}\text { Victim } \\
\text { Age }\end{array}$ & A.A. & Cau. & H.A. & A.S.A.M. & $\begin{array}{l}\text { Total } \\
\text { by } \\
\text { Age }\end{array}$ \\
\hline \multirow[t]{3}{*}{$<26$} & $0 \%$ & $75 \%$ & $25 \%$ & $0 \%$ & $100 \%$ \\
\hline & $(0)$ & (12) & (4) & $(0)$ & (16) \\
\hline & $0^{*}$ & $38.7 \%$ & $28.6 \%$ & 0 & $35.5 \%$ \\
\hline \multirow[t]{3}{*}{$26-33$} & $0 \%$ & $66.7 \%$ & $33.3 \%$ & $0 \%$ & $100 \%$ \\
\hline & $(0)$ & (6) & (3) & $(0)$ & (9) \\
\hline & 0 & $19.4 \%$ & $21.4 \%$ & 0 & $20 \%$ \\
\hline \multirow[t]{3}{*}{$34-45$} & $0 \%$ & $66.7 \%$ & $33.3 \%$ & $0 \%$ & $100 \%$ \\
\hline & $(0)$ & (10) & $(5)$ & $(0)$ & (15) \\
\hline & 0 & $32.3 \%$ & $35.7 \%$ & 0 & $33.3 \%$ \\
\hline \multirow[t]{3}{*}{$>45$} & $0 \%$ & $60 \%$ & $40 \%$ & $0 \%$ & $100 \%$ \\
\hline & $(0)$ & (3) & (2) & $(0)$ & (5) \\
\hline & 0 & $9.7 \%$ & $14.3 \%$ & 0 & $11.1 \%$ \\
\hline Total & $0 \%$ & $68.9 \%$ & $31.1 \%$ & $0 \%$ & \\
\hline & $(0)$ & $(31)$ & (14) & $(0)$ & $N=$ \\
\hline $\begin{array}{l}\text { Officer } \\
\text { Race }\end{array}$ & 0 & $100 \%$ & $100 \%$ & 0 & 45 \\
\hline
\end{tabular}


Table 5D

Age of Caucasian Victims Killed by Lethal Force $\times$ Race of Officer (2014)*

Officer's Race (Caucasian Victims' Ages)

\begin{tabular}{llllll}
\hline $\begin{array}{l}\text { Victim } \\
\text { Age }\end{array}$ & A.A. & Cau. & H.A. & A.S.A.M. & $\begin{array}{l}\text { Total } \\
\text { by } \\
\text { Age }\end{array}$ \\
\hline$<26$ & $3 \%$ & $93.9 \%$ & $3 \%$ & $0 \%$ & $100 \%$ \\
& $(1)$ & $(31)$ & $(1)$ & $(0)$ & $(33)$ \\
& $33.3 \% *$ & $21.7 \%$ & $12.5 \%$ & 0 & $21.4 \%$ \\
$26-33$ & $2.8 \%$ & $91.7 \%$ & $5.6 \%$ & $0 \%$ & $100 \%$ \\
& $(1)$ & $(33)$ & $(2)$ & $(0)$ & $(36)$ \\
& $33.3 \%$ & $23.1 \%$ & $25 \%$ & 0 & $23.4 \%$ \\
$34-45$ & $0 \%$ & $97 \%$ & $3 \%$ & $0 \%$ & $100 \%$ \\
& $(0)$ & $(32)$ & $(1)$ & $(0)$ & $(33)$ \\
$>45$ & 0 & $22.4 \%$ & $12.5 \%$ & 0 & $21.4 \%$ \\
& $1.9 \%$ & $90.4 \%$ & $7.7 \%$ & $0 \%$ & $100 \%$ \\
Total & $1.9 \%$ & $92.9 \%$ & $5.2 \%$ & $0 \%$ & $(52)$ \\
by & $(3)$ & $(143)$ & $(8)$ & $(0)$ & $N=$ \\
Officer & $100 \%$ & $100 \%$ & $100 \%$ & 0 & 154 \\
Race & & & & & \\
\hline
\end{tabular}

Note. Data taken from 2014: Intentional Lethal Force Data (Menifield \& Laughlin, 2018). [Copyright: Michael Laughlin]; $p>.05$.

* Column totals reported third vertically in Tables 5A-5D.

Tables $6,7 \mathrm{~A}, 7 \mathrm{~B}$, and 7C indicate the presence of weapons at incidents and victims' behavior when possessing weapons. These tables are directly considering one of the factors in the situational perspective, to determine whether officers are primarily deploying lethal force in situations that are most likely to be deemed justified lethal force. Again, the assumption is that if officers are deploying lethal force in a justified manner, then it is less likely that race is playing a factor in those micro-level deployment decisions.

We considered whether individuals killed by police were armed due to the U.S. Supreme Court's instructions regarding how lower courts should consider the legality of 
use of lethal force in law enforcement incidents. Additionally, the presence of a weapon characteristic (i.e., whether the victim was armed with any type of weapon) is relevant to the literature and media narrative around Caucasian officers targeting unarmed African American men.

Table 6 displays the number of persons who were armed or unarmed and killed by police in 2014. Cramer's V revealed that the race of victims and whether they were armed had a moderately strong relationship ( $N=830$ due to missing data for 30 victims). Approximately $21 \%$ of African American victims did not have a weapon. Although the sample of Native Americans was smaller, $20 \%$ of victims did not have a weapon. Hispanics comprised the next highest proportion of unarmed victims, with nearly $14 \%$ killed without a weapon. Caucasians comprised the lowest proportion of victims killed without a weapon (i.e., less than 9\%). These data reveal an association between possession of a weapon and the victim's race; African Americans were more than twice as likely to be killed when unarmed than Caucasians.

Table 6

Lethal Force Victim Armed Versus Unarmed $\times$ Race (2014)***

\begin{tabular}{llll}
\hline $\begin{array}{l}\text { Victim } \\
\text { Race }\end{array}$ & $\begin{array}{l}\text { Un- } \\
\text { Armed }\end{array}$ & Armed & Total \\
\hline A.A. & $\begin{array}{l}20.7 \% \\
(48)\end{array}$ & $\begin{array}{l}79.3 \% \\
(184)\end{array}$ & $\begin{array}{l}100 \% \\
(232)\end{array}$ \\
A.S.A.M. & $14.3 \%$ & $85.7 \%$ & $100 \%$ \\
& $(2)$ & $(12)$ & $(14)$ \\
H.A. & $13.8 \%$ & $86.2 \%$ & $100 \%$ \\
& $(22)$ & $(137)$ & $(159)$ \\
Cau. & $8.8 \%$ & $91.2 \%$ & $100 \%$ \\
& $(37)$ & $(383)$ & $(420)$ \\
N.A. & $20 \%$ & $80 \%$ & $100 \%$ \\
& $(1)$ & $(4)$ & $(5)$ \\
Total & $13.2 \%$ & $86.8 \%$ & \\
& $(109)$ & $(716)$ & \\
\hline
\end{tabular}




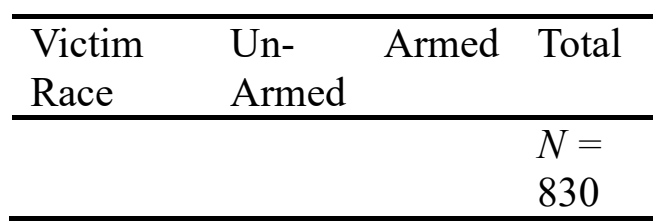

Note. Data taken from 2014: Intentional Lethal Force Data (Menifield \& Laughlin, 2018). [Copyright: Michael Laughlin]. $p<.05$.

Table 7A presents whether a victim's weapon was a gun (e.g., compared to a knife or bat) and then separates victim proportions by race $(N=725$ due to missing data). According to Cramer's V, victims' race and gun status had a moderately strong relationship that was significant according to Pearson's Chi-square test. In all, $16.7 \%$ of Asian victims possessed a gun followed by $60.9 \%$ of Hispanic victims and $66.8 \%$ of African American victims. Over $72 \%$ of Caucasian victims possessed a gun, the largest proportion of any race. Tables 6 and 7 delineate the relationship between race and possession of a weapon. Per Table 6, among persons killed in 2014, Caucasian persons were less likely to be unarmed compared to African Americans or Hispanics. Table 7 shows that in 2014, Caucasians were killed least often when not carrying a gun.

Table 7A

Lethal Force Victim Armed with Gun (or Not) $\times$ Race (2014)***

\begin{tabular}{llll}
\hline $\begin{array}{l}\text { Victim } \\
\text { Race }\end{array}$ & $\begin{array}{l}\text { No } \\
\text { Gun }\end{array}$ & Gun & Total \\
\hline A.A. & $\begin{array}{l}33.2 \% \\
(62)\end{array}$ & $\begin{array}{l}66.8 \% \\
(125)\end{array}$ & $\begin{array}{l}100 \% \\
(187)\end{array}$ \\
A.S.A.M. & $83.3 \%$ & $16.7 \%$ & $100 \%$ \\
& $(10)$ & $(2)$ & $(12)$ \\
H.A. & $39.1 \%$ & $60.9 \%$ & $100 \%$ \\
& $(54)$ & $(84)$ & $(138)$ \\
Cau. & $27.9 \%$ & $72.1 \%$ & $100 \%$ \\
& $(107)$ & $(277)$ & $(384)$ \\
N.A. & $50 \%$ & $50 \%$ & $100 \%$ \\
& $(2)$ & $(2)$ & $(4)$ \\
Total & $32.5 \%$ & $67.5 \%$ & \\
& $(233)$ & $(488)$ & $N=$ \\
& & & 725 \\
\hline
\end{tabular}


Note. Data taken from 2014: Intentional Lethal Force Data (Menifield \& Laughlin, 2018). [Copyright: Michael Laughlin]. $p<.05$.

Tables 7B and 7C present the actions of armed victims (with a gun) separated by victims' race. Table 7B explores the relationship between the race of the victims who possessed a gun and whether they aimed a gun or not. The sample size was 385 when solely considering victims in possession of a gun. Victims' race and whether they aimed a gun had a weak and non-significant relationship. About $80 \%$ of all victims who possessed a gun and were killed by police also aimed the gun. Specifically, $75 \%$ of Asian victims, $76 \%$ of African American victims, $81 \%$ of Hispanic victims, $82 \%$ of Caucasian victims, and $100 \%$ of Native American victims aimed a gun during an incident in which law enforcement deployed lethal force.

Table 7B

Lethal Force Victim Armed with Gun and Aimed Gun (or Not) $\times$ Race (2014)

\begin{tabular}{llll}
\hline $\begin{array}{l}\text { Victim } \\
\text { Race }\end{array}$ & $\begin{array}{l}\text { Did } \\
\text { Not } \\
\text { Aim }\end{array}$ & Aimed & Total \\
\hline A.A. & $23.9 \%$ & $76.1 \%$ & $100 \%$ \\
& $(26)$ & $(83)$ & $(109)$ \\
A.S.A.M. & $25 \%$ & $75 \%$ & $100 \%$ \\
& $(2)$ & $(6)$ & $(8)$ \\
H.A. & $18.8 \%$ & $81.2 \%$ & $100 \%$ \\
& $(13)$ & $(56)$ & $(69)$ \\
Cau. & $17.3 \%$ & $82.7 \%$ & $100 \%$ \\
& $(34)$ & $(163)$ & $(197)$ \\
N.A. & $0 \%$ & $100 \%$ & $100 \%$ \\
& $(0)$ & $(2)$ & $(2)$ \\
Total & $19.5 \%$ & $80.5 \%$ & \\
& $(75)$ & $(310)$ & $N=$ \\
& & & 385 \\
\hline
\end{tabular}

Note. Data taken from 2014: Intentional Lethal Force Data (Menifield \& Laughlin, 2018). [Copyright: Michael Laughlin]. $p>.05$. 
Table 7C depicts the race of victims who possessed a gun and whether they fired it; the sample size fell to 379 when only considering victims who possessed a gun.

Victims' race and whether they aimed a gun had a weak and non-significant relationship, particularly because the sample included so few Native Americans. About $42 \%$ of all victims who possessed a gun also shot the gun. Specifically, 57.1\% of Asian victims, $44.9 \%$ of African American victims, 31.8\% of Hispanic victims, $41.6 \%$ of Caucasian victims, and no Native American victims fired a gun during an incident in which law enforcement deployed lethal force.

Table 7C

Lethal Force Victim Armed with Gun and Shot Gun (or Not) $\times$ Race (2014)

\begin{tabular}{|c|c|c|c|}
\hline $\begin{array}{l}\text { Victim } \\
\text { Race }\end{array}$ & $\begin{array}{l}\text { Did } \\
\text { Not } \\
\text { Shoot }\end{array}$ & Shot & Total \\
\hline A.A. & $\begin{array}{l}55.1 \% \\
(59)\end{array}$ & $\begin{array}{l}44.9 \% \\
(48)\end{array}$ & $\begin{array}{l}100 \% \\
(107)\end{array}$ \\
\hline A.S.A.M. & $\begin{array}{l}42.9 \% \\
(3)\end{array}$ & $\begin{array}{l}57.1 \% \\
(4)\end{array}$ & $\begin{array}{l}100 \% \\
(7)\end{array}$ \\
\hline H.A. & $\begin{array}{l}68.2 \% \\
(45)\end{array}$ & $\begin{array}{l}31.8 \% \\
(21)\end{array}$ & $\begin{array}{l}100 \% \\
(66)\end{array}$ \\
\hline Cau. & $\begin{array}{l}58.4 \% \\
(115)\end{array}$ & $\begin{array}{l}41.6 \% \\
(82)\end{array}$ & $\begin{array}{l}100 \% \\
(197)\end{array}$ \\
\hline N.A. & $\begin{array}{l}100 \% \\
\text { (2) }\end{array}$ & $\begin{array}{l}0 \% \\
(0)\end{array}$ & $\begin{array}{l}100 \% \\
\text { (2) }\end{array}$ \\
\hline Total & $\begin{array}{l}58.3 \% \\
(224)\end{array}$ & $\begin{array}{l}41.7 \% \\
(158)\end{array}$ & $\begin{array}{l}N= \\
379\end{array}$ \\
\hline
\end{tabular}

Note. Data taken from 2014: Intentional Lethal Force Data (Menifield \& Laughlin, 2018). [Copyright: Michael Laughlin]. $p>.05$.

Tables 8 and 9 consider whether there is evidence that a lack of passive representation at the meso-level may contribute to racially disparate outcomes. Additionally, tables 8 and 9 examine whether there is evidence that disparate outcomes 
may be due to internal causes (lack of passive representation) (Table 8) or external causes (Table 9). Table 8 shows the race of law enforcement leaders at agencies where police used lethal force. The race of leadership suggests the importance of passive representation within police organizations in line with the literature $(N=546$ due to missing data). The race of the victims and of law enforcement organizational leaders demonstrated a moderately strong relationship as indicated by Cramer's V; this association was significant according to Pearson's Chi-square test. In 2014, African American victims killed by police were overrepresented among departments with African American leaders and underrepresented among departments with Caucasian or Hispanic leaders. Although only about $14 \%$ of all victims were killed by officers from departments with African American leaders, those departments accounted for roughly $24 \%$ of African American victims. Departments with Caucasian or Hispanic leaders showed a similar but less pronounced trend of overrepresentation of victims who shared the same race as a law enforcement leader. 
Table 8

Race of Lethal Force Victim $\times$ Race of Police Chief/Sheriff (2014)***

Race of Police Chief/Sheriff

\begin{tabular}{llllll}
\hline $\begin{array}{l}\text { Victim } \\
\text { Race }\end{array}$ & A.A. & A.S.A.M. & H.A. & Cau. & Total \\
\hline A.A. & $24.2 \%$ & $0.6 \%$ & $2.4 \%$ & $72.7 \%$ & $100 \%$ \\
& $(40)$ & $(1)$ & $(4)$ & $(120)$ & $(165)$ \\
& $52.6 \% *$ & $33.3 \%$ & $15.4 \%$ & $27.2 \%$ & $30.2 \%$ \\
A.S.A.M. & 0 & $14.3 \%$ & 0 & $85.7 \%$ & $100 \%$ \\
& $(0)$ & $(1)$ & $(0)$ & $(6)$ & $(7)$ \\
& 0 & $33.3 \%$ & 0 & $1.4 \%$ & $1.3 \%$ \\
H.A. & $10.1 \%$ & $0.9 \%$ & $10.1 \%$ & $78.9 \%$ & $100 \%$ \\
& $(11)$ & $(1)$ & $(11)$ & $(86)$ & $(109)$ \\
& $14.5 \%$ & $33.3 \%$ & $42.3 \%$ & $19.5 \%$ & $20.0 \%$ \\
Cau. & $9.4 \%$ & $0 \%$ & $4.2 \%$ & $86.4 \%$ & $100 \%$ \\
& $(25)$ & $(0)$ & $(11)$ & $(229)$ & $(265)$ \\
& $32.9 \%$ & 0 & $42.3 \%$ & $51.9 \%$ & $48.5 \%$ \\
Total & $13.7 \%$ & $0.5 \%$ & $4.8 \%$ & $80.8 \%$ & \\
& $(76)$ & $(3)$ & $(26)$ & $(441)$ & $N=$ \\
& $100 \%$ & $100 \%$ & $100 \%$ & $100 \%$ & 546 \\
\hline
\end{tabular}

Note. Data taken from 2014: Intentional Lethal Force Data (Menifield \& Laughlin, 2018). [Copyright: Michael Laughlin]. $p<.05$.

*Column totals reported third vertically in Table 8 .

Table 9 shows victims' race separated by the race of the community leader (mayor) under whom lethal force occurred in law enforcement $(N=529$ due to missing data). The victims' race and that of community leaders displayed a moderately strong relationship per Cramer's V that was significant according to Pearson's Chi-square test. The results in Table 9 are similar to those in Table 8 regarding overrepresentation of victims whose race was the same as the community leader. Again, African American victims were disproportionately killed in departments with African American community leaders and underrepresented in departments with Caucasian or Hispanic community leaders. Although only about $11 \%$ of all victims were killed by officers from departments with African American community leaders, those departments accounted for around 22\% 
of African American victims. Departments with Caucasian community leaders displayed a less profound relationship between the race of the victim and the race of the community leader. The passive representation literature (Linn, 2006; Nicholson-Crotty et al, 2017; Wilkens, Williams, 2008; Xiao et al, 2014), has shown that greater representation of minority officers and leaders within police departments could decrease racial disparities among victims killed by lethal force; however, the data in Tables 8 and 9 do not support this argument.

Table 9

Race of Lethal Force Victim $\times$ Race of Community Mayor (2014)*** Race of Community Mayor

\begin{tabular}{llllll}
\hline $\begin{array}{l}\text { Race of } \\
\text { Victim }\end{array}$ & A.A. & A.S.A.M. & H.A. & Cau. & Total \\
\hline A.A. & $21.6 \%$ & $0.6 \%$ & $5.4 \%$ & $72.4 \%$ & $100 \%$ \\
& $(36)$ & $(1)$ & $(9)$ & $(121)$ & $(167)$ \\
& $64.3 \% *$ & $14.3 \%$ & $37.5 \%$ & $27.4 \%$ & $31.6 \%$ \\
A.S.A.M. & 0 & $14.3 \%$ & 0 & $85.7 \%$ & $100 \%$ \\
& $(0)$ & $(1)$ & $(0)$ & $(6)$ & $(7)$ \\
& 0 & $14.3 \%$ & 0 & $1.4 \%$ & $1.3 \%$ \\
H.A. & $4.0 \%$ & $5.1 \%$ & $5.1 \%$ & $85.9 \%$ & $100 \%$ \\
& $(4)$ & $(5)$ & $(5)$ & $(85)$ & $(99)$ \\
& $7.1 \%$ & $71.4 \%$ & $20.8 \%$ & $19.2 \%$ & $18.7 \%$ \\
Cau. & $6.3 \%$ & $0 \%$ & $3.9 \%$ & $89.8 \%$ & $100 \%$ \\
& $(16)$ & $(0)$ & $(10)$ & $(230)$ & $(256)$ \\
& $28.6 \%$ & 0 & $41.7 \%$ & $52 \%$ & $48.4 \%$ \\
Total & $10.6 \%$ & $1.3 \%$ & $4.5 \%$ & $83.6 \%$ & \\
& $(56)$ & $(7)$ & $(24)$ & $(442)$ & $N=$ \\
& $100 \%$ & $100 \%$ & $100 \%$ & $100 \%$ & 529 \\
\hline
\end{tabular}

Note. Data taken from 2014: Intentional Lethal Force Data (Menifield \& Laughlin, 2018). [Copyright: Michael Laughlin]. $p<.05$.

*Column totals reported third vertically in Table 9 .

Based on Cramer's V, the race of victims and presence of a non-police witness demonstrated a moderately strong relationship; this association was significant according to Pearson's Chi-square test as shown in Table 10. Presumably, if law enforcement 
officers are intentionally killing persons when they know they should not, then the presence of a non-police witness would reduce the likelihood of an officer choosing to kill a victim. Alternatively, depending on the relationship between non-police witnesses and race, use of lethal force in law enforcement may be rooted in the context of an incident involving an officer and the deceased.

Data in Table 10 were based on a sample size of 730 due to missing data concerning non-police witnesses at lethal force incidents. Asian victims (63.3\%) were killed most often when a non-police witness was present, followed by African Americans (57.5\%), Hispanics (52.1\%), and Caucasians (47.8\%).

Table 10

Presence of Non-Police Witness $\times$ Race of Lethal Force Victim (2014)**

Presence of a Non-Police Witness

\begin{tabular}{llll}
\hline $\begin{array}{l}\text { Victim } \\
\text { Race }\end{array}$ & No & Yes & Total \\
\hline A.S.A.M. & $36.4 \%$ & $63.3 \%$ & $100 \%$ \\
& $(4)$ & $(7)$ & $(11)$ \\
A.A. & $42.5 \%$ & $57.5 \%$ & $100 \%$ \\
& $(88)$ & $(119)$ & $(207)$ \\
H.A. & $47.9 \%$ & $52.1 \%$ & $100 \%$ \\
& $(67)$ & $(73)$ & $(140)$ \\
Cau. & $52.2 \%$ & $47.8 \%$ & $100 \%$ \\
& $(194)$ & $(178)$ & $(372)$ \\
Total w/ & $48.4 \%$ & $51.6 \%$ & \\
witness & $(353)$ & $(377)$ & $N=$ \\
& & & 730 \\
\hline
\end{tabular}

Note. Data taken from 2014: Intentional Lethal Force Data (Menifield \& Laughlin, 2018). [Copyright: Michael Laughlin]. $p<.05$.

The expectation of violence in the call to which officers were responding aligns with part of the U.S. Supreme Court's instructions regarding how lower courts should evaluate the legality of lethal force in law enforcement incidents, and therefore is 
examining the situational perspective. Table 11 reveals whether officers were responding to a call involving anticipated violence and if the victim's race was associated with expected violence. Calls were divided into the following categories: domestic violence, argument, fighting, suicide, burglary, robbery, road-related, reported shooting, suspicious behavior, disturbance, domestic disturbance, drug-related, warrant, murder, accident, other, and missing or unknown. Categories were further separated as follows:

- Yes: high expectation of violence: (domestic violence, fighting, suicide, robbery, reported shooting, domestic disturbance, murder)

- No: low expectation of violence (argument, burglary, road-related, suspicious behavior, disturbance, drug-related, warrant, other, accident).

These are considered near-accurate proxies for the expectation of violence, as court decisions have declared an expectation of violence in certain cases (i.e., drug deals, some warrants, and some burglaries). However, these proxies are not ideal: road- and drugrelated calls were classified as having no expectation of violence, although officers are nearly as likely to be killed during a traffic stop as during arrest situations (FBI UCR, 2014). Yet there is a strong argument for classifying traffic stops as non-violent because the high number of traffic stop-related law enforcement deaths reflects that traffic stops comprise nearly half of officers' contact with the public (Bureau of Justice Statistics [BJS], 2018). Few would argue that the majority of traffic stops result in violence. Further, Judge Timothy Wilson noted that one could assume drug dealers will likely possess firearms; indeed, "an urban heroin dealer not in possession of a firearm would be an anomaly" (Missouri v. Stockley, 2017, p. 26). Although one may then assume that a 
drug dealer could be armed or violent, one cannot assume that all drug calls are likely to result in violence nor that all drug dealers or drug possessors are in fact armed.

Data in Table 11 included a sample size of 806 due to missing data. Victims' race and the expectation of violence had a weak and non-significant relationship based on Cramer's V and Pearson's Chi-square test, respectively. Across races, most victims were killed during calls with a higher expectation of violence. Less than $40 \%$ of calls in which Caucasian persons were victims (38.8\%) did not include an expectation of violence. For African American victims, slightly less than half (45.3\%) of calls did not include an expectation of violence.

Table 11

Type of Call: Violence Likely or Not $\times$ Race of Lethal Force Victim (2014)

Violence Likely

\begin{tabular}{llll}
\hline $\begin{array}{l}\text { Victim } \\
\text { Race }\end{array}$ & No & Yes & Total \\
\hline A.A. & $45.3 \%$ & $54.6 \%$ & $100 \%$ \\
& $(102)$ & $(123)$ & $(225)$ \\
Cau. & $38.8 \%$ & $61.2 \%$ & $100 \%$ \\
& $(160)$ & $(252)$ & $(412)$ \\
H.A. & $43.2 \%$ & $56.8 \%$ & $100 \%$ \\
& $(67)$ & $(88)$ & $(155)$ \\
A.S.A.M. & $42.9 \%$ & $57.1 \%$ & $100 \%$ \\
& $(6)$ & $(8)$ & $(14)$ \\
Total & $41.6 \%$ & $58.4 \%$ & \\
& $(335)$ & $(471)$ & $N=$ \\
& & & 806 \\
\hline
\end{tabular}

Note. Data taken from 2014: Intentional Lethal Force Data (Menifield \& Laughlin, 2018). [Copyright: Michael Laughlin]. $p>.05$.

The 12A-14B are exploring the time and location of the police killings. The time of call characteristic examines whether police killings are happening later in the day, which would coincide with violent crime and may suggest that there are external causes (Belief Perspective 2) that are driving racially different outcomes. The latter location 
tables are considering the micro-level location (inside, outside, residential, or business) whereas Table 12A and 12B are considering the region of the lethal force situations, which may provide answers relevant to Belief Perspective 1 or 2, based on U.S. history (discussed further in Chapter 5).

Table 12A $(N=860)$ displays regions of the U.S. where victims were killed by law enforcement compared to the U.S. Census Bureau's estimates of the U.S. population by region in 2014. Data revealed overrepresentation of persons killed by law enforcement in the South (42\%) and West (36\%) compared to the U.S. Census Bureau's (2018) population distribution estimates for these regions (South: 37.6\%; West: 23.5\%). The West had the most substantial overrepresentation of persons killed by law enforcement (36\%) compared to population estimates (23.5\%). The Northeast (5.9\%) and Midwest (16\%) each displayed an underrepresentation of persons killed by law enforcement compared to the U.S. Census Bureau's population estimates; $17.6 \%$ and $21.3 \%$, respectively.

Table 12B displays the race of persons killed by police based on region $(N=825)$. Cramer's V indicated that victims' race and region had a moderately strong relationship, which was also significant according to Pearson's Chi-square test. The U.S. does not have an equal distribution of crime between regions or an equal distribution of people based on race between regions. We could not identify a reasonable proxy for regional differences in criminal offending rates, but some sources provided information on differences in the distribution of people by race. For example, of all African Americans in the U.S., approximately 55\% live in the South, $18 \%$ live in the Northeast, $17 \%$ live in the Midwest, and only 10\% live in the West (Black Demographics, 2019). Caucasians 
comprise $78 \%$ of residents in the Midwest, $69 \%$ in the Northeast, $60 \%$ in the South, and 53\% in the West (Arismendi \& Penaluna, 2016).

If U.S. population estimates by race are a primary proxy to explore individuals killed by police, we cannot assume that each region has equal distributions of people by race. According to Table 12B, the highest proportions of African American victims were in the South (51\%), Midwest (22\%), and West (19\%). The high proportion of African American victims in the South is logical in light of Black Demographics (2019) population estimates of where African Americans live but could be considered an underrepresentation compared to the 55\% of African Americans in the South. Also based on Black Demographics (2019) estimates, African Americans are overrepresented in the West by nearly $200 \%$, slightly overrepresented in the Midwest, and underrepresented in the Northeast by about $60 \%$.

However, African Americans were killed at twice the expected rate (26.9\%) compared to their proportion of the U.S. population (13.2\%). Therefore, although African Americans were overrepresented in the overall sample of those killed by police in the U.S., this overrepresentation was not equally distributed throughout the country. African Americans reside more densely in the South (55\%) and the Northeast (18\%), the only two regions where the proportions of African Americans killed (51\% and 8\%, respectively) were lower than population distribution estimates.

Caucasian persons killed in the U.S. were underrepresented in all regions compared to their proportion of the U.S. population (61.8\%), with the greatest underrepresentation in the Northeast ( $45.1 \%$ of those killed). Table $12 \mathrm{C}$ presents the relationship between regional estimates of Caucasian/non-Caucasian persons compared to 
those killed by police who were Caucasian/non-Caucasian in the same region; in this case, Caucasian victims were underrepresented in the South (53\%), Northeast (45\%), Midwest (56\%), and West (46\%) compared to population estimates $(60 \%, 69 \%, 78 \%$, and 53\%, respectively) (Arismendi \& Penaluna, 2016). Caucasian victims were most similarly represented in the South (53\% to 60\%) and West (46\% to $53 \%)$ and most underrepresented in the Northeast (45\% to $69 \%$ ) and Midwest (55\% to $78 \%$ ).

According to Table 12B, Hispanics were underrepresented in the South (10.8\%), Northeast (15.7\%), and Midwest (4.4\%) compared to their overall proportions of the U.S. population (17.8\%) and compared to the proportion of Hispanics killed via lethal force (18.5\%). Hispanics were highly overrepresented in the West $(36.6 \%)$, where the proportion of all Hispanic persons killed was approximately twice the expected proportion based on the overall U.S. population proportion and the proportion of Hispanic victims in our database.

However, Hispanics are not equally distributed throughout the U.S.; they comprise approximately $18 \%$ of the U.S. population, but in 2010 , over $75 \%$ of Hispanics lived in the South and the West in total (36\% and $41 \%$, respectively). Less than onequarter of Hispanics lived in the Northeast and the Midwest (14\% and 9\%, respectively) (U.S. Census Bureau, 2011). When compared to their overall U.S. proportion (17.8\%), Hispanics appear regionally overrepresented in the West, where they accounted for $29 \%$ of the population; and underrepresented in the South, Northeast, and Midwest $(16 \%$, $13 \%$, and 7\%, respectively) (U.S. Census Bureau, 2011).

When comparing this regional distribution to the proportion of those killed by police by region, the picture changes. While Hispanics are highly overrepresented in the 
West compared to their overall U.S. population, when referring to regional information, Hispanics killed by police are only slightly overrepresented (36.6\% compared to $29 \%$ ). Hispanics killed by police also appear slightly overrepresented compared to regional estimates for the Northeast (15.7\% compared to $14 \%)$. Hispanics killed by police are underrepresented compared to regional estimates for the South (10.8\% compared to $16 \%)$ and the Midwest (4.4\% compared to 7\%). Finally, the distribution of all Hispanics killed by police $($ South $=23.3 \%$, Northeast $=5 \%$, Midwest $=3.8 \%$, and West $=67.9 \%)$ compared to the distribution of all Hispanics within the U.S. (South $=36 \%$, Northeast $=$ $14 \%$, Midwest $=9 \%$, West $=41 \%$ ) indicates that the largest (regional) proportion of Hispanics is associated with the greatest likelihood of Hispanics being killed by police. However, this pattern does not manifest in other regions (i.e., the region with the lowest proportion of Hispanics does not have the lowest likelihood of Hispanics being killed by police). 
Table 12A

Lethal Force Victims by U.S. Region (2014)

\begin{tabular}{llllll}
\hline & South & Northeast & Midwest & West & Total \\
\hline $\begin{array}{l}\text { Number } \\
\text { of } \\
\text { victims }\end{array}$ & 361 & 51 & 138 & 310 & 860 \\
$\begin{array}{l}\% \text { of } \\
\text { total }\end{array}$ & $42.0 \%$ & $5.9 \%$ & $16.0 \%$ & $46.0 \%$ & $100 \%$ \\
$\begin{array}{l}\text { victims } \\
\text { U.S. }\end{array}$ & $37.6 \%$ & $17.6 \%$ & $21.3 \%$ & $23.5 \%$ & 318.6 \\
$\begin{array}{l}\text { Census } \\
(2018)\end{array}$ & & & & & million \\
Total $\%$ & & & & & \\
\hline
\end{tabular}

Table 12B

Race of Lethal Force Victim by U.S. Region (2014)*

\begin{tabular}{llllll} 
& & & \multicolumn{3}{c}{ Region } \\
\hline $\begin{array}{lllll}\text { Victim } \\
\text { Race }\end{array}$ & South & Northeast & Midwest & West & Total \\
\hline A.A. & $51.3 \%$ & $8.2 \%$ & $22 \%$ & $18.5 \%$ & $100 \%$ \\
& $(119)$ & $(19)$ & $(51)$ & $(43)$ & $(232)$ \\
& $34.7 \%$ & $37.3 \%$ & $37.5 \%$ & $14.6 \%$ & \\
Cau. & $43.8 \%$ & $5.5 \%$ & $18.1 \%$ & $32.6 \%$ & $100 \%$ \\
& $(184)$ & $(23)$ & $(76)$ & $(137)$ & $(420)$ \\
& $53.6 \%$ & $45.1 \%$ & $55.9 \%$ & $46.4 \%$ & \\
H.A. & $23.3 \%$ & $5 \%$ & $3.8 \%$ & $67.9 \%$ & $100 \%$ \\
& $(37)$ & $(8)$ & $(6)$ & $(108)$ & $(159)$ \\
& $10.8 \%$ & $15.7 \%$ & $4.4 \%$ & $36.6 \%$ & \\
A.S.A.M. & $21.4 \%$ & $7.1 \%$ & $21.4 \%$ & $50 \%$ & $100 \%$ \\
& $(3)$ & $(1)$ & $(3)$ & $(7)$ & $(14)$ \\
& $0.9 \%$ & $2.0 \%$ & $2.2 \%$ & $2.4 \%$ & \\
Total in & $41.6 \%$ & $6.2 \%$ & $16.5 \%$ & $35.8 \%$ & \\
region & $(343)$ & $(51)$ & $(136)$ & $(295)$ & $N=$ \\
& & & & & 825 \\
\hline
\end{tabular}

Note. Data taken from 2014: Intentional Lethal Force Data (Menifield \& Laughlin, 2018). [Copyright: Michael Laughlin]. Table 12B: $p<.05$; Table 12C: $p>.05$.

*In Table $12 \mathrm{~B}$, the top percentage for each race is calculated by row ( $\%$ of those killed by race), and the bottom percentage is calculated within columns ( $\%$ of those killed within region). 
Table $12 \mathrm{C}$

Caucasian v. Non-Caucasian Victims by Region (2014)

\begin{tabular}{llllll} 
& & & \multicolumn{3}{c}{ Region } \\
\hline Race & South & Northeast & Midwest & West & Total \\
\hline Cau. & $60 \%$ & $69 \%$ & $78 \%$ & $53 \%$ & N/A \\
Census & & & & & \\
Cau. & $53.6 \%{ }^{* *}$ & $45.1 \%$ & $55.9 \%$ & $46.4 \%$ & \\
victims & $(184)$ & $(23)$ & $(76)$ & $(137)$ & $(420)$ \\
$\begin{array}{l}\text { Non- } \\
\text { Cau. }\end{array}$ & $40 \%$ & $31 \%$ & $22 \%$ & $47 \%$ & N/A \\
$\begin{array}{l}\text { Census } \\
\text { Non- }\end{array}$ & $46.4 \%$ & $54.9 \%$ & $44.1 \%$ & $53.6 \%$ & \\
$\begin{array}{l}\text { Cau. } \\
\text { victims }\end{array}$ & $(159)$ & $(28)$ & $(60)$ & $(158)$ & $(405)$ \\
Total & $100 \%$ & $100 \%$ & $100 \%$ & $100 \%$ & \\
$\begin{array}{l}\text { in } \\
\text { region }\end{array}$ & $(343)$ & $(51)$ & $(136)$ & $(295)$ & $N=$ \\
\hline
\end{tabular}

Note. Data taken from 2014: Intentional Lethal Force Data (Menifield \& Laughlin, 2018). [Copyright: Michael Laughlin]. Table 12B: $p<.05$; Table 12C: $p>.05$.

*In Table $12 \mathrm{~B}$, the top percentage for each race is calculated by row $(\%$ of those killed by race), and the bottom percentage is calculated within columns ( $\%$ of those killed within region).

**Percentages in Table $12 \mathrm{C}$ are calculated within columns rather than across rows.

Figure 1 lists incident locations using four categories: outside, residential, vehicle, and business. In the residential and business categories, the victim was within a residential building or business when use of lethal force occurred. The vehicle category indicates that the victim was inside a vehicle when use of lethal force occurred. For the outside category, the victim was killed in some place other than a vehicle or building. Of the 860 persons intentionally killed by police, we uncovered 856 incident locations: 342 victims (40.0\%) were killed outside, 320 victims (37.4\%) were killed in a residential building, 70 victims $(8.2 \%)$ were killed in a vehicle, and 124 victims $(14.5 \%)$ were killed in a business. 
Table 13B presents victims' race and the locations where victims were killed $(N$ $=822$ ). These characteristics had a moderately strong relationship as evidenced by Cramer's V; this association was significant according to Pearson's Chi-square test. The top two locations where victims of all races were killed were 'outside' and 'residential.' Police killed nearly half of African American victims (46.5\%) and Hispanic victims (47.8\%) 'outside' and more than one-fourth of African American victims (27.6\%) and Hispanic victims (30.2\%) in residential buildings. Police killed one-third of Caucasian victims 'outside' (33.3\%) and slightly less than half of Caucasian victims in residential buildings (45.3\%). The lowest proportions of African American victims (7.3\%), Hispanic victims (8.2\%), and Caucasian victims (8.2\%) were killed in vehicles. 
Figure 1

\section{Lethal Force Incident Location (2014)}

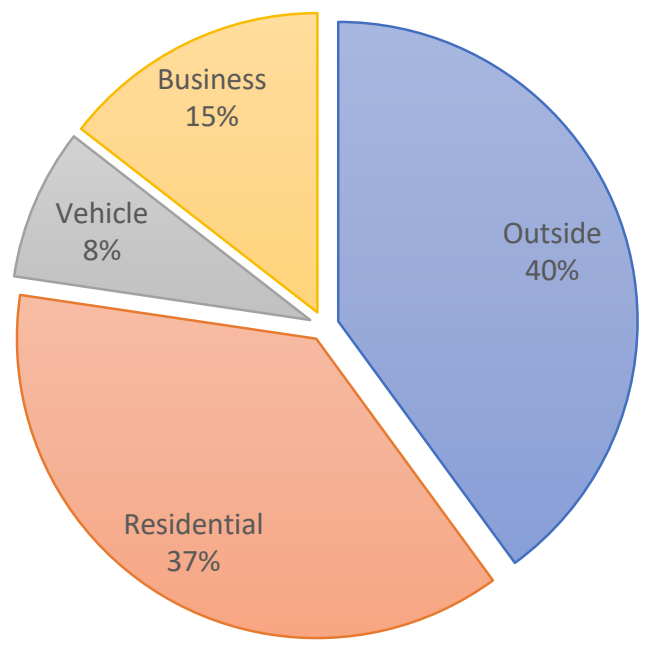

口Outside $\square$ Residential $\square$ Vehicle $\square$ Business

Table 13B

Race of Lethal Force Victim $\times$ Location Type (2014)***

Incident Location

\begin{tabular}{llllll}
\hline $\begin{array}{l}\text { Victim } \\
\text { Race }\end{array}$ & Outside & Residential & Vehicle & Business & Total \\
\hline A.A. & $46.6 \%$ & $27.6 \%$ & $7.3 \%$ & $18.5 \%$ & $100 \%$ \\
& $(108)$ & $(64)$ & $(17)$ & $(43)$ & $(232)$ \\
Cau. & $33.3 \%$ & $45.3 \%$ & $8.2 \%$ & $13.2 \%$ & $100 \%$ \\
& $(139)$ & $(189)$ & $(34)$ & $(55)$ & $(417)$ \\
H.A. & $47.8 \%$ & $30.2 \%$ & $8.2 \%$ & $13.8 \%$ & $100 \%$ \\
& $(76)$ & $(48)$ & $(13)$ & $(22)$ & $(159)$ \\
A.S.A.M. & $57.1 \%$ & $21.4 \%$ & $14.3 \%$ & $7.1 \%$ & $100 \%$ \\
& $(8)$ & $(3)$ & $(2)$ & $(1)$ & $(14)$ \\
$\%$ of & $40.0 \%$ & $37.4 \%$ & $8.2 \%$ & $14.5 \%$ & \\
Total & $(331)$ & $(304)$ & $(66)$ & $(121)$ & $N=$ \\
Victims & & & & & 822 \\
\hline
\end{tabular}

Note. Data taken from 2014: Intentional Lethal Force Data (Menifield \& Laughlin, 2018). [Copyright: Michael Laughlin]. Table 13B: $p<.05$.

Figure 2 displays the time of day that law enforcement deployed lethal force, differentiated by night, evening, afternoon, morning, and early morning $(N=846)$. Police 
killed the most victims at night (40\%) and the fewest in the early morning hours $(7.1 \%)$. Table 14B displays the race of victims by the time of day they were killed $(N=810)$. The victims' race and time of day of the incident were weakly related per Cramer's V, and the relationship was not significant according to Pearson's Chi-square test.

In Table 14B, the largest proportions of African American victims (44.1\%), Caucasian victims (38.7\%), and Hispanic victims (39.7\%) were killed at night; however, only African Americans (44.1\%) were overrepresented as nighttime victims compared to the average proportion of the time at which incidents occurred $(40.1 \%$ of all races were killed at night). The lowest proportion of all victims were killed during the early morning hours; generally, the number of persons killed by law enforcement increased as the day went on (excluding Asian victims). 
Figure 2

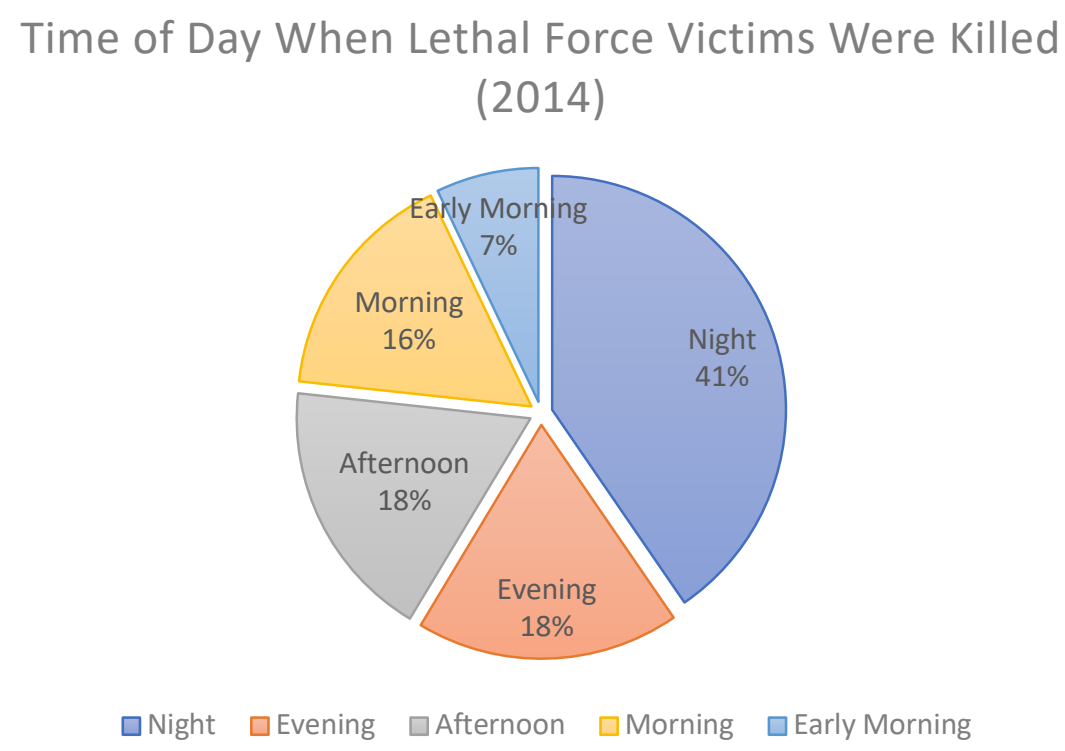

Table 14B

Race of Lethal Force Victim $\times$ Time of Day (2014)

Time of Day

\begin{tabular}{lllllll}
\hline $\begin{array}{l}\text { Race of } \\
\text { Victim }\end{array}$ & Night & Evening & Afternoon & Morning & $\begin{array}{l}\text { Early } \\
\text { M. }\end{array}$ & Total \\
\hline A.A. & $44.1 \%$ & $17.9 \%$ & $14.4 \%$ & $16.6 \%$ & $7.0 \%$ & $100 \%$ \\
& $(101)$ & $(41)$ & $(33)$ & $(38)$ & $(16)$ & $(229)$ \\
Cau. & $38.7 \%$ & $18.2 \%$ & $21.4 \%$ & $15.1 \%$ & $6.6 \%$ & $100 \%$ \\
& $(159)$ & $(75)$ & $(88)$ & $(62)$ & $(27)$ & $(411)$ \\
H.A. & $39.7 \%$ & $19.2 \%$ & $16.7 \%$ & $15.4 \%$ & $9.0 \%$ & $100 \%$ \\
& $(62)$ & $(30)$ & $(26)$ & $(24)$ & $(14)$ & $(156)$ \\
A.S.A.M. & $21.4 \%$ & $35.7 \%$ & $14.3 \%$ & $21.4 \%$ & $7.1 \%$ & $100 \%$ \\
& $(3)$ & $(5)$ & $(2)$ & $(3)$ & $(1)$ & $(14)$ \\
\% of & $40.4 \%$ & $18.2 \%$ & $18.1 \%$ & $16.2 \%$ & $7.1 \%$ & \\
total & $(325)$ & $(151)$ & $(149)$ & $(127)$ & $(58)$ & $N=$ \\
victims & & & & & & 810 \\
\hline
\end{tabular}

Note. Data taken from 2014: Intentional Lethal Force Data (Menifield \& Laughlin, 2018). [Copyright: Michael Laughlin]. 14B: $p>.05$

Table 15A depicts the relationship between officers who used lethal force and their years of experience; Table 15B shows the relationship between officers' years of 
experience and victims' race. Differences in officers' deployment of lethal force based on experience could signal an internal cause; deficiency in training (if early officers are primarily deploying lethal force) or implicit bias (if the most experienced officers are primarily deploying lethal force). Officers' years of experience were differentiated as follows: $0-1$ years, $2-5$ years, $6-10$ years, $11-15$ years, and more than 15 years $(N=282$ officers). Police officers with 6-10 years' experience killed the most people (34.8\%), followed by officers with $11-15$ years $(24.9 \%), 2-5$ years $(19.9 \%)$, and $15+$ years (16.3\%) of experience. The newest officers, possessing $0-1$ years' experience, killed the lowest proportion of people at only $3.2 \%$.

Table 15B presents victims' race separated by officers' years of experience $(N=$ 269 victims), which demonstrated a moderately strong but non-significant relationship according to Cramer's V and Pearson's Chi-square test. Officers with 6-10 years' experience killed the largest proportion of African American victims (37.4\%) and Caucasian victims (34.4\%). Officers with 11-15 years of experience killed the greatest proportion of Hispanic victims $(32.7 \%)$. For each victim race category, officers with the least experience ( $0-1$ years) killed the smallest proportion of victims ( $3.3 \%$ total); however, minority victims accounted for $77.8 \%$ of those killed by the least experienced officers. 
Table 15A

Officer Experience in Years (2014)

\begin{tabular}{lllllll}
\hline & $0-1$ & $2-5$ & $6-10$ & $11-15$ & $15+$ & Total \\
\hline $\begin{array}{l}\text { Number } \\
\text { of }\end{array}$ & 9 & 56 & 98 & 73 & 46 & 282 \\
$\begin{array}{l}\text { victims } \\
\% \text { of } \\
\text { total }\end{array}$ & $3.2 \%$ & $19.9 \%$ & $34.8 \%$ & $25.9 \%$ & $16.3 \%$ & $100 \%$ \\
victims & & & & & & \\
\hline
\end{tabular}

Table 15B

Race of Lethal Force Victim $\times$ Officer Experience (2014)

Officer Experience (years)

\begin{tabular}{lllllll}
\hline $\begin{array}{l}\text { Victim } \\
\text { Race }\end{array}$ & $0-1$ & $2-5$ & $6-10$ & $11-15$ & $15+$ & Total \\
\hline A.A. & $4.4 \%$ & $19.8 \%$ & $37.4 \%$ & $25.3 \%$ & 13.2 & $100 \%$ \\
& $(4)$ & $(18)$ & $(34)$ & $(23)$ & $(12)$ & $(91)$ \\
& $44.4 \% *$ & $33.3 \%$ & $37.8 \%$ & $32.9 \%$ & $26.1 \%$ & $33.8 \%$ \\
Cau. & $2 \%$ & $19.2 \%$ & $34.4 \%$ & $24 \%$ & $20.8 \%$ & $100 \%$ \\
& $(2)$ & $(24)$ & $(43)$ & $(30)$ & $(26)$ & $(125)$ \\
& $22.2 \%$ & $44.4 \%$ & $47.8 \%$ & $42.8 \%$ & $56.5 \%$ & $46.5 \%$ \\
H.A. & $6.1 \%$ & $22.4 \%$ & $22.4 \%$ & $32.7 \%$ & $16.3 \%$ & $100 \%$ \\
& $(3)$ & $(11)$ & $(11)$ & $(16)$ & $(8)$ & $(49)$ \\
& $33.3 \%$ & $20.4 \%$ & $12.2 \%$ & $22.9 \%$ & $17.4 \%$ & $18.2 \%$ \\
A.S.A.M. & $0 \%$ & $25 \%$ & $50 \%$ & $25 \%$ & $0 \%$ & $1.2 \%$ \\
& $(0)$ & $(1)$ & $(2)$ & $(1)$ & $(0)$ & $(4)$ \\
& 0 & $1.9 \%$ & $2.2 \%$ & $1.4 \%$ & 0 & $1.5 \%$ \\
\% of & $3.3 \%$ & $20.1 \%$ & $33.5 \%$ & $26 \%$ & $17.1 \%$ & \\
Total & $(9)$ & $(54)$ & $(90)$ & $(70)$ & $(46)$ & $N=$ \\
Victims & $100 \%$ & $100 \%$ & $100 \%$ & $100 \%$ & $100 \%$ & 269 \\
\hline
\end{tabular}

Note. Data taken from 2014: Intentional Lethal Force Data (Menifield \& Laughlin, 2018). [Copyright: Michael Laughlin]. Table 15B: $p>.05$.

*Column totals reported third vertically in Table $15 \mathrm{~B}$.

Tables 16A-17B are examining whether there are differences based on income or diversity at the zip-code level that appear to be factors in the racially disparate outcomes 
in lethal force. These factors explore whether there is evidence that the racial disparities in police killings due to internal factors (policing) or external factors (societal).

Table 16A presents racial diversity within zip codes where law enforcement deployed lethal force. According to the U.S. Census Bureau (2017), approximately $61 \%$ of the U.S. identifies as Caucasian (non-Hispanic). Zip codes were classified as diverse if $61 \%$ or less of their population identified as Caucasian (non-Hispanic) and not diverse if $62 \%$ or more of the population identified as Caucasian (non-Hispanic); as shown, nearly $53 \%$ of zip codes were diverse. Table $16 \mathrm{~B}$ displays the race of those killed by law enforcement separated by whether the incident occurred in a diverse or non-diverse zip code $(N=819$ victims). Victims' race and diversity of the zip code per incident showed a strong relationship according to Cramer's V. About $71 \%$ of Asian American victims, nearly $77 \%$ of African American victims, and nearly $79 \%$ of Hispanic victims were killed in diverse zip codes. Nearly $72 \%$ of Caucasian victims were killed in non-diverse zip codes. Therefore, zip codes with higher Caucasian populations had higher proportions of Caucasian victims, whereas zip codes with higher populations of minorities had higher proportions of minority victims.

Table 16A

Zip Code Diversity (2014)

\begin{tabular}{llll}
\hline & No & Yes & Total \\
\hline $\begin{array}{l}\text { Number } \\
\text { of }\end{array}$ & 404 & 448 & 852 \\
$\begin{array}{l}\text { victims } \\
\text { \% of }\end{array}$ & $47.4 \%$ & $52.6 \%$ & $100 \%$ \\
total & & & \\
victims & & & \\
\hline
\end{tabular}

Note. Data taken from 2014: Intentional Lethal Force Data (Menifield \& Laughlin, 2018). [Copyright: Michael Laughlin]. 
Table 16B

Race of Lethal Force Victim $\times$ Zip Code Diversity (2014)***

Diverse zip code

\begin{tabular}{llll}
\hline $\begin{array}{l}\text { Victim } \\
\text { Race }\end{array}$ & No & Yes & Total \\
\hline A.A. & $\begin{array}{l}23.2 \% \\
(53)\end{array}$ & $\begin{array}{l}76.8 \% \\
(175)\end{array}$ & $\begin{array}{l}100 \% \\
(228)\end{array}$ \\
Cau. & $71.5 \%$ & $28.5 \%$ & $100 \%$ \\
& $(299)$ & $(119)$ & $(418)$ \\
H.A. & $21.4 \%$ & $78.6 \%$ & $100 \%$ \\
& $(34)$ & $(125)$ & $(159)$ \\
A.S.A.M. & $28.6 \%$ & $71.4 \%$ & $100 \%$ \\
& $(4)$ & $(10)$ & $(14)$ \\
\% of & $47.7 \%$ & $52.9 \%$ & \\
Total & $(391)$ & $(433)$ & $N=$ \\
Victims & & & 819 \\
\hline
\end{tabular}

Note. Data taken from 2014: Intentional Lethal Force Data (Menifield \& Laughlin, 2018). [Copyright: Michael Laughlin]. Table 15B: $p<.05$.

Table 17A reports the income levels of zip codes where law enforcement incidents of lethal force occurred in 2014. Table 17B expands on Table 17A in depicting associations between victims' race and the income level of zip codes where officers deployed lethal force. A categorical characteristic for zip code income level using the 2014 poverty line (assuming a family size of 3 ) was used in Tables 17A and B; this characteristic was categorized as follows:

0 : Below half the poverty line $(<\$ 9895)$

1: half the poverty to the poverty line minus $1(\$ 9895-\$ 19,789)$

2: poverty line to $150 \%$ of the poverty line minus $1(\$ 19,790-\$ 29,684)$ $\$ 39,579)$

3: $150 \%$ of the poverty line to $200 \%$ of the poverty line minus $1(\$ 29,685-$

4: $200 \%$ of the poverty line to $300 \%$ of the poverty line minus $1(\$ 39,580-$ $\$ 59,369)$

5: $300 \%$ of the poverty line or greater $(\geq \$ 59,370)$ 
In Table 17A, only one person was killed in the lowest income category (below half the poverty line), and eight persons were killed in the second lowest category (between the poverty line and half the poverty line). Only about $1 \%$ of police killings occurred in zip codes where the average income was below the poverty line. Further, $10 \%$ of killings occurred in zip codes in the third lowest income category (from the poverty line up to $149.9 \%$ of the poverty line).

Nearly $90 \%$ of police killings occurred in zip codes in the three upper-income categories. The greatest proportion (45.1\%) occurred in zip codes in the second highest income category ( $200 \%$ of the poverty line to one below the $299.9 \%$ above the poverty line). The second highest proportion (27.8\%) of police killings occurred in zip codes in the third highest category ( $150 \%$ of the poverty line to one below $199.9 \%$ of the poverty line); the third highest proportion (16\%) occurred in zip codes in the highest income category ( $300 \%$ of the poverty line and above).

In Table 17B, victims' race and zip code income level demonstrated a moderately strong relationship according to Cramer's $\mathrm{V}$, which was significant according to Pearson's Chi-square test. In Table 17B, which separates victims by race, the relationship of victims and zip code income level noted in Table 17A is mirrored; the highest proportion of victims are in the three categories with the highest income (except for African Americans). Police officers primarily killed Caucasian, Hispanics, and Asians in the top three high-income categories $(94.8 \%, 90.6 \%$, and $92.9 \%$, respectively). However, police killed the majority (55\%) of African Americans in the four low-income zip code categories, and the greatest three proportions of African Americans were killed in income levels 2,3 , and 4 (as opposed to 3, 4, and 5 for every other race). In other words, African 
Americans occupied the smallest proportion of any race killed in the highest income category $(10.6 \%$; average for high-income category $=15.9 \%)$.

Table 17A

Officers'Use of Lethal Force by Zip Code Income Level (2014)

\begin{tabular}{llllllll}
\hline & 0 & 1 & 2 & 3 & 4 & 5 & Total \\
\hline $\begin{array}{l}\text { Number } \\
\text { of }\end{array}$ & 1 & 8 & 85 & 237 & 384 & 136 & 851 \\
$\begin{array}{l}\text { victims } \\
\% \text { of } \\
\text { total } \\
\text { victims }\end{array}$ & $0.1 \%$ & $0.9 \%$ & $10.0 \%$ & $27.8 \%$ & $45.1 \%$ & $16.0 \%$ & $100 \%$ \\
\hline
\end{tabular}

Table 17B

Race of Lethal Force Victim $\times$ Zip code Income Level (2014)***

Zip Code Income Level

\begin{tabular}{|c|c|c|c|c|c|c|c|}
\hline $\begin{array}{l}\text { Victim } \\
\text { Race }\end{array}$ & 0 & 1 & 2 & 3 & 4 & 5 & Total \\
\hline A.A. & $\begin{array}{l}0 \% \\
(0)\end{array}$ & $\begin{array}{l}3.5 \% \\
(8)\end{array}$ & $\begin{array}{l}19.8 \% \\
(45)\end{array}$ & $\begin{array}{l}30.8 \% \\
(70)\end{array}$ & $\begin{array}{l}35.2 \% \\
(80)\end{array}$ & $\begin{array}{l}10.6 \% \\
(24)\end{array}$ & $\begin{array}{l}100 \% \\
(227)\end{array}$ \\
\hline Cau. & $\begin{array}{l}0 \% \\
(0)\end{array}$ & $\begin{array}{l}0 \% \\
(0)\end{array}$ & $\begin{array}{l}5.3 \% \\
(22)\end{array}$ & $\begin{array}{l}24.2 \% \\
(101)\end{array}$ & $\begin{array}{l}52.2 \% \\
(218)\end{array}$ & $\begin{array}{l}18.4 \% \\
(77)\end{array}$ & $\begin{array}{l}100 \% \\
(418)\end{array}$ \\
\hline H.A. & $\begin{array}{l}0.6 \% \\
(1)\end{array}$ & $\begin{array}{l}0 \% \\
(0)\end{array}$ & $\begin{array}{l}8.8 \% \\
(14)\end{array}$ & $\begin{array}{l}30.2 \% \\
(48)\end{array}$ & $\begin{array}{l}44.7 \% \\
(71)\end{array}$ & $\begin{array}{l}15.7 \% \\
(25)\end{array}$ & $\begin{array}{l}100 \% \\
(159)\end{array}$ \\
\hline A.S.A.M. & $\begin{array}{l}0 \% \\
(0)\end{array}$ & $\begin{array}{l}0 \% \\
(0)\end{array}$ & $\begin{array}{l}7.1 \% \\
\text { (1) }\end{array}$ & $\begin{array}{l}28.6 \% \\
(4)\end{array}$ & $\begin{array}{l}35.7 \% \\
(5)\end{array}$ & $\begin{array}{l}28.6 \% \\
(4)\end{array}$ & $\begin{array}{l}100 \% \\
(14)\end{array}$ \\
\hline $\begin{array}{l}\% \text { of } \\
\text { Total } \\
\text { Victims }\end{array}$ & $\begin{array}{l}0.1 \% \\
(1)\end{array}$ & $\begin{array}{l}1.0 \% \\
(8)\end{array}$ & $\begin{array}{l}10 \% \\
(82)\end{array}$ & $\begin{array}{l}27.3 \% \\
(223)\end{array}$ & $\begin{array}{l}45.7 \% \\
(374)\end{array}$ & $\begin{array}{l}15.9 \% \\
(130)\end{array}$ & $\begin{array}{l}N= \\
818\end{array}$ \\
\hline
\end{tabular}

Note. Data taken from 2014: Intentional Lethal Force Data (Menifield \& Laughlin, 2018). [Copyright: Michael Laughlin].

Table 17B: $p<.05$. 


\section{Simple test findings: Armed vs. unarmed $\times$ race of victim and race of officer.}

In Table 18, the simple test (ST) tables were compiled to assess the fourth objective, namely whether there was evidence of racial discrimination. According to Fryer (2016), Knowles et al. (2001), and Anwar and Fang (2006), a simple test for discrimination in officer-involved killings can be used to examine the proportions of unarmed victims based on officer race. If the proportion of unarmed victims by race differs by officer race, then the null hypothesis of no discrimination can be rejected. The hypothesis in this dissertation is that I will find evidence of racial discrimination by officers based on the proportions unarmed victims by victims' race; specifically, in line with common media narratives, Caucasian officers will kill a higher proportion of unarmed minority victims compared with minority officers (non-Caucasian officers). The null hypothesis is that Caucasian officers will not kill a higher proportion of unarmed minority victims compared with minority officers.

In S.T. Tables A-D, we separated victims by the race of the officer(s) who killed them and further sorted them by victims' race and whether victims were armed. In S.T. Tables A-C, for African American, Caucasian, and Hispanic police officers, we found a moderate relationship between the race of the victim and whether that victim was armed; however, the direction of that relationship did not indicate micro-level discrimination. In S.T. Table D, we could not calculate the significance or strength of the relationship using Pearson's Chi-square or Cramer's V because the number of incidents in the sample was insufficient $(N=2)$. In S.T. Table E, for non-Caucasian officers, we found a moderate relationship between the victim's race and whether that victim was armed; again, the direction of the relationship did not suggest micro-level discrimination. 
Missing data reduced the sample size in these four tables to 304 victims, 258 of whom were killed by Caucasian officers. The small sample sizes in S.T. Tables A-D made it difficult to conduct statistical analysis; we only had suitable data for 33 victims killed by Hispanic officers, 11 victims killed by African American officers, and 2 victims killed by Asian officers. Data from non-Caucasian officers were therefore combined into a dichotomous 'non-Caucasian' characteristic. S.T. Table E displays the dichotomous evaluation of the respective proportions of victims by race who were armed and killed by non-Caucasian law enforcement officers. S.T. Table F provides further information, including the proportion of unarmed persons killed by race according to the dichotomous 'officer race' characteristic; this table is likely the optimal evaluation of the simple test of this dataset. If the proportion of unarmed minorities is larger for Caucasian officers than non-Caucasian officers, then the null hypothesis of no discrimination can be rejected.

The findings reveal a significantly higher percentage of unarmed African Americans among individuals killed by non-Caucasian police officers. The proportion of unarmed African Americans killed by Caucasian officers (22.1\%) was less than half that killed by non-Caucasian officers (44.4\%). Interestingly, more armed Caucasian persons $(100 \%)$ were killed by non-Caucasian officers compared to the proportion of armed Caucasians killed by Caucasian officers (86.1\%). Slightly more unarmed Hispanics were also killed by non-Caucasian officers, but the proportion of Hispanics who were unarmed and killed by non-Caucasian officers $(14.3 \%)$ was comparable to the proportion of unarmed Hispanic persons who were killed by Caucasian officers (12.9\%). S.T. Tables E-F reveal no evidence of racial discrimination within officers' use of lethal force. Instead, the simple test shows that non-Caucasian officers were more likely to kill 
unarmed non-Caucasians compared with Caucasian officers, and Caucasian officers were more likely to kill unarmed Caucasians compared with non-Caucasian officers.

Table 18

Simple Test (S.T.): Armed vs. Unarmed $\times$ Race of Lethal Force Victim and Race of Officer (2014)

Table 18A: African American Officers (2014)**

Victim Unarmed Armed Total

Race

\begin{tabular}{|c|c|c|c|}
\hline A.A. & $\begin{array}{l}75 \% \\
(6)\end{array}$ & $\begin{array}{l}25 \% \\
(2)\end{array}$ & $\begin{array}{l}100 \% \\
(8)\end{array}$ \\
\hline Cau. & & $100 \%$ & $100 \%$ \\
\hline H.A. & & $\begin{array}{l}0 \% \\
(0)\end{array}$ & $\begin{array}{l}0 \\
(0)\end{array}$ \\
\hline A.S.A.M. & & $\begin{array}{l}0 \% \\
(0)\end{array}$ & $\begin{array}{l}0 \\
(0)\end{array}$ \\
\hline Totals & $\begin{array}{l}54.5 \% \\
(6)\end{array}$ & $\begin{array}{l}46.5 \% \\
(5)\end{array}$ & $\begin{array}{l}N= \\
11\end{array}$ \\
\hline Table 18B: & Caucasian & fficers ( & 2014)* \\
\hline $\begin{array}{l}\text { Victim } \\
\text { Race }\end{array}$ & Unarmed & Armed & Total \\
\hline A.A. & $\begin{array}{l}22.1 \% \\
(17)\end{array}$ & $\begin{array}{l}77.9 \% \\
(60)\end{array}$ & $\begin{array}{l}100 \% \\
(77)\end{array}$ \\
\hline Cau. & $\begin{array}{l}13.9 \% \\
(20)\end{array}$ & $\begin{array}{l}85.1 \% \\
(124)\end{array}$ & $\begin{array}{l}100 \% \\
(144)\end{array}$ \\
\hline H.A. & $\begin{array}{l}12.9 \% \\
(4)\end{array}$ & $\begin{array}{l}87.1 \% \\
(27)\end{array}$ & $\begin{array}{l}100 \% \\
(31)\end{array}$ \\
\hline A.S.A.M. & $\begin{array}{l}16.7 \% \\
\text { (1) }\end{array}$ & $\begin{array}{l}83.3 \% \\
\text { (5) }\end{array}$ & $\begin{array}{l}100 \% \\
\text { (6) }\end{array}$ \\
\hline Totals & $\begin{array}{l}16.3 \% \\
(42)\end{array}$ & $\begin{array}{l}83.7 \% \\
(216)\end{array}$ & $\begin{array}{l}N= \\
258\end{array}$ \\
\hline
\end{tabular}


Table 18C: Hispanic Officers (2014)

\begin{tabular}{llll}
\hline $\begin{array}{l}\text { Victim } \\
\text { Race }\end{array}$ & Unarmed & Armed & Total \\
\hline A.A. & $20 \%$ & $80 \%$ & $30.3 \%$ \\
& $(2)$ & $(8)$ & $(10)$ \\
Cau. & $0 \%$ & $100 \%$ & $100 \%$ \\
& $(0)$ & $(8)$ & $(8)$ \\
H.A. & $14.3 \%$ & $85.7 \%$ & $100 \%$ \\
& $(2)$ & $(12)$ & $(14)$ \\
A.S.A.M. & $0 \%$ & $100 \%$ & $100 \%$ \\
& $(0)$ & $(1)$ & $(1)$ \\
Totals & $12.1 \%$ & $87.9 \%$ & \\
& $(4)$ & $(29)$ & $N=$ \\
& & & 33 \\
\hline
\end{tabular}

Table 18D: Asian Officers (2014)

\begin{tabular}{llll}
\hline $\begin{array}{l}\text { Victim } \\
\text { Race }\end{array}$ & Unarmed & Armed & Total \\
\hline A.A. & $0 \%$ & $0 \%$ & $0 \%$ \\
& $(0)$ & $(0)$ & $(0)$ \\
Cau. & $0 \%$ & $100 \%$ & $100 \%$ \\
& $(0)$ & $(2)$ & $(2)$ \\
H.A. & $0 \%$ & $0 \%$ & $0 \%$ \\
& $(0)$ & $(0)$ & $(0)$ \\
A.S.A.M. & $0 \%$ & $0 \%$ & $0 \%$ \\
& $(0)$ & $(0)$ & $(0)$ \\
Totals & $0 \%$ & $100 \%$ & \\
& $(0)$ & $(2)$ & $N=$ \\
& & & 2 \\
\hline
\end{tabular}

Table 18E: Non-Caucasian Officers (2014)**

\begin{tabular}{llll}
\hline $\begin{array}{l}\text { Victim } \\
\text { Race }\end{array}$ & Unarmed & Armed & Total \\
\hline A.A. & $44.4 \%$ & $55.6 \%$ & $100 \%$ \\
& $(8)$ & $(10)$ & $(18)$ \\
Cau. & $0 \%$ & $100 \%$ & $100 \%$ \\
& $(0)$ & $(13)$ & $(13)$ \\
H.A. & $14.3 \%$ & $85.7 \%$ & $100 \%$ \\
& $(2)$ & $(12)$ & $(14)$ \\
A.S.A.M. & $0 \%$ & $100 \%$ & $100 \%$ \\
& $(0)$ & $(1)$ & $(1)$ \\
Totals & $21.7 \%$ & $78.3 \%$ & \\
& $(10)$ & $(29)$ & $N=$ \\
& & & 46 \\
\hline
\end{tabular}


Table 18F: Cau. Officer/Non-Cau. Officer $\times$ Proportion Unarmed Victims by Race**

\begin{tabular}{lccl}
\hline $\begin{array}{l}\text { Officer } \\
\text { Race } \times\end{array}$ & Unarmed & Armed & $\begin{array}{l}\text { Proportion } \\
\text { Unarmed }\end{array}$ \\
$\begin{array}{l}\text { Victim } \\
\text { Race }\end{array}$ & & & \\
\hline Cau by & $22.1 \%$ & $77.9 \%$ & $22 \%$ \\
$\begin{array}{l}\text { A.A. } \\
\text { Non-Cau } \\
\text { by A.A. }\end{array}$ & $44.4 \%$ & $55.6 \%$ & $44 \%$ \\
$\begin{array}{l}\text { Cau by } \\
\text { Hisp }\end{array}$ & $12.9 \%$ & $87.1 \%$ & $13 \%$ \\
$\begin{array}{l}\text { Non-Cau } \\
\text { by Hisp }\end{array}$ & $14.3 \%$ & $85.7 \%$ & $14 \%$ \\
$\begin{array}{l}\text { Cau by } \\
\text { Cau }\end{array}$ & $13.9 \%$ & $85.1 \%$ & $14 \%$ \\
$\begin{array}{l}\text { Non-Cau } \\
\text { by Cau }\end{array}$ & $0 \%$ & $100 \%$ & $0 \%$ \\
\hline
\end{tabular}

Note. Data taken from 2014: Intentional Lethal Force Data (Menifield \& Laughlin, 2018). [Copyright: Michael Laughlin]. S.T. Tables A, E, F: $p<.05 ;$ S.T. Tables B, C, D: $p$ $>.05$.

Multivariate analyses findings. Using the aforementioned theories (belief perspectives 1 and 2 and the situational perspective) and considering the above findings I turn to a multivariate analysis in Table 19. The multivariate analyses are considerations into whether characteristics related to law enforcement (Belief Perspective 1), characteristics from the community (Belief Perspective 2), the victim's actions and the situational context of the encounter (theoretical perspective) influence the likelihood that a Caucasian officer will kill an African American or Hispanic victim. To do so, I estimate four models: in the first model, I regress victim race against characteristics of the police officer and the race of the policing organization's leadership to consider evidence for Belief Perspective 1 (internal causes for disparities); in the second model I regress victim race against a number of characteristics and factors from the community (external causes for disparities); in the third model I regress victim race against a number of factors 
related to the situational perspective (suspect armed, violence likely based on reason for contact) and whether the situation is likely to be one which has a higher level of danger (witness present, call at night, suspect had warrant, victim's age); in the fourth model I regress the victim's race against the officer's race controlling for whether the victim was armed (the unarmed model for the simple test could not be run due to a small number of observations).

To estimate the above models, I utilized multinomial logistic regression to because victim race is a categorical variable. In all models, the omitted comparison group is Caucasian victims. Additionally, I omitted Asian American victims from these analyses, because there is a small sample of Asian Americans in this data.

The models in Table 19 strongly reinforce the results from the cross-tabulations. All models which include officer race indicate that Caucasian police officers are no more likely to kill African American victims, and the model based on the situational perspective (testing danger of call and if victim is armed) indicates that Caucasian officers are slightly less likely to kill African American victims. In the situational perspective model the results also indicate that African Americans are less likely to be armed when killed than Caucasian victims, which is reflective of what was found in the cross-tabulations.

Additionally, all the models that include officer race estimate that Caucasian officers are significantly less likely to kill Hispanic victims than non-Caucasian officers. Further, the Belief Perspective 1 model (internal causes) shows no evidence that internal factors are contributing to the disparity. The Belief Perspective 2 model does show that the race of a population (zip level), the region of the U.S., the community leader, the time 
of day, and the location of the incident may be factors which influence the incidence of lethal force. More specifically, for African American victims they are slightly less likely than Caucasians to be killed in zip codes with a high proportion of Caucasians and less likely than Caucasians to be killed in a community with a Caucasian Mayor. Hispanic victims were more likely to be killed in zip codes with a higher proportion of Hispanics. For both African American victims and Hispanic victims, they were more likely than Caucasian victims to be killed outside and at night. These findings do not show support law enforcement factors (internal), suspect actions, or the context of the call being strong influencers in police killings. However, these findings do show support for external causes (Belief Perspective 2) as contributors to racial disparities in law enforcement use of lethal force. The findings for all four regression models are presented in Table 19. 
Table 19: Testing the Theories (Belief Perspective 1, Belief Perspective 2, Situational perspective, and Simple Test (unarmed not included due to missing observations)

\begin{tabular}{|c|c|c|c|c|c|c|c|c|}
\hline \multirow{2}{*}{$\begin{array}{l}\text { Table } 19 \\
\text { Variables }\end{array}$} & \multicolumn{2}{|c|}{ Perspective 1 (Internal) } & \multicolumn{2}{|c|}{ Perspective 2 (External) } & \multicolumn{2}{|c|}{ Theoretical Framework } & \multicolumn{2}{|c|}{ Simple Test: V. Armed } \\
\hline & Victim A.A. & Victim H.A. & Victim A.A. & Victim H.A. & Victim A.A. & Victim H.A. & Victim A.A. & Victim H.A. \\
\hline \multirow[t]{2}{*}{ Officer Caucasian } & -0.17 & $-0.99 *$ & & & $-0.79 * *$ & $-1.54 * * *$ & -0.39 & $-1.37^{* * *}$ \\
\hline & $(0.55)$ & $(0.58)$ & & & $(0.39)$ & $(0.45)$ & $(0.44)$ & $(0.45)$ \\
\hline \multirow[t]{2}{*}{ Officer Years of Experience } & -0.03 & -0.06 & & & & & & \\
\hline & $(0.03)$ & $(0.05)$ & & & & & & \\
\hline \multirow[t]{2}{*}{ LE Org Leader Caucasian } & -0.70 & -0.66 & & & & & & \\
\hline & $(0.41)$ & $(0.50)$ & & & & & & \\
\hline \multirow[t]{2}{*}{ Victim Age } & & & & & $-0.03^{* * *}$ & $-0.04 * *$ & & \\
\hline & & & & & $(0.01)$ & $(0.01)$ & & \\
\hline \multirow[t]{2}{*}{ Violent Crime Led to Contact } & & & & & -0.20 & 0.19 & & \\
\hline & & & & & $(0.27)$ & $(0.34)$ & & \\
\hline \multirow[t]{2}{*}{ Suspect Had Warrant } & & & & & -0.19 & -0.25 & & \\
\hline & & & & & $(0.35)$ & $(0.44)$ & & \\
\hline \multirow[t]{2}{*}{ Suspect Was Armed } & & & & & $-0.68^{*}$ & 0.13 & & \\
\hline & & & & & $(0.35)$ & $(0.52)$ & & \\
\hline \multirow[t]{2}{*}{ Non-LE Witness Present } & & & & & 0.08 & 0.10 & & \\
\hline & & & & & $(0.22)$ & $(0.28)$ & & \\
\hline \multirow[t]{2}{*}{$\%$ of Population A.A. (zip) } & & & 0.02 & -0.01 & & & & \\
\hline & & & $(0.01)$ & $(0.2)$ & & & & \\
\hline \multirow[t]{2}{*}{ \% of Population H.A. (zip) } & & & -0.00 & $0.04 * * *$ & & & & \\
\hline & & & $(0.01)$ & $(0.01)$ & & & & \\
\hline \multirow[t]{2}{*}{$\%$ of Population Cau. (zip) } & & & $-0.04^{* * *}$ & -0.02 & & & & \\
\hline & & & $(0.01)$ & $(0.01)$ & & & & \\
\hline \multirow[t]{2}{*}{ Northeast } & & & 0.47 & 0.68 & & & & \\
\hline & & & $(0.36)$ & $(0.55)$ & & & & \\
\hline \multirow[t]{2}{*}{ Midwest } & & & 0.25 & -0.53 & & & & \\
\hline & & & $(0.28)$ & $(0.50)$ & & & & \\
\hline \multirow[t]{2}{*}{ West } & & & $-0.62^{* *}$ & 0.44 & & & & \\
\hline & & & $(0.29)$ & $(0.29)$ & & & & \\
\hline \multirow[t]{2}{*}{ Median Income (zip) } & & & -0.00 & 0.00 & & & & \\
\hline & & & $(0.00)$ & $(0.00)$ & & & & \\
\hline \multirow[t]{2}{*}{ Mayor Caucasian } & & & $-0.35^{* *}$ & -0.25 & & & & \\
\hline & & & $(0.16)$ & $(0.18)$ & & & & \\
\hline \multirow[t]{2}{*}{ Outside } & & & $0.48^{* *}$ & $0.52^{* *}$ & & & & \\
\hline & & & $(0.20)$ & $(0.22)$ & & & & \\
\hline \multirow[t]{2}{*}{ Night } & & & $0.43^{* *}$ & $0.39 *$ & -0.01 & 0.32 & & \\
\hline & & & $(0.21)$ & $(0.28)$ & $(0.28)$ & $(0.37)$ & & \\
\hline \multirow[t]{2}{*}{ Constant } & 0.95 & 1.005 & 1.08 & -1.93 & $1.95^{* * *}$ & 1.09 & -0.34 & -0.15 \\
\hline & $(0.62)$ & $(0.74)$ & (1.39) & $(1.49)$ & $(0.63)$ & $(0.78)$ & $(0.41)$ & $(0.39)$ \\
\hline Observations & 114 & 114 & 803 & 803 & 294 & 294 & 247 & 247 \\
\hline Pseudo R-Squared & 0.044 & 0.044 & 0.295 & 0.295 & 0.059 & 0.059 & 0.019 & 0.019 \\
\hline
\end{tabular}

Note. Data taken from 2014: Intentional Lethal Force Data (Menifield \& Laughlin, 2018). [Copyright: Michael Laughlin]. Estimates are multinomial logit

coefficients. The ommited comparison group is for Caucasian victims. Robust standard errors are in parentheses. ${ }^{* * *} p<0.01,{ }^{* *} p<0.05,{ }^{*} p<0.1$. 


\section{Chapter 5.}

\section{Discussion of Findings and Policy Implications}

\section{Introduction}

The primary purpose of this study was to advance the discussion around racial disparities in law enforcement officers' use of lethal force. I recognize that national data on the use of lethal force in law enforcement are lacking, hence the aim to expand data and corresponding analyses on racial disparities in police killings. Such information can hopefully foster greater understanding of the factors contributing to such disparities. This study increases available data by assembling a new database (2014: Intentional Lethal Force Data; Menifield \& Laughlin, 2018) to supplement existing sources. Additionally, the examination of the 2014: Intentional Lethal Force Data presented in prior chapters reveals important information related to officers' use of lethal force.

In this dissertation, I use a situational perspective that law enforcement officers' interactions include the following considerations: (1) officers (with choices and costs); (2) citizens (with choices and costs); (3) the situation or nature of the call; and (4) the presence of weapons. These components determine whether and how the criminal justice system justifies an officer's choice to use lethal force. See Appendix C for a visual representation of this theoretical perspective; or refer to Chapter 1 for a more detailed explanation of U.S. court decisions that have guided justification around officers' use of force. The assumption is that when officers are deploying lethal force in situations that are most likely to be justified, then it is less likely that they are using race as a factor for their micro-level decision to deploy lethal force. 
The literature has unveiled two primary belief perspectives regarding causes of racial disparities in outcomes related to policing and use of lethal force (see Appendix A). Belief Perspective 1 suggests that racial disparities are caused by factors internal to law enforcement, whereas Belief Perspective 2 argues that racial disparities are caused by factors which are external to law enforcement. These belief perspectives require further exploration vis-à-vis African American overrepresentation in the lethal force population. Also, if there is evidence that the majority of the cause for the racial disparity in law enforcement lethal force is due to external factors, then that would likewise suggest that race is less likely a factor in officers' micro-level decisions to use lethal force. Further, since time and money are limited for policy implementation, it is useful to consider broadly where to best treat these disparities. In this study, I evaluated the 2014:

Intentional Lethal Force Data to determine whether compelling evidence exists for either belief perspective.

Despite clear racial disparities in the proportions of individuals killed by police (compared to U.S. Census population estimates), most studies have either found mixed results or no evidence of micro-level discrimination in law enforcement officers' deployment of lethal force. However, media narratives present a fairly consistent picture of Caucasian officers using lethal force to target non-Caucasian suspects (Menifield et al., 2019). Collaborating with a team of students and Dr. Menifield, I sought to compile and evaluate additional data in order to examine the veracity of this overarching narrative and the accuracy of prior studies.

The need for increased data on police killings informed the primary purpose of this study, the increased data is necessary to conduct empirical research to explore 
whether race influences police officers' micro-level decision to use lethal force. In this study, I also assessed other characteristics related to officers' use of lethal force. Another goal of this work was to promote informed conversations and decisions (e.g., by policymakers and within police organizations) while expanding the availability and reliability of data on police killings.

In part because the 2014: Intentional Lethal Force Data are novel in their breadth and depth, the second objective of this research was to describe characteristics of police killings in the U.S. in 2014. Relevant characteristics included the race, age, and gender of victims; presence of a weapon (on the victim); officers' race and years of law enforcement experience; race of leadership (i.e., mayor and chief or sheriff); description of the incident area via zip code (e.g., income level, diversity level, and U.S. region); whether the call was dangerous; incident location; and the time of day when the incident occurred. These exploratoins into the data also serve to test the relevance of Belief Perspective 1,2, and the situational perspective.

The third objective of this study was tied to the second objective but considered the relationship between race and officers' use of lethal force (i.e., whether incident characteristics varied by the victim's race). In the case of variation by race, I addressed whether the variation was as expected according to the prevailing media narrative of Caucasian officers killing unarmed African American men. The second and third objectives also consider the two belief perspectives (internal or external), the situational perspective (justified use of lethal force or not), and the varying levels where race can play a factor to also evaluate whether it looks like the racial disparities in law enforcement use of lethal force are likely due to police officers' using race as a factor in 
their micro-level decisions to deploy lethal force or whether there is evidence the differential outcomes grow out of other areas.

The fourth objective of this study was to identify evidence of racial discrimination in police killings based on a simple test, similar to previous studies (Anwar \& Fang, 2006; Fryer, 2016; Knowles et al., 2001), to explore whether race is a factor in law enforcement actions. I argued that there would be evidence of micro-level discrimination in police officers' lethal force decisions, wherein Caucasian officers would kill a larger proportion of minorities who were unarmed compared to minority officers. The null hypothesis was that there will be no evidence of discrimination. The simple test assesses differences in proportions; thus, if Caucasian officers were more likely to shoot unarmed non-Caucasians compared to non-Caucasian officers, then one could reject the null hypothesis of no discrimination.

Multivariate analyses are also included to test whether there is evidence that internal factors, external factors, victim actions, danger, or micro-level officer decisions appear to influence the incidence of police killings. The multivariate analysis tests the assumptions of three theories (Belief Perspectives 1 and 2, the situational perspective, and the assumptions of the simple test) that are interwoven into this dissertation and also address objectives 2,3 , and 4 .

This chapter addresses the study findings by considering the populations (i.e., officers who deployed lethal force and the victims) and summarizing results on the basis of this dissertation's theoretical perspective. I also discuss the findings with respect to Belief Perspectives 1 and 2, and I interpret the simple test and multivariate regression results. I will present a broad discussion of this new dataset rather than a more defined 
causal study, which is uncommon in the criminal justice field. After discussing the findings, I will explore how this study fits into the broader literature, provide policy implications, and suggest avenues for future research.

\section{Discussion of Findings}

Considering the populations. These data provide valuable information about individuals killed by police, officers deploying lethal force, and the context of these encounters. Upon examining the race of persons killed by police and of officers using lethal force, it is clear that race is an important characteristic to consider when studying lethal force in law enforcement. At twice the expected figure, African Americans were highly overrepresented among persons killed by police in 2014 (when compared to overall U.S. population estimates). Additionally, these results demonstrate that Caucasians were underrepresented among those killed by police, which numerically accounts for nearly all overrepresentation of African Americans.

Those killed by police. Research has compared the number of individuals killed by police to the overall U.S. population; however, it is important to consider whether those killed by police might reflect racial distribution in the U.S. In criminology, few would expect the same number of women to be killed by police as men because offending rates differ by gender (Rennison \& Dodge, 2018). Considering violent offenders may serve as a more appropriate measure of who is likely to be killed by police versus a general population distribution. Logically, one could also assume that individuals who commit violent crimes are more likely representative of those killed by police; population statistics may not reveal trends in those killed by police. Because there is no true measure 
of violent crime offending rates, it is necessary to use the best proxy to estimate violent offending rates by race.

A more controversial proxy for offending rates by race is the FBI's UCR. This measure is controversial because not all crimes are reported to police, and some police departments have been caught submitting erroneous crime statistics to UCR (Rennison \& Dodge, 2018). Even so, the proportions of the U.S. population by race and of violent offenders by race are clearly different. The FBI's UCR (2017) has suggested that Caucasians (46.3\%) are reported as violent offenders only slightly more often than African Americans (44.0\%). Native Americans have been identified as violent offenders in $1 \%$ of police reports, and Asians have been identified as such in $0.7 \%$ of reports (FBI UCR, 2017). According to this proxy, African Americans (26.9\%) and Native Americans $(0.5 \%)$ were underrepresented among those killed by police in 2014; Asians were overrepresented (1.6\%) and Caucasians (48.8\%) were nearly perfectly represented among those killed by police during the same year.

In this dissertation, I applied a less controversial proxy for violent crime offending rates by race (Violent Offender Race) based on NCVS data as summarized by Morgan (2017). If Violent Offender Race is an accurate estimate of violent offending rates in the U.S., then disparities in the use of lethal force should appear different by race than when using other proxies (i.e., UCR violent offender estimates and Census population estimates). When comparing NCVS violent offender estimates to statistics of those killed by police, African Americans and Hispanics killed by police remained slightly overrepresented ( 4.2 percentage points and 4.1 percentage points, respectively). Likewise, when comparing those killed by police to the Violent Offender Race 
percentages, the proportion of Caucasian victims was slightly underrepresented (5.0 percentage points). However, racial disparities in those killed by police in 2014 were nearly entirely accounted for by disparities in violent offending rates per victims' reports of violent crimes in the NCVS (Morgan, 2017).

These data allow for a wider look at the population killed by police along with consideration of victims' genders and ages. As might be expected based on violent offending rates, individuals killed by police in 2014 were mostly men (95\%) and under the age of 45 (75\%). Criminology has provided substantial evidence of high offending rates among men, who commit most violent crime, and people under 50, who commit about $77 \%$ of all violent crime (FBI UCR, 2017). In 2014 , more than $80 \%$ of persons killed by police were younger than 51 , and more than $75 \%$ were below the age of 45 , which aligns well with the FBI's UCR (2017) estimate of 77\% of violent crime being committed by persons under the age of 50 and the well-documented relationship between crime and age (Ulmer \& Steffensmeier, 2014). Therefore, when gender and age are considered, it is more important to consider violent offending rates than U.S. Census proportion estimates of gender and age.

These proxies, although imperfect, are useful; if they reflect violent offending rates, then they suggest that disparities in the use of lethal force among law enforcement in 2014 may have been less associated with officer-based race discrimination and more correlated with racial disparities in violent offending rates—or at least racial disparities in how violent offenses are reported (co-contamination). Violent offending proxies may be more directly related to those killed by police and thus more accurate than Census estimates, as indicated by similarities in disparities in offending and those killed by police 
by gender and age. I argue that Violent Offender Race should be considered as a proxy for future lethal force studies. Furthermore, additional studies should be done to test whether Violent Offender Race or the U.S. Census population estimates serves as a better proxy when considering those killed by police. However, the remainder of this chapter focuses on U.S. Census Population estimates, which is a more commonly used and widely accepted proxy than Violent Offender Race. However, the reader should bear in mind that there are notably fewer differences in representation by race when comparing Violent Offender Race to individuals killed by police in 2014.

U.S. population of police officers. Just as the population of those killed by police and those reported as violent offenders are not indicative of racial distribution estimates throughout the U.S., the population of police officers in the U.S. is also not reflective of the U.S. population proportions by race or gender (Askenas \& Park, 2015; Deloitte, 2017; Reaves, 2015); one would expect a large overrepresentation of Caucasian officers among police who deploy lethal force. In fact, Caucasian officers are still slightly overrepresented in our sample, comprising $85 \%$ of officers who used lethal force instead of the expected $80 \%$ based on DataUSA (2018) estimates of U.S. police officer race. When considering the number of individuals killed by police and the number of officers who deployed lethal force, the 2014 data appear to partially substantiate the media narrative that Caucasian officers are killing young African American men at an increased rate. Yet these statistics must be put into context.

In any study concerning law enforcement, the proportion of U.S. police officers who were Caucasian, and Caucasian officers who deployed lethal force, is essential to consider. However, as noted in Chapter 1, these indicators do not necessarily imply race 
to be a factor in lethal force; rather, differences in representation are primarily an indication of the population from which officers are drawn. Any population in which a certain segment comprises $80 \%$ of that population would presumably contain an overrepresentation of that population segment. In this case, the fact that $85 \%$ of officers who deployed lethal force were Caucasian is not that alarming because the sample of officers using lethal force was pulled from an overall officer population comprised of nearly $80 \%$ Caucasian men. Additionally, the fact that Caucasian officers appear to be over-represented in a database of police killings should not be considered prima facie evidence that police killings are driven by Caucasian officers. Particularly because I only have reliable officer race for about $1 / 3$ of my data, and secondly the media frame tends to make it more likely that Caucasian officers will receive media attention, particularly when those officer kill African American men. Further, within the 2014 lethal force data, if less than $85 \%$ of Caucasian officers exhibited any characteristic, then that characteristic could be considered as underrepresenting Caucasian officers because $85 \%$ of officers within the dataset were Caucasian men. In addition to underscoring the importance of officer race, this study also paints a clearer picture of the use of lethal force in law enforcement in 2014.

When considering the population killed by police, Caucasian officers should be expected to use lethal force most often due to the high percentage of Caucasian officers in the U.S. (DataUSA, 2018). Further, due to the overrepresentation of Caucasian officers (around 85\%) among those who deployed lethal force, one should expect around $85 \%$ of the officers to be Caucasian when examining all characteristics. Similarly, African Americans would likely be expected to be killed by police at a higher rate than their 
estimated proportion of the U.S. population because they are overrepresented in proxies for violent offending rates by race (FBI UCR, 2017; Morgan, 2017) compared to U.S. Census population estimates; therefore, African Americans are more likely to have contact with police officers. However, neither of these observations suggests micro-level racial discrimination in officers' actions; rather, these trends imply that the populations considered do not precisely reflect U.S. Census estimates by race, again calling into question whether race is the best metric when considering representation expectations surrounding officers' use of lethal force.

Police officers who deployed lethal force. As noted in the previous section, Caucasian officers were overrepresented among those who deployed lethal force $(85 \%)$ even when accounting for the overrepresentation of Caucasian officers $(80 \%)$. Irrespective of race, officers who deployed lethal force were more likely to deploy lethal force intra-racially. The greatest percentage of individuals killed by Caucasian officers were Caucasian themselves; the greatest percentage of persons killed by African American officers were African American; and the greatest percentage of victims killed by Hispanic officers were Hispanic. These data demonstrate that officers more often used lethal force against their own race, thus providing no evidence for micro-level discrimination in officers' deployment of lethal force.

This intra-racial phenomenon persisted when considering the race of the law enforcement leader or community leader along with that of the victim. Similar to police officer race characteristics, the community leader and law enforcement leader characteristics each featured an overrepresentation of Caucasian leaders. Therefore, it is 
unsurprising that in each category of victim race, officers from organizations with Caucasian leaders killed the largest number of victims of any race.

Police organizations with Caucasian or African American leaders demonstrated an intra-racial association among officers who deployed force: for African American leaders, $57.8 \%$ of victims killed by their officers were African American; for Caucasian leaders, $52.0 \%$ of victims killed by their officers were Caucasian. The trend shifted for Hispanic leaders of police organizations, where $32 \%$ of victims killed by their officers were Hispanic and $42 \%$ were Caucasian. These same patterns emerged among community leaders. These data do not provide support for the hypothesis that leadership-based racial discrimination shapes officers' decisions to use lethal force. These numbers also do not argue against passive representation, but instead more likely reflect the fact that leadership in police organizations and in communities is more likely to reflect the race of the community. Accordingly, communities with low diversity are more likely to have Caucasian leaders than communities with high numbers of minority community members.

Noteworthy differences are also apparent when victim race, officer race, and victim age are considered collectively. Among Hispanic and Caucasian officers, all victims were killed at about the same rate regardless of age. Conversely, for African American officers, most victims were younger than age 34; further, most African American victims killed by African American officers were younger than age 26 . Countering the mainstream narrative, available data indicate that African American officers killed the highest proportion of young men and young African American men. 
Police officer accountability measures. Some of the incorporated characteristics could be considered police officer accountability measures, as variations in this characteristic could influence whether a person or police officer will likely act illegally. The presence of a non-police witness is a measure of police accountability suggesting that police officers may be less likely to deploy unjustified lethal force if there are nonpolice witnesses on scene. This presumption mirrors the expectation that individuals have a reduced likelihood of offending when they realize their actions are visible to cameras or witnesses. This presumption also exemplifies one reason why body-worn cameras may reduce police misconduct.

In 2014, Caucasian victims comprised a high proportion (52\%) of victims killed without a non-police witness. Conversely, African American victims were more often killed in our sample (63\%) with a non-police witness present. If the assumption is correct that police officers are less likely to deploy unjustified lethal force amidst witnesses, then these data suggest that Caucasians were more frequently involved in situations involving such force. These findings do not support the narrative that police officers are targeting minorities or deploying unjustified lethal force due to racial discrimination.

There could also be another factor related to the presence of a non-police witness variable. U.S. courts have also held that the number of people present at a call is a factor which can be considered when determining threat levels. In essence if there is a larger number of non-police people present at a call then it could increase the likelihood that the police officer could be overcome. So with the presence of witness variable, where there is an increase in the number of people at a call (i.e. the presence of a witness), that could also increase the threat level. 
U.S. Supreme Court decisions have revealed two additional characteristics as measures of police accountability: the type of call (namely whether violence is likely) and whether the suspect is armed. In nearly $60 \%$ of calls where officers deployed lethal force, violence appeared likely based on the incident description. Further, nearly $90 \%$ of persons killed by police were armed. Therefore, police officers in this sample tended to be involved in calls that were more dangerous and included armed suspects.

The relationship between race and the proportion of victims armed explored in Table 6 highlights victim race as a potential factor in officers' decisions to use force. Most importantly, when considering whether victims were armed by race, one can see that African American victims were unarmed twice as often (20\%) as Caucasian victims $(9 \%)$. This is a disturbing data point that reveals a noteworthy racial difference in the likelihood of persons to be shot when unarmed. When Table 6 is viewed independently, it paints a grave picture of racial disparities in officers' use of force. However, since nearly twice as many Caucasian victims were killed by police as African American victims in 2014, this disparity is hidden when considering the proportion of victims unarmed by race out of the total number of people killed by police.

Further consideration of these characteristics along with victims' race reveals that only about $5 \%$ of all victims were unarmed African Americans; about 4\% were unarmed Caucasians; and about 2.5\% were unarmed Hispanics. There was little difference among races in the number of unarmed persons killed by police. Additionally, of Caucasian suspects who were killed, the proportion of those who were unarmed exceeded the proportion of unarmed Hispanics who were killed from the total population. These figures also do not support the narrative that police officers are indiscriminately killing 
unarmed persons of any race; in fact, based on these findings, officers in 2014 appear to have deployed lethal force nearly exclusively in situations in which the public would likely deem such force necessary. Again, the data in Table 6 clearly substantiate race as a possible factor in officers' decisions to use force.

The multivariate analysis testing the situational perspective did not show that the victims age was an important consideration for African Americans and Hispanics, as was the officer race. However, this model estimates that Caucasian officers are less likely to kill both Hispanics and African Americans than Caucasians. For African American victims, whether they were armed or not indicated influence, and that they were less likely to be armed when killed than Caucasian victims.

Thus, our data on officers who deployed lethal force in 2014 imply that although racial disparities existed in terms of victims and in the proportion of unarmed victims within races, these differences may or may not be due to micro-level discrimination. However, a lack of training or experience does not appear to have led to these disparities. Officers did not seem to be deploying force against minority victims in less-dangerous situations, nor were police using force on substantially larger proportions of unarmed minorities than unarmed Caucasians. Officers also did not tend to use force against minorities in incidents without witnesses (i.e., where officers may be more likely to use unjustified force). Regardless of race, officers did not deploy lethal force more frequently inter-racially than intra-racially. Leadership race was not associated with victim race, as would be expected if race were a factor in lethal force deployment decisions. Overall, officers used lethal force on a low number of unarmed suspects and were not substantially more likely to deploy lethal force against unarmed non-Caucasians than 
unarmed Caucasians. Furthermore, race was not a prominent factor among officers who used lethal force, their leadership, or the context of such use.

Victims and race. As noted above, when considering the proportion of the U.S. population (U.S. Census Quick Facts, 2017) to those killed by police, African Americans were killed at twice the expected rate in 2014; Caucasian victims were killed at a lower rate than expected; and Hispanic victims were killed at a slightly higher rate than expected. The law enforcement literature on use of force and lethal force has shown that the relative rates of police killings among races are as expected based on past research (Chaney \& Robertson, 2015; DeGue et al., 2016; Fryer, 2016; Fyfe, 1982, 1988; Gross, 2015, Goldkamp, 1976; Klinger, 2012; Menifield et al., 2019; Miller, 2015; Moore et al., 2016). The 2014: Intentional Lethal Force Data offer additional insight into the associations between victim race and several relevant characteristics in 2014 .

Police killed about half as many African Americans as Caucasians; however, given that Caucasians comprise $62 \%$ of the U.S. population and African Americans comprise only 13\% (U.S. Census Quick Facts, 2017), relative to the distribution of the U.S. population, police killed African Americans 2.5 times more often than Caucasians in 2014. African American and Hispanic victims killed by police were younger than Caucasian victims on average. The proportion of Caucasian victims older than 45 was about three times higher (33\%) than the proportion of Hispanics (11\%) and African Americans (12\%) of the same age. African Americans (21\%) were the most common unarmed victims, followed by Asians (14\%), Hispanics (13.8\%), and Caucasians (9\%). African Americans were most often killed at calls that, when reported, had a low likelihood of violence (all races were within 6\%). 
It is important to consider U.S. history when exploring victim race and officer experience. The experience of officers who used lethal force in 2014 appeared relevant in killings of African American and Caucasian victims. Officers with the least experience (less than 2 years) killed a greater proportion of African American victims, whereas officers with the most experience (15+ years) killed the lowest proportion. Similarly, officers with the most experience (15+ years) killed Caucasian victims at a higher rate, and officers with the least experience killed these victims at the lowest rate. This relationship is the opposite of what one might expect if implicit bias manifested in officers' lethal force decisions. Few would argue that younger people in the U.S. are more likely to be biased against African Americans than older people; as such, the trend of newer (and presumably younger) officers killing a higher proportion of African Americans in 2014 compared with more experienced (presumably older) officers does not support the hypothesis that race was a factor in officers' decisions to use lethal force.

Location. The rate at which victims were killed by police varied based on location (i.e., U.S. region and location type). Overall, based on 2017 U.S. Census estimates, victims were overrepresented in the South and West and underrepresented in the Midwest and Northeast; however, people were not equally distributed by race among these four regions. Caucasian victims were underrepresented in the South (53\%), Northeast (45\%), Midwest (56\%), and West (46\%) compared to population estimates $(60 \%, 69 \%, 78 \%$, and $53 \%$, respectively) from Arismendi and Penaluna (2016). Interestingly, Caucasian victims were most similarly represented in the South (53\% to $60 \%)$ and West (46\% to 53\%) and disparately represented in the Northeast ( $45 \%$ to $69 \%$ ) and Midwest (55\% to $78 \%$ ). If one 
were studying whether diverse populations reduce the likelihood of use of lethal force in law enforcement at the regional level, then the above estimates present conflicting results.

Regarding African American victims, most live in the South (55\%), followed by the Northeast (18\%), the Midwest (17\%), and the West (10\%) (Black Demographics, 2019). Based on this distribution, a greater number of African Americans would presumably be killed in the South. Indeed, of the 232 African American victims killed by police, 119 (51\%) were killed in the South. The next highest proportions were killed in the Midwest (22\%), West (19\%), and the Northeast (8\%). African Americans killed by police were thus slightly underrepresented in the South, highly underrepresented in the Northeast, slightly overrepresented in the Midwest, and highly overrepresented (at nearly twice the expected rate) in the West. Based on historical treatment of African Americans in the U.S. as well as regional differences in such treatment, these figures do not support the argument that institutional bias drove disparities in those killed by police. Greater institutional bias would be expected in the South (Payne, Vuletich, \& Brown-Iannuzzi, 2019), where African American victims were in fact underrepresented compared to Census population estimates by race.

Hispanic regional estimates provide similar results to those discussed above concerning Caucasians and African Americans. Conversely, Hispanic regional estimates provide conflicting results when considering whether diverse populations reduce the likelihood of use of lethal force in law enforcement at the regional level. Hispanic regional estimates also do not support the expected relationship of greater institutional bias in the South (Payne et al., 2019). 
To further explore the relationships among race, location, and police officers' use of lethal force, we compared the regional distribution of Caucasians and non-Caucasians to the proportions of races killed by police. When considering where people reside by race alongside within-region diversity, the West is the most diverse, followed by the South, the Northeast, and the Midwest (U.S. Census, 2017). The proportion of nonCaucasian victims killed by police did not align with regional diversity; non-Caucasians made up $44 \%$ of victims killed in the Midwest (an overrepresentation of 22 percentage points), $55 \%$ of those killed in the Northeast (an overrepresentation of 21 percentage points), 54\% of those killed in the West (an overrepresentation of 7 percentage points), and $6 \%$ of those killed in the South (an overrepresentation of 6 percentage points). The two least diverse regions had the greatest overrepresentation of non-Caucasians killed by police when comparing percentages of those killed by police to within-region population estimates by bivariate race. These findings are consistent with the hypothesis that greater racial diversity within communities could result in lower racial disparities among individuals killed by police. However, these are macro-level region estimates and may not be extrapolated to the meso-level (i.e., zip codes or neighborhoods).

Therefore, we also considered zip code diversity as a separate characteristic in the 2014: Intentional Lethal Force Data. High proportions of African American, Hispanic, and Asian victims (77\%, 79\%, and 71\%, respectively) were killed in areas with diverse populations per zip code diversity estimates; a high proportion of Caucasians (72\%) were killed in low-diversity areas. It is unsurprising that police killed non-Caucasians in zip codes with higher concentrations of minorities and killed Caucasians in zip codes with higher concentrations of Caucasians if race was not a factor in police killings. The multi- 
variate analysis testing Belief Perspective 2 mirrored the above findings, and show that as the proportion of Caucasians increases in a zip code African Americans are less likely to be victims (as compared to Caucasian victims) and likewise as the proportion of Hispanics increases in a zip code, Hispanics are more likely to be victims (as compared to Caucasian victims). These data show that victims of any race are more likely to be killed in areas with higher proportions of that race.

Additional location-based considerations in terms of where police killed victims include location (micro-level) and income-level estimates for zip codes where shootings occurred. In terms of where officers deployed lethal force, most victims were killed outside (40\%), followed by within residential buildings (37\%), inside businesses (15\%), and inside vehicles $(8 \%)$. The top two location types for victims of all races were outside and residential, but some differences emerged by race. Police killed nearly half of African American victims (47\%) and Hispanic victims (49\%) outside, but roughly half (45\%) of Caucasian victims were killed within residential buildings. Further, police killed more than one-fourth of African American victims (28\%) and Hispanic victims (30\%) in residential buildings but approximately one-third of Caucasian victims (33\%) outside. The multi-variate analysis showed that when traffic stops are included in the "outside" category, then both Hispanics and African Americans are more likely to be killed outside as compared to Caucasians. Location type could be considered a police accountability measure because a person committing an illegal/unjustified act may be less likely to be apprehended for that act if they committed it within a confined space, which would limit the number of potential witnesses. If this assumption is correct, then the 2014 pattern of 
police killing African Americans and Hispanics at higher rates outside would not support the hypothesis that race was a factor in those decisions.

In 2014, police killed nearly all Caucasians, Hispanics, and Asians in zip codes where the average income level was at $150 \%$ of the poverty line or higher; roughly onequarter of African Americans were killed in zip codes with an average income below $150 \%$ of the poverty line. Police killings by zip code income reveal disparate outcomes based on race, which may warrant further study. The trend of African Americans being killed at higher rates in lower-income zip codes could reflect African American families' greater likelihood of being in the lowest average income categories (Simms, 2009). Therefore, zip code measures suggest that people of any race may be more likely to be killed in zip codes with a higher proportion of their race. This evidence further refutes the hypothesis that race was a factor in officers' decisions to deploy lethal force in 2014.

In summary, when considering victims' race, our data indicate that African Americans were highly overrepresented compared to the U.S. Census (2017) proxy for racial proportions of the population; however, the number of persons killed by police appear more reflective of violent offending proxy estimates by race (FBI UCR, 2017; Morgan, 2017). African American and Hispanic victims died from lethal force at younger ages than Caucasian victims. African Americans were most likely to be killed when unarmed and most likely to be killed at calls with less expected violence.

Use of lethal force by location was related to several characteristics. In most cases, victims were most likely to be killed by race in locations where that race was most likely to be present (i.e., non-Caucasians were more often killed by police in zip codes with higher proportions of non-Caucasians). Regional evidence also implies that greater 
within-region diversity may lead to fewer disparities between the proportions of nonCaucasians killed by police and the proportions of non-Caucasians living in a given region.

Discussion of findings related to the theoretical perspective. The theoretical perspective underpinning this dissertation posits that law enforcement officers' interactions involve four factors: (1) officers (with choices and costs); (2) citizens (with choices and costs); (3) the situation or nature of the call; and (4) the presence of weapons. These components contribute to whether courts will likely perceive an officer's decision to use lethal force as justified. The 2014: Intentional Lethal Force Data provide more information on these factors than most databases on police lethal force. The evaluative context for use of force based on U.S. court decisions is presented in Chapter 1.

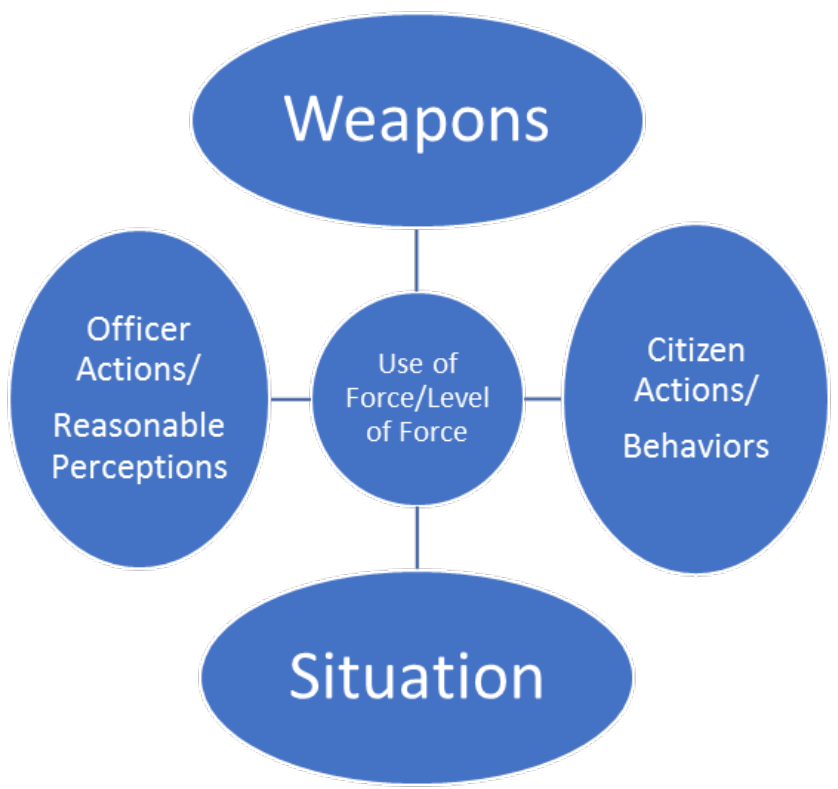

Figure 3. Theoretical model. The situational perspective in this study illustrates factors to consider when evaluating a law enforcement officer's use of force. This framework depicts the relationship between law enforcement officers' actions and reasonable perceptions, presence of weapons, situational context, and citizens' behaviors and actions before and after the officer arrives on scene. This model is an original concept from 
Laughlin (2019) informed by U.S. Supreme Court decisions regarding use of force. [Copyright: Michael Laughlin, 2019].

Victims' actions and presence of weapon. The suspect's actions are essential to consider when studying use of lethal force because these actions shape an officer's perceptions of the degree of threat. The first consideration is whether the suspect is armed. Among unarmed victims of police killings in 2014, about 5\% were African American, about 4\% were Caucasian, and about 2.5\% were Hispanic. However, within races, twice the proportion of African American victims were unarmed (20\%) than Caucasian victims (9\%). This pattern suggests that police may perceive unarmed African Americans to be a greater threat than unarmed Caucasians.

Approximately $66 \%$ of all victims possessed guns, with Caucasian victims most likely to have one; only $17 \%$ of Asian victims had a gun. Many victims of all races who possessed a gun (80\%) aimed it towards officers. By contrast, less than half of victims $(42 \%)$ with a gun fired the weapon. Most importantly, around $90 \%$ of persons killed by police were armed (66\% held a gun). These figures are consistent with other research on police killings; typically, a high percentage of those killed by police were armed at the time (Kindy \& Elliot, 2015; Selby et al., 2016; Shane \& Swenson, 2018). Further, as noted in the literature review, the assumption that unarmed is analogous to non-dangerous is erroneous (Shane \& Swenson, 2018).

Situational factors. The second part of the situational perspective examines situational factors when officers deployed lethal force. The first factor, which relates directly to court decisions, is whether violence was likely at the dispatched call. This characteristic is a proxy for the expectation of violence and is not perfect, particularly 
because traffic stops and drug-related calls were included in calls with lower expectations of violence (despite courts having identified both types of calls as situations where violence may be likely). Around $60 \%$ of victims of lethal force were killed at calls where violence could be highly expected. Of those, Hispanics and African Americans were killed more often at incidents when violence was less likely ( $43 \%$ and $44 \%$, respectively). Caucasians were killed least often (38\%) during calls with a lower likelihood of violence. Although the difference between Hispanics and Caucasians was only $6 \%$, race may have been a factor in anticipated violence.

The time of the incident is another important situational factor. According to our data, officers killed the highest proportion (40\%) of victims at night, with the number of victims declining throughout earlier in the day (18\% evening, 18\% afternoon, $16 \%$ morning, and 7\%, early morning). No substantial differences appeared in when victims were killed by race, except that Caucasians were killed least often at night (38\%) and most often in the afternoon (21\%).

As noted earlier in this chapter, the presence of non-police witness $\times$ race of victim characteristic is also a measure of police accountability. This is partially based on the assumption that police officers were less likely to deploy unjustified lethal force when non-police witnesses were present. If this hypothesis is correct, then the results in Table 10 do not support the narrative that police officers target minorities based on race: in terms of the presence of a witness, Caucasian victims (52\%) were most often killed without a non-police witness; African American victims (63\%) were most often killed with a non-police witness. However, this characteristic is hard to measure, because as you increase the number of non-law enforcement persons at a call, you are also 
increasing the likelihood that an officer could be overcome, and therefore increasing the potential for perceived danger.

In summary, these results related to situational characteristics are inconsistent in supporting the hypothesis that race influences officers' decisions to use lethal force. Most of the time (i.e., in about $60 \%$ of incidents), officers deployed lethal force at calls that seemed more likely to be dangerous. However, officers deployed lethal force against Caucasian victims least often in calls with a lower expectation of danger. Therefore, race may have been a factor in whether officers perceived a call as dangerous. Use of lethal force $\times$ time of day suggests that officers were more likely to use lethal force during the times of day when violent crime was more likely. Presence of a non-police witness indicates that officers deployed lethal force against African American victims at the highest proportion of calls with non-police witnesses, which should have deterred unjustified or illegal police behavior, or could have increased the potential for officers perceiving a threat.

Summary of findings related to the theoretical perspective. Data on victims' behavior and the presence of a weapon indicate that these factors were the best predictors of officers using lethal force in 2014. Around 90\% of individuals killed by police were armed (most with guns) when killed, and the majority of victims possessing guns aimed and/or fired. Further, as noted previously, use of lethal force on unarmed victims was relatively rare; $5 \%$ of all victims were unarmed African Americans, $4 \%$ were unarmed Caucasians, and 2.5\% were unarmed Hispanics. There were some differences between races in the behaviors of victims and whether the victims were armed, most of these data do not support race as a factor in the officers' decisions to deploy lethal force. However, 
the trend of twice as many African American than Caucasian victims being unarmed clearly suggests that race may play a factor in how threatening officers perceive unarmed persons to be based on race.

The situational context of lethal force was more varied. The higher proportion of non-police witnesses present at killings of African Americans does not support the hypothesis that race was a factor in those killings. However, the higher proportion of African American and Hispanic victims who were killed at calls with a lower expectation of violence could provide support for the hypothesis that race played a factor. Overall, most characteristics used to evaluate the situational perspective provide support for the conclusion that, by and large, police officers deployed lethal force during situations where that force was more likely to be justified. Additionally, there is not compelling evidence among characteristics related to the situational perspective that race played a more notable role in officers' lethal force decisions than the context of those situations.

Discussion of findings for simple test. The simple test explores the relationship between officers' race and victims' race by including whether the proportions of armed or unarmed victims varied by officer race. The simple test is exploring whether there is evidence that race is a factor in the officers' micro-level decision to deploy lethal force. Findings revealed that the proportions of unarmed African American victims killed by African American officers (75\%) and non-Caucasian officers (45\%) were much higher than the proportions of unarmed African American victims killed by Caucasian officers (22\%). The proportion of unarmed Hispanic victims killed by non-Caucasian officers was only slightly higher than the proportion killed by Caucasian officers (14\% and 13\%, respectively). Interestingly, particularly given the history of policing (i.e., limiting 
policing power based on race) and the racial history of the U.S., is that non-Caucasian police officers did not kill any unarmed Caucasians in our dataset, and only $14 \%$ of victims killed by Caucasian officers were unarmed. The simple test conveys an intra-race relationship that opposes expectations if race were a factor in police officers' decision to use lethal force. Accordingly, the null hypothesis of no micro-level officer discrimination cannot be rejected.

Discussion of findings for belief perspectives. There are two broad belief perspectives on the emergence of racial disparities in law enforcement actions/outcomes. These belief perspectives have been used when considering policing outcomes for more than 40 years. If the data suggests that there are external causes driving the differential outcomes by race in law enforcement use of lethal force, then that would likewise suggest that race is less likely to be a factor at the micro-level officer decision. Although they represent a false dichotomy, these viewpoints provide a platform for considering where to invest money and policies to improve racial disparities in policing outcomes. If one cannot allocate funding to address all problems related to policing disparities, then it is important to consider whether there is greater evidence that disparities in policing are due to trends occurring within or outside of policing.

Belief Perspective 1 (internal causes) points to the criminal justice system or law enforcement agencies as the root of racial disparities; the second perspective (Belief Perspective 2, external causes) points to the social context in which the criminal justice system and law enforcement agencies operate as the cause.

Internal causes of racial disparities. Some potential internal causes for racial disparities that have been identified include the following: lack of passive representation 
(Linn, 2006; Nicholson-Crotty et al, 2017; Wilkens, Williams, 2008), critical race theory/intentional/explicit discrimination (Chaney \& Robertson 2015; Gotanda, N., \& Peller, G., 1995), subtle/unconscious discrimination (Chaney \& Robertson 2015; Godsil \& Johnson, 2013), statistical discrimination/racial profiling (Western, 2006), organizational/structural discrimination (Epp, Maynard-Moody, Hairder-Markel, 2017; Fryer, 2017; Menifield et al., 2019; Rennison \& Dodge, 2018), organizational culture/stress (Anderson et al., 2017; Gilmartin, 2002), training (Anderson et al., 2016; Menifield et al, 2019; Ross, 2013), and utility maximizers (i.e., the density of police presence based on crime) (Fryer, 2017).

Although not all of the above hypothetical causes of racially disparate outcomes in policing were not addressed in the present study, some relevant characteristics were considered. For example, the argument for passive representation as a cause of disparities appears to be outdated. In 2014, around 12\% of U.S. police officers were African American (DataUSA, 2018), similar to the proportion (13\%) of African Americans in the country (US Census, 2017). Table 3 shows higher proportions of Hispanic officers than Hispanic persons in the U.S. These data do not support the hypothesis that passive representation is a major cause of racially disparate outcomes in lethal force; thus, other causes must influence the overrepresentation of African Americans (and other minorities). However, it is important to note that these results do not indicate that police forces should slow their efforts to increase diversity among law enforcement workers. Police officers in general are still overrepresented by Caucasian men, and an increase in minorities and women in law enforcement would likely increase police performance and trust; this possibility will be discussed in greater detail later in this chapter. 
Most of the literature on law enforcement's use of lethal force, and this dataset, provide no support for critical race theory (discussed briefly in Chapter 2 of this dissertation), intentional or explicit discrimination, subtle or unconscious discrimination, statistical discrimination (racial profiling), organizational (structural) discrimination, or that a lack of training are likely causes of the racial disparities in law enforcement use of lethal force. In fact, there is no evidence that micro-level racism is a factor in officers' decisions to use lethal force in the simple test and no evidence in the multi-variate models that there are internal factors within law enforcement that are contributing to the racially disparate outcomes in lethal force.

Likewise, although Menifield et al. (2019) used the same data and argued that meso- or macro-level policing policies can lead to racial disparities, our dataset shows no evidence that policing policies are to blame. However, it is important to consider whether well-meaning officers and police administrators can deliver equitable justice using policies, laws, and practices implemented during times characterized by more explicit and/or implicit racial biases. Likewise, it is important to consider how external institutional bias (internal or external) can lead to greater co-contamination from reportees and may appear as greater implicit bias within police officers' discretionary actions.

External causes of racial disparities. Some potential external causes for racial disparities include the following: co-contamination (Loeffler \& Bovaird, 2019); socioeconomic disparities (e.g., in education or income) (Alexander et al., 2014; Simms, 2009; Reeves \& Sawhill, 2014); opportunity/cost differences (Becker, 1974); Putnam’s (2016)“Goodnight Moon time" and "airbags"; violent crime rate/Becker’s (1974) 
economic theory of criminal behavior; neighborhood crime (Lee et al., 2014); and disparities in police trust (Carter, 2019; COPS-USDOJ, 2015; Enns, 2016; Menifield et al., 2019).

While our dataset did not address all potential external causes of racially disparate outcomes in policing, data did reveal sufficient information about some. The racially disparate outcomes for education and income (discussed briefly in Chapter 1) are somewhat reflected in differences within the criminal justice system's outcomes by race and by those killed by police. Further, it is unsurprising that differences in trust of police follow racial lines when considering the established historical record of poor treatment of African Americans by police in the U.S. This poor treatment understandably leads to a greater likelihood of generationally passing down warnings about police and therefore passing down reduced trust for police within the African American population, which would presumably evoke greater stress in African Americans when encountering police.

There is also evidence that police organizations are operating as "utility maximizers" (Fryer, 2016, p. 2); deploying officers at higher concentrations based on perceived crime and criminal activity reported to law enforcement (FBI UCR, 2017; Morgan, 2017), which leads to differential amounts of contact with law enforcement. Proxies for persons who commit violent offenses demonstrate substantial support for the criminal justice system not treating African Americans differently due to internal decisions; rather, African Americans are treated differently due to either co-contamination (i.e., the public typically reports, selects, or targets individuals who police contact and may be doing so disparately based on race) or ongoing racial differences in socioeconomic outcomes. American culture and continued mistreatment of African 
Americans may still result in more adverse social outcomes for African Americans, which can lead to distinct cost-benefit analyses of criminal activity. Co-contamination and disparate socioeconomic outcomes may also explain racial disparities in violent offending rate proxies (FBI UCR, 2017; Morgan, 2017).

Violent victimization data provide support for the importance of socioeconomic outcomes. According to Harrell et al. (2014), persons at or below the poverty line had the highest rates of violent victimization, and African Americans and Hispanics were overrepresented in households at or below the poverty line. The reality is that not only have African Americans suffered historical mistreatment in the U.S., but today at birth, a higher percentage of African American children have a lower likelihood of future success (based on the education level of their parents) (Putnam, 2016). Unfortunately, disparate outcomes for African Americans in the criminal justice system are not eradicated and represent an inter-generational problem; there is no greater parental outcome predictor of juvenile offending rate than the incarceration of a juvenile's parent (Siegal \& Welsch, 2017).

One could argue that the zip code diversity findings in the cross-tabulations substantiate racial threat theory (discussed briefly in Chapter 1 of this dissertation). However, these data more likely reflect the fact that the greater the number of people of any given race within a zip code, the greater the likelihood that persons of that race will be included in those killed by police within that zip code (or typical expectations from population sampling). The multi-variate regression results in Table 19 further give evidence to this being a sampling issue rather than a racial threat issue. The multi-variate model testing potential external causes shows the greater the percentage of Caucasians in 
a zip code, the less likely an African American is to get killed in that zip code (when compared to Caucasians). Similarly, the same model estimates that as the proportion of Hispanics increases in a zip code, the likelihood that the victims will be Hispanic instead of Caucasian also increases.

Similarly, the regional data in Table 12C for Caucasians and African Americans reveal no support for racial threat theory. For Hispanics, results are ambiguous.

Additionally, evidence of an intra-race officer-victim relationship when using lethal force could suggest that police organizations' deployment decisions are related to race, such that organizations attempt to deploy non-Caucasian officers to more diverse neighborhoods. Similarly, this pattern may be attributable to minorities being more likely to serve as police officers within communities with higher proportions of minorities. This pattern may partially explain why police killings included higher proportions of intraracial than inter-racial deaths.

Finally, in the multi-variate regression model testing external causes for racially differential outcomes in lethal force the race of the mayor, the region of the U.S., the diversity of the zip code, the time of day, and the location of the incident were all factors which may influence the incidence of law enforcement lethal force.

Summary of discussion on belief perspectives. When considering this study in the context of other criminology and sociology research, there is a great deal more evidence in these data when combined with existing literature that racial disparities in policing outcomes overall, and lethal force outcomes specifically, are more likely due to factors external to police departments than to internal factors. Further, this study supports what most some previous research on law enforcement's use of lethal force has shown: 
no evidence of micro-level discrimination or biased policing by Caucasian officers when using lethal force (Becker, 1974; Fryer, 2016; Fyfe, 1982, 1988; Goldkamp, 1976; Gross, 2015; Klinger, 2012; Krapfl, 2017; Miller, 2015; Newport, 2014; Putnam, 2016).

However, as long as there are racially disparate outcomes in use of lethal force, policing, and incarceration, the criminal justice system and others should continue evaluating such disparities and aim to reduce them.

Discussion of findings for multivariate regression analyses. The multivariate regression models indicate that the disproportionate killings of African Americans were not driven by Caucasian police officers. As in the simple test, the null hypothesis that there is no evidence that race was a factor in micro-level officer decisions to deploy lethal force cannot be rejected. In fact, three of the four models indicate that Caucasian officers were less likely than non-Caucasian officers to kill Hispanic victims and one model estimated that Caucasian officers were less likely to kill African American victims when compared to non-Caucasian officers. This research provides corroboration to recent laboratory studies and partial U.S. lethal force studies that there is little to no evidence that the disparities in law enforcement use of lethal force are due to officers' using race as a factor in their decision to deploy lethal force. This study found that Caucasian officers killed African American and Hispanic victims at a lower rate than non-Caucasian officers; whether those victims were armed or unarmed. Further, this study found no evidence that factors internal to law enforcement were causing the racially different outcomes in the use of lethal force, but did find some evidence that factors external to law enforcement could be contributors. These models, when combined with other evidence in this dataset provide insight into several potential areas for improvement in 
law enforcement policy, but also call into question some of the assumptions researchers have made when studying racially disparate outcomes in law enforcement use of lethal force.

\section{Contribution to Literature}

This dissertation, based on data from the 2014: Intentional Lethal Force Data, extends prior research on police-minority interactions, particularly in terms of African Americans. Our data indicate that African Americans are highly overrepresented among persons killed by police compared to the proxy of U.S. population estimates. However, our dataset also reveals only a slight overrepresentation of African Americans among those killed by police when compared to the proxy for violent offending rates, which provides further support that violent offending rates may be a more appropriate comparison than U.S. population proportion estimates, as argued by Cesario et al. (2019). This research provides an argument for continued exploration of whether the U.S. Census general population numbers, violent offending rates, or some other proxy would be most appropriate when considering law enforcement's use of lethal force. Individuals killed by police, based on age and gender, were much more reflective of violent offending rates than U.S. population estimates. Therefore, practitioners may wish to examine violent offending estimates instead of population estimates when determining who will likely be represented among persons killed by police.

Because the study by Menifield et al. (2019) used the same database, it is important to differentiate the contributions of that study and this dissertation. The former considered whether evidence showed that Caucasian police officers were targeting minority suspects when using lethal force; Menifield et al. (2019) ultimately found that 
Caucasian officers were less likely than minority officers to use lethal force on minorities. The present study confirms this pattern but also explores the relationship between lethal force and age, lethal force and gender, lethal force and income, and lethal force and several other characteristics.

This dissertation adds to available data on the use of lethal force in law enforcement, a subject area that warrants closer attention. The breadth of this dataset and this dissertation better contextualizes the reality of officers' use of lethal force and offers insight into who is deploying lethal force, who is being killed by police officers, and the circumstances in which such incidents transpire. Findings from this dissertation reveal a relationship between lethal force and age, and this relationship mirrors that between age and crime (Ulmer \& Steffensmeier, 2014). Findings also indicate a relationship between lethal force and gender and lethal force and time of day, echoing the association between gender and crime and time of day and crime.

The multivariate analyses, cross tabulations, and simple test all confirm prior research that there is little to no evidence that racist Caucasian police officers are targeting minority suspects. The multivariate analyses show more support factors external to law enforcement as contributors to the incidents of police killings. However, the multivariate analyses also do not show strong support for the victims' actions (being armed or not) or the dangerousness of the situation having a strong influence on racial disparities in police killings.

These results primarily explore whether race is a factor at the micro-level police officer decision to deploy lethal force, but use a number of tools to more broadly consider the potential factors. By including the two belief perspectives, I am able to ascertain 
whether there is evidence that limited time and money on policy changes should be deployed to affect change within policing, within society, or both. The findings in the belief perspectives suggest that any changes to policing without also addressing disparities in society, will likely result in minimal or no effect towards reducing differential racial outcomes in law enforcement use of lethal force. The considerations using the situational perspective suggest that law enforcement officers are primarily deploying lethal force in situations that are most likely to be justified, which could suggest that it is the situations (level of danger, armed, etc.) themselves that are contributing to these (micro-level) decisions and also suggests that race may play less of a factor in those decisions than some assume.

These results further highlight the importance of considering regional information, income, diversity (zip code, within leadership, and within policing), and the offender's actions when considering lethal force. Finally, and perhaps most importantly, results highlight deficiencies in previous data, particularly that even a rigorous data collection process can result in many missing characteristics. The limited amount of information available for some characteristics after such a thorough data collection process substantially underscores the need for a national database and why that database should have mandated reporting.

\section{Policy Implications}

\section{Recommendations from this research.}

Policing policy recommendations. Perhaps the most important policy recommendation is for police departments to submit all requested information to the FBI's National Use of Force Data Collection Center. If law enforcement is deploying 
force in a justified manner, then law enforcement should be eager to capitalize on an opportunity to provide the public with a more complete picture of law enforcement's use of lethal force. Regardless of what that reality may be, the public may well assume that failure to report all use-of-force information signals that law enforcement agencies are not being transparent. When professionals who are tasked with protecting the public kill civilians, the highest level of scrutiny should be applied. Beginning in 2020, the Federal government should only share federal funding with police departments that contribute to the FBI's National Use of Force Data Collection Center.

A common policy recommendation around use of lethal force is to increase training. Over time, the number of state-mandated hours for initial police officer certification has increased; therefore, older officers may have received less pre-policing training before starting their careers. However, states have continued to increase the required number of in-service training hours for officers to maintain their state police officer certification. Correspondingly, one may assume that the longer an officer has been in policing, the more training he/she has received. Newer, unseasoned, or less trained officers may be presumed more likely to use lethal force than more experienced officers. Conversely, long-standing officers may be thought to be most likely to deploy lethal force due to lower standards of training when their careers began.

An examination of officers' years of experience revealed that in 2014, new officers did not deploy lethal force at a higher rate; rather, most (97\%) officers who used lethal force had two years or more experience in policing. Further, of experienced officers who used lethal force, the most seasoned officers (15+ years of experience) deployed the smallest proportion. These data indicate that years of experience, and perhaps the amount 
of training received, did not likely influence these officers' probability of using lethal force. As a policy implication, it appears that the quality and type of training matter more than the amount of training or years of experience.

Media policy recommendations (with thanks and credit to Williams, 1914). The media is necessary to inform the public, and I believe that journalism is integral to the success of a democratic society. Members of the media are trustees for the public and should only write what they believe to be true, accurate, and for the common good while using clear thinking and clear statements to do so. The news should not be suppressed, nor should it report inaccuracies or ignore reality to gain viewership, readership, or sponsorship. Journalists cannot avoid their accountability to public trust through acts of administrative evil (see Adams \& Balfour, 2015), whereby they report what they are told and toe the company line rather than ensuring they report the most complete truth for the public good.

The supreme test of journalistic standards should be the public service an outlet provides, and each outlet should seek to serve consumers' best interests while adhering to the truth. When considering law enforcement officers' use of lethal force, journalists should abide by the following: "[the best journalism] fears God and honors Man; is stoutly independent, unmoved by pride of opinion or greed of power, constructive, tolerant but never careless, self-controlled, patient, always respectful of its readers but always unafraid, is quickly indignant at injustice; is unswayed by the appeal of privilege or the clamor of the mob; seeks to give every man a chance" (Williams, 1914).

Officers' use of lethal force has not been sufficiently researched (due to a lack of available data to this point) but is garnering more consideration. Journalists cannot ignore 
information, data, and studies that seem to contradict the prevailing media narrative, even if that narrative is the most likely to retain viewership. The media's narrative does not align with the best available research on lethal force in policing, and the media seem to highlight the worst incidents while ignoring the overall reality. Media must strive for more accurate and just reporting for the public good.

General policy recommendations. Most of our data do not provide support for micro-level racial discrimination or for internal issues within law enforcement. However, the fact that there is not support in this data for race as a factor in micro-level officer decisions to deploy lethal force, does not mean that race has no affect in these disparities. Disparities in reported offenders, arrested persons, and incarcerated individuals particularly when considered alongside disparities in education, income, and wealthsuggest that much remains to be done to ensure equitable outcomes for people within the U.S. based on race. Head Start programs and Title I programs can help even the field for youth before elementary school. Experts must also recognize that early school sorting may result in highly capable children being sorted to a lower tier simply because their parents may have had less "Good-Night Moon time" (Putnam, 2016) prior to embarking on their educational endeavors. It is highly unlikely that disparities in offending, arrests, and incarceration are not related to the other societal disparities. More efforts are needed to effectively address disparities within and outside of criminal justice. Shifting the blame to one while ignoring its relationship to the other is unlikely to be successful.

Carter (2015) contended that every family must ensure that their children are trained in how to interact properly with law enforcement when law enforcement uses "appropriate legal commands and appropriate levels of force" (p. 37). However, in my 
opinion, this is an example of a community raising a child. Individuals do not expect children to know what to do when there is a fire in their house, nor are parents expected to inform their children to "stop, drop, and roll" in such circumstances. Similarly, given the stress and uncertainty the average person may feel during a traffic stop, it seems logical that police should be brought into schools to inform children about what to expect when contacted by police in public or during a traffic stop and how citizens can safely navigate those encounters. Schools could therefore use the D.A.R.E. program or the Stop, Drop, and Roll platform to introduce police into schools as an informational, trustbuilding opportunity. Participation among police departments or schools could also be compulsory, such as by mandating traffic stop training and other safety recommendations in schools or on driver's license exams (e.g., to maintain access to federal highway funding or school funding).

Using funding to compel states to enact policies is not a novel idea. Another problem in policing, which could be curbed by federally mandated data collection, is the problem of "Gypsy cops"; that is, some cops engage in malfeasance on the job, which leads to an internal investigation. Some officers are dismissed or resign during an internal investigation but can later be hired by other departments. Certain acts of malfeasance should be logged in an automatic reporting system, whereby officers who have been reported are added to a national system that excludes them from being hired as an officer in any other department. This measure would be the equivalent of a state licensing board revoking a license for a professional to continue operating in their professional capacity; however, the law enforcement reporting system would operate at the national level. For example, a police officer from Missouri who performs certain acts of malfeasance would 
be unable to obtain a job in Florida. This system, similar to the Use of Force Data Collection Center, would need to be federally funded to ensure that police departments enter reports appropriately when an officer's actions require intervention. The criteria for automated reporting would need to be carefully considered, but the current absence of such an accountability mechanism has allowed some officers to evade sufficient punishment.

Such cases may include police officers with overt bias, but officers with unchecked implicit bias are similarly concerning. Police officers must undergo highquality implicit bias training. Every person has implicit biases that affect how they interpret and respond to situations in daily life. It is therefore important to educate police officers on how to become more aware of their biases towards groups or individuals. It is also necessary to de-stigmatize implicit bias to ensure that officers understand that having such bias does not equate to being racist. Individuals may possess implicit biases about many issues, including around people based on race. Even a well-meaning officer who does their best to treat everyone equally will likely exhibit unintended discrepancies in outcomes if they implicitly favor some groups but react less favorably towards others.

\section{Recommendations based on general literature.}

Policing policy recommendations. Although national police estimates suggest greater racial diversity in policing than in the past, law enforcement agencies should continue seeking to increase their racial and gender diversity. Female officers have been found to use less force than male officers (Rennison \& Dodge, 2018). Additionally, departments should maintain and/or increase their educational requirements for police officers, as studies have shown that more highly educated officers use force less often 
(Fyfe, 1988; Rennison \& Dodge); specifically, "college-educated police are less likely to fire their weapons (Fyfe, 1988), more likely to use 'reasonable force' (Worden, 1996), communicate more effectively with the community (Carter et al., 1989), and are less likely to receive citizens' complaints (Cascio, 1977)" (Stickle, 2016, p. 12).

Related to communication is a widespread call for greater police training on deescalation. However, de-escalation is often not well- or consistently defined. As McFarlin (2017) noted, although many de-escalation techniques have been identified, "they all involve discourse and communication. Whether it be spoken, unspoken, or through body language, communication is central to the policing function. Discourse is the mechanism through which de-escalation is ultimately achieved." De-escalation refers to a reduction in the level of intensity (McFarlin, 2017). Officers apply three methods in de-escalation: 1) slowing down; 2) compassionate, but firm, diffusing communication; and 3) use of discretion to the officer's advantage (McFarlin, 2017). A de-escalation technique that is particularly relevant to lethal force encounters is slowing down or backing off. The courts have clearly recognized officers' need to make split-second decisions in intense and rapidly evolving situations. However, when possible, officers must also identify when they can back down from immediate intervention; doing so may prevent them from accelerating their decision-making process unnecessarily.

Regarding de-escalation, McFarlin (2017) added that officers should not feel ashamed if they choose to leave and return later, especially when the alternative might result in erroneously shooting or hurting a person because an officer has misidentified discretionary contact as a situation that must be rectified immediately. Further, officers should not see de-escalation as a trend but instead consider it a component of proper 
policing. Relevant techniques can be helpful to officers' health and careers (McFarlin, 2017). Greater communication and discourse will promote reduced use of force along with stronger community relationships.

Related to community relationships is building community trust. Trust was not measured directly in this dataset but emerged as an important theme in the literature review, especially in interactions between the police and African Americans. Illegal behaviors, as described through Carter's (2019) experiences with a St. Louis police department, must be reported and rooted out quickly. The "Code of Silence" must end; an officer who is committing crimes or racial profiling should no longer be considered a police officer, particularly by other officers. Every police department should have some form of silent or anonymous reporting to aid police or the public in identifying officers who act illegally or inappropriately based on their position.

Increased transparency is also related to enhancing community relationships and community trust. There have been widespread calls for broader use of body-worn cameras and other evidence-recording devices. Police departments should increase the use of body-worn cameras; research has demonstrated that, most of the time when video is collected at an officer-involved shooting, the footage exonerates the officer. In other circumstances, video evidence can be crucial in determining that an officer's actions were not justified. In either instance, the truth of the incident is most important, and video evidence provides invaluable context about what happened. A lack of video evidence raises more questions and public doubt about whether a shooting was justified. Police forces must be prepared to keep pace with the development of body-worn cameras so the functionalities can be improved as technology allows. For example, some body-worn 
cameras can be synced to begin recording upon deployment of conducted electrical weapons, and some cities have sensors that notify them when gunfire occurs in the city. Future technological advances could, for example, enable a body-worn camera to activate any time a firearm is drawn (e.g., via a sensor attached to a holster) or any time a gunshot is heard (e.g., via a sound sensor). The camera would likely activate at times when it should not, but even that would increase the likelihood that the camera would be activated during highly dangerous situations. Such technology would likely be more reliable than requiring officers to double-tap a body-worn camera during highly stressful encounters.

The stress of these incidents is also why use of force and lethal force training must be refined. According to Ross (2013), the courts have called for more realistic training. Consistent with this idea, Anderson, Pitel, Weerasinghe, and Papazoglou (2016) reported that range training focuses excessively on classroom learning with too little exposure to realistic scenarios. Rostker et al. (2008) found that police officers hit their target $30 \%$ of the time (an increase over $18 \%$ of the time) when the suspect did not shoot back, likely because those situations were more reflective of officers' range training (i.e., stationary targets that do not return fire). Training must be frequent and must train officers not just to shoot or use force but to make use-of-force and lethal force decisions in high-stress situations (Andersen et al., 2016; Ross, 2013). Importantly, however, useof-force and shooting training should not replace Boyd's (2018) 'Observe, Orient, Decide, Act' loop with Duhigg's (2014) 'Habit' loop; training must teach officers to think and decide before taking action in stressful situations. 
Andersen et al. (2016) found that better, more realistic, and more extensive training that induces physiological stress is necessary for officers to prepare for realworld critical incidents. Blowing a whistle or yelling "threat" cannot be the only stimulus; training must better incorporate decision making into officers' decisions to shoot. As highlighted in some of the cases in our database, Ross (2013) discussed the need for range-training scenarios to include situations in which a person is brandishing an item in a threatening manner, which may lead an officer to expect a weapon. In this instance, the officer would be required to see what is presented, not simply how it is presented. Officers arguably need more realistic training around shooting accurately in high-stress situations along with more applicable training in decision making (including shooting decisions), including determining whether or not an object is in hand and is a weapon before deciding to shoot.

Law enforcement must also catch up with other technological changes, such as the 24-hour news cycle and the prevalence of social media and online media. Historically, the response from law enforcement after officer-involved incidents has been either "no comment' or "no comment because it is an ongoing investigation." Today, law enforcement enables others to construct a narrative when officials decline to comment. "Nature abhors a vacuum and in that vacuum" (quote attributed to Aristotle), the media will provide the most accurate story they can — but they will also strive to be the first to break a story. If law enforcement wishes to help ensure the accuracy of posted information, then they need to contribute earlier. This does not mean that law enforcement should risk disseminating incorrect information; rather, officials should share verified information as quickly as possible. Video should also be released as soon 
as possible. Officials could follow recent law enforcement leaders' examples of providing routine (e.g., daily) updates about ongoing investigations. News outlets are going to report on officer-involved killings; law enforcement can either choose to be a voice in the story or let others determine how the narrative unfolds. The same applies to social media and online narratives: again, law enforcement can either take an active role in the story or wait for others to fill in the blanks. The story will unfold regardless, and sources may provide corrections as needed, but such altered reports rarely receive as much attention as the original story because viewers move on quickly.

At this point, the most important thing police departments can do is to engage in more effective community outreach. Efforts may include cultivating partnerships and relationships with community members and organizations. These measures are especially vital in communities marked by lower trust of law enforcement. Over time, such relationships can improve racial disparities in terms of trust as well as enhance the public's opinion of law enforcement, which may have been marred by a checkered relationship among law enforcement and minorities (particularly African Americans). Examples of outreach include contacting religious organizations and offering to help them with traffic or patrolling their lots during services to ensure cars are not broken into. Department officials could also reach out to religious leaders to ask about how police could assist, or build better relationships with, their members. Additionally, these connections can afford police organizations with a better sense of the type of service a given community values by encouraging community members to share community problems with police. 


\section{Future Research}

For future research to be successful, more information should be readily available. Ideally, the FBI's National Use of Force Data Collection Center can begin receiving submissions from all law enforcement agencies in the U.S. that have a qualifying event. Once those data become available, scholars should examine relevant datasets to understand the context of recent use of lethal force in law enforcement. However, such data collection only officially began on January 1, 2019. A further recommendation is to replicate the process undertaken in this dissertation for years 2015, 2016, 2017, and 2018. Doing so will provide five years of more reliable and comprehensive data on the use of lethal force in U.S. law enforcement. Additionally, these datasets will serve as a litmus test to gauge the presumed accuracy of reporting to the FBI's National Use of Force Data Collection Center.

Laboratory studies and other research that focuses on regions of the U.S., rather than the entire nation, are similarly important. All subsequent studies can help to alleviate the dearth of knowledge on the use of lethal force in law enforcement. Qualitative studies that focus on the experiences of the families of those killed by law enforcement would provide more information on the impact that one death can have on a community's trust in police. Likewise, evaluating the experiences of officers who deployed lethal force (and their families) could prove particularly informative. Numerous examples have emerged of apparently legally justified cases of lethal force (i.e., cases deemed justifiable by the courts), but reactions from the media or general public have potentially imperiled officers' future employment opportunities. Qualitatively investigating victims' and 
officers' experiences could shed more light on the havoc that accidental, unjustified, or even justified use of lethal force can wreak on a community and involved individuals.

Despite widespread public concern and media interest surrounding use of lethal force, the available information and related scholarly pursuits have yet to elucidate this topic as thoroughly as necessary. More comprehensive, up-to-date, and accessible data are required regarding use of lethal force in law enforcement encounters. Furthermore, evaluation of whether U.S. Census estimates, Violent Offender Rates, or some other measure is most appropriate when examining and comparing data on law enforcement's use of lethal force is needed. Finally, the assumed benefits of transparency are twofold: openness could help to promote community trust in law enforcement as well as responsible deployment of lethal force.

\section{Concluding Thoughts}

This dissertation began due to a perception media coverage of recent shootings of young African American males may lead some to believe that Caucasian police officers are more likely to deploy lethal force on young African American males. This dissertation confirms an overrepresentation of African Americans in those killed by police when compared to U.S. population estimates, but also shows strong support that race is not a factor in micro-level officer decisions to deploy lethal force. In fact, the analyses in this study along with numerous laboratory studies and non-laboratory studies from the literature review indicate that Caucasian officers are no more likely to deploy lethal force on African American males (armed or unarmed) than non-Caucasian officers, and do not support the rejection of the null hypothesis (that race is not a factor in microlevel officer lethal force decisions). 
However, these results should not be interpreted to suggest that race is in no way related to the over-representation of African Americans in those killed by police. Instead, they should encourage greater scrutiny on both law enforcement and society to develop more clear answers on how these different outcomes should be addressed both within law enforcement, within society as a whole, and how disparities in either reflect back and contribute to disparities in the other. A deficiency of the U.S. criminal justice system, which is often presented as a strength, is that the system is set up to be impartial and universal; the system is set up to be blind.

If justice is blind, then justice is also blind to racially disparate outcomes. In the criminal justice system, blind justice does not seek equal outcomes by population proportion; instead, it seeks equitable outcomes based on offending. Thus, if a criminal justice system is operating properly, then its outcomes will likely mirror outcomes of the society in which it operates; that is, a properly operating criminal justice system will have racially equitable outcomes in a society with such outcomes and vice versa. Does an examination of U.S. society reveal a criminal justice system reflecting an island of racially disparate outcomes in a sea of equity, or a criminal justice system reflecting a society of racially disparate outcomes?

Taking medicine as an example, one should understand the difference between a symptom of a disease and a cause of a disease. If a person develops a bacterial sinus infection that leads to congestion, which they then attempt to treat by placing a Band-Aid on their nose, then others would likely say that person is making an uninformed decision. Also - and perhaps more importantly - the illness would not improve. To effectively treat congestion caused by bacterial infection, the person must take an antibiotic to kill the 
bacteria. In medical practice, practitioners determine the cause and then treat that cause, not only the symptom.

Likewise, a systemic disparity signals that the system should be investigated—but not without considering the context in which the system operates. Everyone (citizen and law enforcement personnel alike) should be a proponent for criminal justice reform and should strive to minimize racially disparate outcomes within the criminal justice system. However, if wider societal racial disparities are not addressed, then we are merely putting a Band-Aid on our noses to make us feel better. I argue that the criminal justice system reflects a society of racially disparate outcomes, causes of disparities within the criminal justice system are difficult to measure because they persist along with disparities in the wider U.S. society. Further, I contend that it is important to establish the cause of racial disparities and then treat the cause rather than a symptom. Therefore, in order to fix disparities within and outside the criminal justice system, internal and external causes must both be examined and addressed more effectively. 


\section{References}

Alexander, K., Entwisle, D., \& Olson, L. (2014). The long shadow: Family background, disadvantaged urban youth, and the transition to adulthood. New York, NY: Russell Sage Foundation.

Ali, S. S. (2017). Tamir Rice shooting: Newly released interview reveals cop's shifting story. NBC News. Retrieved from https:/www.nbcnewscom/news/us-news/newlyreleased-interview-footage-reveal-shifting-stories-officers-who-shot-n751401

Allen, J., Goldberg, B. and Szekely, P. (2015). Factbox: U.S. police officers who kill unarmed black men often avoid criminal liability. Reuters. Retrieved from https://www.reuters.com/article/us-usa-police-garner-factbox/factbox-u-s-policeofficers-who-kill-unarmed-black-men-often-avoid-criminal-liabilityidUSKCN1V91MT

Andersen, J., Pitel, M., Hons, B.S., Weerashinghe, A., \& Papaxoglou, K. (2017). Highly realistic scenario based training simulates the psychophysiology of real world use of force encounters: implications for improved police officer performance.

Journal of Law Enforcement, 5(4). Retrieved from

https://tspace.library.utoronto.ca/handle/1807/73822

Anwar, S., \& Fang, H. (2006). An alternative test of racial prejudice in motor vehicle searches: Theory and evidence. American Economic Review, 96(1), 127-151. Retrieved from https://www.aeaweb.org/articles?id=10.1257/000282806776157579

Ashkenas, J., \& Park, H. (2015). The race gap in America's police departments. The New York Times, 8. Retrieved from 
https://www.nytimes.com/interactive/2014/09/03/us/the-race-gap-in-americaspolice-departments.html

Argyris, C. (1999). On Organizational Learning. Malden, MA: Blackwell Publishers.

Arismendi, I., \& Penaluna, B. E. (2016). Examining diversity inequities in fisheries science: a call to action. BioScience, 66(7), 584-591. Retrieved from https://www.researchgate.net/publication/301299816_Examining_Diversity_Ineq uities_in_Fisheries_Science_A_Call_to_Action

Azar, B. (2008). IAT: Fad or fabulous?. Monitor on Psychology. 39: 44. Retrieved from https://www.apa.org/monitor/2008/07-08/psychometric

Becker, G. S. (1974). Crime and punishment: An economic approach. In Essays in the Economics of Crime and Punishment (pp. 1-54). UMI, William M. Landes, eds. Retrieved from https://link.springer.com/chapter/10.1007/978-1-349-62853-7_2

Becker, G. S. (1993). Nobel lecture: The economic way of looking at behavior. Journal of Political Economy, 385-409.

Black Demographics (2019). Black Population Statistics. Retrieved from https://blackdemographics.com/population/

Blair, J. P., Pollock, J., Montague, D., Nichols, T., Curnutt, J., \& Burns, D. (2011). Reasonableness and reaction time. Police Quarterly, 14(4), 323-343. Retrieved from http://www.hptinstitute.com/wp-content/uploads/2014/01/Reasonablenessand-Reaction-Time.pdf

Blau, J. R., \& Blau, P. M. (1982). The cost of inequality: Metropolitan structure and violent crime. American Sociological Review, Vol. 47 (No. 1), 114-129. Retrieved from https://www.jstor.org/stable/2095046?seq=1\#metadata_info_tab_contents 
BJS. (2018). Traffic stops. Office of Justice Programs: Bureau of Justice Statistics.

Revised on 05/28/2018. Retrieved from

https://www.bjs.gov/index.cfm?tid=702\&ty=tp

Boyd, J. (2018). A discourse on winning and losing. Air University Press, Curtis E.

LeMay Center for Doctrine Development and Education. Retrieved from https://www.airuniversity.af.edu/Portals/10/AUPress/Books/B_0151_Boyd_Disco

urse_Winning_Losing.pdf

Brazzell, D., Crayton, A., Mukamal, D. A., Solomon, A. L., \& Lindahl, N. (2009). From the classroom to the community: Exploring the role of education during incarceration and reentry. Urban Institute (NJ1). Retrieved from https://eric.ed.gov/?id=ED508246

Burris, J. L., \& Whitney, C. (2015). Blue vs. Black: Let's End the Conflict Between Cops and Minorities. New York, NY: St. Martins Press.

Buehler, J. W. (2017). Racial/ethnic disparities in the use of lethal force by US police, 2010-2014. American Journal of Public Health, 107(2), 295-297. Retrieved from https://ajph.aphapublications.org/doi/full/10.2105/AJPH.2016.303575

Campbell, F. R., Cataldie, L., McIntosh, J., \& Millet, K. (2004). An active postvention program. Crisis, 25(1), 30-32. Retrieved from https://www.ncbi.nlm.nih.gov/pubmed/15384655

Carbado, D. W. (2016). Blue-on-Black Violence: A Provisional Model of Some of the Causes. Georgetown Law Journal, 16-31. Retrieved from https://heinonline.org/HOL/LandingPage?handle=hein.journals/glj104\&div=49\&i $\mathrm{d}=$ \&page $=$ 
Carter, T. (2019). Police on a Pedestal: Responsible Policing in a Culture of Worship. Denver, CO: Praeger.

Carter, T. (2015). Walking the Blue Line: A Police Officer Turned Community Activist. St. Louis, MO: Betti Youngs Books Publishing Inc.

Cesario, J., Johnson, D. J., \& Terrill, W. (2019). Is there evidence of racial disparity in police use of deadly force? Analyses of officer-involved fatal shootings in 20152016. Social Psychological and Personality Science, 10(5), 586-595. Retrieved from https://journals.sagepub.com/doi/full/10.1177/1948550618775108.

Clair, M., \& Denis, J. S. (2015). Sociology of racism. The international encyclopedia of the social and behavioral sciences, 19, 857-863. Retrieved from https://scholar.harvard.edu/files/matthewclair/files/sociology_of_racism_clairande nis_2015.pdf

Comey, J. (2015). FBI Director James Comey's testimony for the House of Representatives. Washington, DC. October 2015.

Congressional Research Service (2014). Summary of H.R. 1444-113 ${ }^{\text {th }}$ Congress. Public Law Number 113-242 enacted in 12/18/2014. Retrieved from https://www.congress.gov/bill/113th-congress/house-bill/1447

Cornelius, C. V., Lynch, C. J., \& Gore, R. (2017). Aging out of crime: exploring the relationship between age and crime with agent based modeling. Society for Modeling and Simulation International. Retrieved from http://scs.org/wpcontent/uploads/2017/06/6_Final_Manuscript.pdf

Correll, J., Wittenbrink, B., Park, B., Judd, C. M., \& Goyle, A. (2011). Dangerous enough: Moderating racial bias with contextual threat cues. Journal of 
Experimental Social Psychology, 47(1), 184-189. Retrieved from https://www.sciencedirect.com/science/article/pii/S0022103110002040

Cox, W. T.L., Devine, P., Plant, A. Schwartz, L. (2014). Toward a Comprehensive Understanding of Officers' Shooting Decisions: No Simple Answers to This Complex Problem. Basic and Applied Social Psychology. 36: 356-364. Retrieved from https://www.tandfonline.com/doi/abs/10.1080/01973533.2014.923312

Chaney, C., \& Robertson, R. V. (2015). Armed and dangerous? An examination of fatal shootings of unarmed black people by police. Journal of Pan African Studies, 8(4), 45-79. Retrieved from https://s3.amazonaws.com/academia.edu.documents/38947351/Armed_and_Dang erous.pdf?AWSAccessKeyId=AKIAIWOWYYGZ2Y53UL3A\&Expires=155268 4248\&Signature $=84 \mathrm{pC} 5 \mathrm{cBHBV}$ s6fI6wL8rGxd\%2F1A9E\%3D\&responsecontentdisposition=inline $\% 3 \mathrm{~B} \% 20$ filename\%3DArmed_and_Dangerous_An_Examinati on_of_Fa.pdf

COPS-USDOJ (2015). President's Task Force on 21st Century Policing. Final report of the President's task force on 21st century policing. Retrieved from https://cops.usdoj.gov/pdf/taskforce/taskforce_finalreport.pdf

DataUSA. (2018). Race and Ethnicity in 2014. DataUSA: Police Officers. Retrieved from https://datausa.io/profile/soc/333050/\#demographics

DeGue, S., Fowler, K. A., \& Calkins, C. (2016). Deaths Due to Use of Lethal Force by Law Enforcement: Findings From the National Violent Death Reporting System, 17 US States, 2009-2012. American Journal of Preventive Medicine, 51(5), S173- 
S187. Retrieved from

https://www.sciencedirect.com/science/article/pii/S0749379716303841

Deloitte. (2017). Police Officers 2016 Diversity. DataUSA. Retrieved from https://datausa.io/profile/soc/333050/\#demographics

Diamond, M. A. \& Allcorn, S. (2009). Private selves in public organizations: The psychodynamics of organizational diagnosis and change. London. Palgrave McMillan.

Dixon, T. L., \& Williams, C. L. (2014). The changing misrepresentation of race and crime on network and cable news. Journal of Communication, 65(1), 24-39. Retrieved from https://academic.oup.com/joc/article-abstract/65/1/24/4082305

Donders, N. C., Correll, J., \& Wittenbrink, B. (2008). Danger stereotypes predict racially biased attentional allocation. Journal of Experimental Social Psychology, 44(5), 1328-1333. Retrieved from https://www.sciencedirect.com/science/article/pii/S0022103108000656

Duhigg, Charles (2014). The Power of Habit: Why we Do What We Do in Life and Business. New York City, NY: Random House Publishing.

Enos, R. D. (2016). What the demolition of public housing teaches us about the impact of racial threat on political behavior. American Journal of Political Science, 60(1), 123-142. Retrieved from https://onlinelibrary.wiley.com/doi/abs/10.1111/ajps.12156

Epp, C. R., Maynard-Moody, S., \& Haider-Markel, D. P. (2014). Pulled over: How police stops define race and citizenship. Chicago, IL: University of Chicago Press. 
FBI: UCR. (2014). Law Enforcement Officers Killed and Assaulted Report. Federal Bureau of Investigations, U.S. Department of Justice. Retrieved from https://ucr.fbi.gov/leoka/2014

FBI: UCR. (2017). Federal Bureau of Investigations: Crime Data Explorer. Retrieved from https://crime-data-explorer.fr.cloud.gov/explorer/national/unitedstates/crime/2007/2017

Federal Bureau of Prisons. (2013). Annual Determination of Average Cost of Incarceration. Federal Register published on 03/18/2013. Retrieved from https://federalregister.gov/a/2013-06139

Fischer-Baum, R., \& Johri, A. (2014). Another (much higher) count of homicides by police. FiveThirtyEight. com. Retrieved from https://fivethirtyeight.com/features/another-much-higher-count-of-policehomicides/

Fox, J., Blanco, A., Jenkins, J., Tate, J., \& Lowery, W. (2019). What we've learned about police shootings 5 years after Ferguson. The Washington Post. Retrieved from https://www.washingtonpost.com/nation/2019/08/09/what-weve-learned-aboutpolice-shootings-years-after-ferguson/?arc404=true

Freeman, R. B. (2003). Can we close the revolving door?: Recidivism vs. employment of ex-offenders in the US. The Urban Institute. Retrieved from https://www.urban.org/sites/default/files/publication/59426/410857-Can-WeClose-the-Revolving-Door-.PDF

Fryer Jr, R. G. (2016). An empirical analysis of racial differences in police use of force (No. w22399). Harvard University and National Bureau of Economic 
Research. Retrieved from

https://www.journals.uchicago.edu/doi/abs/10.1086/701423?journalCode=jpe

Fyfe, J. J. (1982). Blind justice: Police shootings in Memphis. The Journal of Criminal Law and Criminology (1973-), 73(2), 707-722. Retrieved from https://heinonline.org/HOL/LandingPage?handle=hein.journals/jclc73\&div=32\&i $\mathrm{d}=$ \&page $=$

Fyfe, J. J. (1988). Police use of deadly force: Research and reform. Justice Quarterly, 5(2), 165-205. Retrieved from https://www.tandfonline.com/doi/abs/10.1080/07418828800089691

The Guardian. (2014). Tamir Rice: Police release video of 12 -year-old's fatal shooting video. The Guardian. 11/26/2014. Retrieved from https://www.theguardian.com/us-news/video/2014/nov/26/cleveland-video-tamirrice-shooting-police

Gilliard, D. D. (2018). Rethinking Incarceration: Advocating for Justice that Restores. Downers Grove, IL: InterVarsity Press.

Glaze, Linda \& Danielle Kaeble. (2014). Correctional Populations in The United States, 2013. Bureau of Justice Statistics. Retrieved from http://www.bjs.gov/index.cfm?ty=pbdetail\&iid=5177

Godsil, R. D., \& Johnson, A. M. (2013). Transforming perception: Black men and boys. Perception Institute. Retrieved from http://perception.org/wpcontent/uploads/2014/11/Transforming-Perception.pdf

Goldkamp, J. S. (1976). Minorities as victims of police shootings: Interpretations of racial disproportionality and police use of deadly force. The Justice System 
Journal, 2 (2) 169-183. Retrieved from

https://www.jstor.org/stable/20877501?seq=1\#page_scan_tab_contents

Gotanda, N., \& Peller, G. (1995). Critical race theory: The key writings that formed the movement. New York City, NY: The New Press.

Graziano, L., Amie Schuck, A. \& Martin, C. (2010) Police Misconduct, Media Coverage, and Public Perceptions of Racial Profiling: An Experiment, Justice Quarterly, 27:1, 52-76, DOI: $10.1080 / 07418820902763046$.

Graham v. Connor, 490 U.S. 386 (1989). Retrieved from LexisNexis Academic database.

Gross, J. P. (2015). Judge, Jury, and Executioner: The Excessive Use of Deadly Force by Police Officers. Tex. J. on $C L \& C R, 21,155$. Retrieved from https://heinonline.org/HOL/LandingPage?handle=hein.journals/tfcl21\&div=12\&i $\mathrm{d}=$ \&page $=$

Galtung, J. (1969). Violence, peace, and peace research. Journal of Peace Research, 6(3), 167-191. Retrieved from https://journals.sagepub.com/doi/pdf/10.1177/002234336900600301

Gilliam Jr, F. D., Iyengar, S., Simon, A., \& Wright, O. (1996). Crime in black and white: The violent, scary world of local news. Harvard International Journal of press/politics, 1(3), 6-23. Retrieved from https://journals.sagepub.com/doi/abs/10.1177/1081180X96001003003

Harrell, E., Langton, L., Berzofsky, M., Couzens, L., \& Smiley-McDonald, H. (2014). Household poverty and nonfatal violent victimization, 2008-2012. US Department of Justice, Office of Justice Programs, Bureau of Justice Statistics. Retrieved from https://www.bjs.gov/index.cfm?ty=pbdetail\&iid=5137 
Hsieh, C. C., \& Pugh, M. D. (1993). Poverty, income inequality, and violent crime: a meta-analysis of recent aggregate data studies. Criminal Justice Review, 18(2), 182-202. Retrieved from https://journals.sagepub.com/doi/abs/10.1177/073401689301800203

Huffington Post. (2019). Unarmed black man. Huffington Post. Retrieved from https://www.huffpost.com/topic/unarmed-black-man

Inderbitzin, M., Bates, K., \& Gainey, R. (2014). Perspectives on deviance and social control. Los Angeles, CA: Sage Publishing. ISBN: 978-1-4522-8885-7.

James, L., James, S. M., \& Vila, B. J. (2016). The reverse racism effect: Are cops more hesitant to shoot Black than White suspects. Criminology \& Public Policy. Retrieved from https://onlinelibrary.wiley.com/doi/abs/10.1111/1745-9133.12187

James, L., Klinger, D., \& Vila, B. J. (2014). Racial and ethnic bias in decisions to shoot seen through a stronger lens: Experimental results from high-fidelity laboratory simulations. Journal of Experimental Criminology, 10(3): 323-340. Retrieved from https://link.springer.com/article/10.1007/s11292-014-9204-9

James, L., Vila, B.J., and Daratha, K. (2013). Results from experimental trials testing participant responses to white, Hispanic and black suspects in high-fidelity deadly force judgment and decision-making simulations. Journal of Experimental Criminology, 9(2): 189-212. Retrieved from https://link.springer.com/article/10.1007/s11292-012-9163-y

Johnson, O. N. (2010). Blue wall of silence: Perceptions of the influence of training on law enforcement suicide. Irvine, CA: Universal-Publishers. 
Johnson, O. N. (2011). Police Suicide: Name it, tame it--the elephant in the department. The Journal of Global Health Care Systems, 1(1). Retrieved from https://jghcs.info/index.php/1/article/view/31/0

Johnson, O. N. (2016). Police Officer Wellness Evaluation Response Survey Results. The Journal of Law Enforcement, 5(3). Retrieved from http://web.b.ebscohost.com/abstract?site=ehost\&scope=site\&jrnl=21610231\&AN $=113171089 \& \mathrm{~h}=\mathrm{bUfFtj} 2 \% 2 \mathrm{~b} 68$ ufzw9PRpG6\%2bCuHIy0b85PKa8\%2bIIRiKWw gFXsTwnDjnnO8vuvz9zq4\%2bHEN4f8jrAZx1HcR5leiEcA\%3d\%3d\&crl=f\&res ultLocal $=$ ErrCrlNoResults\&resultNs $=$ Ehost\&crlhashurl=login. aspx $\% 3$ fdirect $\% 3 \mathrm{~d}$ true $\% 26$ profile $\% 3$ dehost $\% 26$ scope $\% 3$ dsite $\% 26$ authtype $\% 3$ dcrawler $\% 26 j$ rnl $\% 3 \mathrm{~d} 2$ 1610231\%26AN\%3d113171089

Khan, A. (2019). Getting killed by police is a leading cause of death for young black men in America. The LA Times. Retrieved from https://www.latimes.com/science/story/2019-08-15/police-shootings-are-aleading-cause-of-death-for-black-men

Kindy, K., \& Elliott, K. (2015). 2015 Police Shootings Investigation. The Washington Post. Retrieved from https://www.washingtonpost.com/graphics/national/policeshootings/

Kling, J. R. (2006). Incarceration length, employment, and earnings (No. w12003). National Bureau of Economic Research. Retrieved from https://www.aeaweb.org/articles?id=10.1257/aer.96.3.863

Klinger, D. (2012). Into the kill zone: A cop's eye view of deadly force. Hoboken, NJ: John Wiley \& Sons. 
Klinger, D. A. (2001). Suicidal Intent in Victim-Precipitated Homicide: Insights from the Study of "Suicide-by-Cop”. Homicide Studies, 5(3), 206-226. Retrieved from https://journals.sagepub.com/doi/abs/10.1177/1088767901005003002

Klinger, D., Rosenfeld, R., Isom, D., \& Deckard, M. (2016). Race, Crime, and the MicroEcology of Deadly Force. Criminology \& Public Policy, 15(1), 193-222.

Retrieved from https://onlinelibrary.wiley.com/doi/abs/10.1111/1745-9133.12174

Knowles, J., Persico, N., \& Todd, P. (2001). Racial bias in motor vehicle searches:

Theory and evidence. Journal of Political Economy, 109(1), 203-229. Retrieved from https://www.journals.uchicago.edu/doi/abs/10.1086/318603

Krapfl, M. (2017) Iowa Officer Involved Shooting study. Presented at 2017 ILEETA conference.

Lee, H., Vaughn, M. S., \& Lim, H. (2014). The impact of neighborhood crime levels on police use of force: An examination at micro and meso levels. Journal of Criminal Justice, 42(6), 491-499. Retrieved from https://www.sciencedirect.com/science/article/pii/S0047235214000804

Lim, H. H. (2006). Representative bureaucracy: Rethinking substantive effects and active representation. Public administration review, 66(2), 193-204. Retrieved from https://onlinelibrary.wiley.com/doi/abs/10.1111/j.1540-6210.2006.00572.x

Lott, J. R., \& Moody, C. E. (2017). Do white police officers unfairly target black suspects? Social Science Research Network electronic library, 2017 (online), ID2870189. Retrieved from https://papers.ssrn.com/sol3/papers.cfm?abstract_id=2870189 
Loeffler, E., \& Bovaird, T. (2019). Assessing the impact of co-production on pathways to outcomes in public services: the case of policing and criminal justice. International Public Management Journal, 1-26. Retrieved from https://www.tandfonline.com/doi/abs/10.1080/10967494.2019.1668895

Ma, D. S., \& Correll, J. (2011). Target prototypicality moderates racial bias in the decision to shoot. Journal of Experimental Social Psychology, 47(2), 391-396. Retrieved from https://www.sciencedirect.com/science/article/pii/S0022103110002519

Mauer, M., \& King, R. S. (2007). Uneven justice: State rates of incarceration by race and ethnicity (pp. 1-23). Washington, DC: Sentencing Project. Retrieved from https://www.prisonlegalnews.org/media/publications/rd_stateratesofincbyraceand ethnicity.pdf

McFarlin, C. L. (2017). Integrating De-escalation Techniques into Policing. PoliceOne.com. Retrieved from https://www.policeone.com/amu/articles/430619006-Integrating-de-escalationtechniques-into-policing/

Menifield, C. E., Laughlin M.J. (2018). 2014: Intentional Lethal Force Data. Unpublished Dataset.

Menifield, C. E., G. Shin, \& L. Strother. (2019). Do White Law Enforcement Officers Target Minority Suspects? Public Administration Review. Retrieved from https://onlinelibrary.wiley.com/doi/full/10.1111/puar.12956

Merrifield, C. (2019). Black men 2.5 times more likely than white men to be killed by police, new research estimates. Journalist's Resource. Retrieved from 
https://journalistsresource.org/studies/government/criminal-justice/killed-policeblack-men-likely-white-men/

Miller, L. (2015). Why cops kill: The psychology of police deadly force encounters. Aggression and violent behavior, 22, 97-111. Retrieved from https://www.sciencedirect.com/science/article/pii/S1359178915000452

Missouri v. Stockley. (2017). 22 MO 1622-CR02213-01 Retrieved from https://www.documentcloud.org/documents/4047160-Stockleyverdict.html

Moore, S. E., Robinson, M. A., \& Adedoyin, A. C. (2016). Introduction to the special issue on police shooting of unarmed African American males: Implications for the individual, the family, and the community. Journal of Human Behavior in the Social Environment, 26:3-4, 247-250. Retrieved from https://www.tandfonline.com/doi/abs/10.1080/10911359.2016.1139995?journalCo de $=$ whum 20

Morgan, R. E. (2017). Race and Hispanic Origin of Victims and Offenders, 2012-15. Special Report. NCJ 250747, Washington, DC: Bureau of Justice Statistics. Retrieved from https://www.bjs.gov/content/pub/pdf/rhovo1215.pdf

Morrison, G. B. (2006). Deadly force programs among larger US police departments. Police Quarterly, 9(3), 331-360. Retrieved from https:/journals.sagepub.com/doi/abs/10.1177/1098611105276542

Morrison, G. B., \& Garner, T. K. (2011). Latitude in deadly force training: progress or problem? Police Practice and Research, 12(4), 341-361. Retrieved from https://www.tandfonline.com/doi/abs/10.1080/15614263.2011.563968 
National Use of Force Data Collection. (2019). FBI: Criminal Justice Information Services. Retrieved from https://www.fbi.gov/services/cjis/ucr/use-of-force National Use of Force Framework. (2016). Ottawa Police Services Training with DeEscalation Component. Retrieved from https://www.ottawapolice.ca/en/newsand-community/Training-with-De-Escalation-Component.aspx

Newport, F. (2014). Gallup review: Black and White attitudes toward police. Washington, D.C. Gallup. Retrieved from https://news.gallup.com/poll/175088/gallup-reviewblack-white-attitudes-toward-police.aspx

Nicholson-Crotty, S., Nicholson-Crotty, J., \& Fernandez, S. (2017). Will more black cops matter? Officer race and police-involved homicides of black citizens. Public administration review, 77(2), 206-216. Retrieved from https://onlinelibrary.wiley.com/doi/full/10.1111/puar.12734

Oliver, M. B. (2003). African American men as" criminal and dangerous": Implications of media portrayals of crime on the" criminalization" of African American men. Journal of African American Studies, 3-18. Retrieved from https://www.jstor.org/stable/41819017?seq=1/subjects

Pager, D., Western, B., \& Bonikowski, B. (2009). Discrimination in a low-wage labor market: A field experiment. American Sociological Review, 74(5), 777-799. Retrieved from https://journals.sagepub.com/doi/abs/10.1177/000312240907400505

Patterson, G. T., \& Swan, P. G. (2016). Police shootings of unarmed African American males: A systematic review. Journal of human behavior in the social environment, 
26(3-4), 267-278. Retrieved from

https://www.tandfonline.com/doi/abs/10.1080/10911359.2015.1125204

Payne, B. K., Vuletich, H. A., \& Brown-Iannuzzi, J. L. (2019). Historical roots of implicit bias in slavery. Proceedings of the National Academy of Sciences, 116(24), 1169311698. Retrieved from https://www.pnas.org/content/116/24/11693.short

Pew Charitable Trusts. (2008). One in 100: Behind bars in America 2008. Washington, DC: The PEW Center on the States. Retrieved from https://www.pewtrusts.org/en/research-and-analysis/reports/2008/02/28/one-in100-behind-bars-in-america-2008

Potter, G. (1995). The history of policing in the United States. The Encyclopedia of Police Science, p. 114. New York, NY: Garland Publishing.

Putnam, R.D. (2016). Our kids: The American dream in crisis. New York, NY: Simon and Schuster.

Raphael, S. (2011). Incarceration and prisoner reentry in the United States. The Annals of the American Academy of Political and Social Science, 635(1), 192-215. Retrieved from https://journals.sagepub.com/doi/abs/10.1177/0002716210393321

Raphael, S., \& Winter-Ebmer, R. (2001). Identifying the effect of unemployment on crime*. Journal of Law and Economics, 44(1), 259-283. Retrieved from https://www.journals.uchicago.edu/doi/abs/10.1086/320275

Reaves, Brian A. 2015. Local Police Departments, 2013: Personnel, Policies, and Practices. Bureau of Justice Statistics Report, May 14, 2015. Retrieved from http://www.bjs.gov/index.cfm?ty=pbdetail\&iid=5279 
Reeves, R., \& Sawhill, I. (2014). Equality of Opportunity: Definitions, Trends, and Interventions. Federal Reserve Bank of Boston. Retrieved from http://www.bostonfed.org/inequality2014/papers/reeves-sawhill.pdf

Remsberg, C. (2018). Unarmed but still dangerous: The facts behind some OIS headlines. Force Science News. Retrieved from https://www.forcescience.org/2018/11/unarmed-but-still-dangerous-the-factsbehind-some-ois-headlines/

Rennison, C. M., \& Dodge, M. (2018). Introduction to Criminal Justice: Systems, Diversity, and Change, 2nd Edition. (ISBN: 9781506347721). Thousand Oaks, CA: Sage Publications.

Rostker, B. D., Hanser, L. M., Hix, W. M., Jensen, C., \& Morral, A. R. (2008). Evaluation of the New York City Police Department firearm training and firearmdischarge review process. Santa Monica, CA: Rand Corporation.

Ross, C. T. (2015). A Multi-Level Bayesian Analysis of Racial Bias in Police Shootings at the County-Level in the United States, 2011-2014. PloS one, 10(11), e0141854. Retrieved from https://journals.plos.org/plosone/article?id=10.1371/journal.pone.0141854\&utm_ content=bufferc4bc4\&utm_medium=social\&utm_source=twitter.com\&utm_camp aign $=$ buffer

Ross, D. L. (2013). Assessing lethal force liability decisions and human factors research. In Law Enforcement Executive Forum (Vol. 13, No. 2, pp. 85-107). Retrieved from http://www.aele.org/Ross_Forum_2013-2.pdf 
Rufo, R. A., ed. (2015). Police Suicide: Is Police Culture Killing Our Officers?. New York City, NY: CRC Press.

Santhanam, L. (2019). After Ferguson, black men still face the highest risk of being killed by police. PBS News Hour. Retrieved from https://www.pbs.org/newshour/health/after-ferguson-black-men-and-boys-stillface-the-highest-risk-of-being-killed-by-police

Schein, E.H. (2010). Organizational culture and leadership, 4th Edition, San Francisco, CA: Jossey-Bass.

Selby, N., Singleton, B., \& Flosi, E. (2016). In context: Understanding police killings of unarmed civilians. St. Augustine, FL: Contextual Press.

Shane, J., \& Swenson, Z. (2018). Unarmed and Dangerous: Patterns of Threats by Citizens During Deadly Force Encounters with Police. New York, NY: Routledge.

Siegel, L. J., \& Welsh, B. (2017). Juvenile delinquency: Theory, practice, and law. 13th edition with Integrated LMS Mindtap (ISBN: 9781337494274). Boston, MA: Cengage Publishing.

Simms, M. (2009). Racial and ethnic disparities among low-income families. Urban Institute. Retrieved from: http://www.urban.org/sites/default/files/publication/32976/411936-Racial-andEthnic-Disparities-Among-Low-Income-Families.PDF

Somashekhar, S., Lowery, W., Alexander, K., Kindy, K., Tate, J. (2015). A year after Michael Brown's fatal shooting, unarmed black men are seven times more likely than whites to die by police gunfire. The Washington Post. Retrieved from 
https://www.washingtonpost.com/sf/national/2015/08/08/black-and-

unarmed/?utm_term=.bdb5beba0476

Stickle, B. (2016). A national examination of the effect of education, training and preemployment screening on law enforcement use of force. Justice Policy Journal, 13(1), 1-15. Retrieved from http://www.cjcj.org/uploads/cjcj/documents/jpj_education_use_of_force.pdf

Tennessee v. Garner, 471 U.S. 1 (1985). Justia: U.S. Supreme Court. Retrieved from. https://supreme.justia.com/cases/federal/us/471/1/

Terry v. Ohio, 392 U.S. 1 (1968). Justia: U.S. Supreme Court. Retrieved from https://supreme.justia.com/cases/federal/us/392/1/

Truman, J.L. \& Langton, L. (2015). Criminal Victimization, 2014. Bureau of Justice Statistics Bulletin. Washington, DC: Bureau of Justice Statistics. Retrieved from https://www.bjs.gov/content/pub/pdf/cv14.pdf

U.S. Census Bureau (2011). The Hispanic Population: 2010: 2010 Census Briefs. Retrieved from https://www.census.gov/prod/cen2010/briefs/c2010br-04.pdf U.S. Census Bureau (2017). Quick Facts: U.S. Population estimates. Retrieved from https://www.census.gov/quickfacts/fact/table/US/PST045217

U.S. Courts (2017). Retrieved from http://www.uscourts.gov/about-federalcourts/educational-resources/about-educational-outreach/activity-resources/whatdoes-0

Ulmer, J. T., \& Steffensmeier, D. (2014). The age and crime relationship: Social variation, social explanations. Chapter 23 in The nurture versus biosocial debate in criminology: On the origins of criminal behavior and criminality. SAGE 
Publications Inc. Retrieved from

https://www.sagepub.com/sites/default/files/upm-binaries/60294_Chapter_23.pdf

United States Department of Justice (USDOJ), Bureau of Justice Statistics. (1994).

Violent Crime. Bureau of Justice Statistics Selected Findings. Retrieved from https://www.bjs.gov/content/pub/pdf/VIOCRM.PDF

United States Department of Justice (USDOJ), Federal Bureau of Investigation. (2015).

Crime in the United States, 2014. FBI: UCR. Retrieved from

https:/ucr.fbi.gov/crime-in-the-u.s/2014/crime-in-the-u.s.-2014/cius-home

Voigt, R., Camp, N. P., Prabhakaran, V., Hamilton, W. L., Hetey, R. C., Griffiths, C. M., Jurgens, D., Jurafsky, D. and Eberhardt, J.L. (2017). Language from police body camera footage shows racial disparities in officer respect. Proceedings of the National Academy of Sciences, 114(25), 6521-6526. Retrieved from https://arstechnica.com/wpcontent/uploads/2017/06/oaktownanalysisbodycams.pdf

Wagner, K. (2014). U.S. Police Shootings Database, database available at http://goo.gl/Su60Cm database updates available from https://deadspin.com/deadspin-police-shooting-database-update-were-still-go1627414202

Ward, J. D., \& Menifield, C. E. (2017). Policing and Race. Public Administration Review, 77(2), 159-161. Retrieved from https://onlinelibrary.wiley.com/doi/abs/10.1111/puar.12751

Weber, M. (2013). The Protestant ethic and the spirit of capitalism. (Originally translated to English by Talcott Parsons c. 1930). Boston, MA: Routledge. 
Western, B. (2006). Punishment and inequality in America. New York, NY: Russell Sage Foundation.

White, M. D. (2000). Assessing the impact of administrative policy on use of deadly force by on-and off-duty police. Evaluation Review, 24(3), 295-318. Retrieved from https://journals.sagepub.com/doi/abs/10.1177/0193841X0002400303

Williams, Walter A. (1914). The Journalist's Creed. Retrieved from https://journalism.missouri.edu/wp-content/uploads/2017/03/journalists-creeddownload.pdf

Wilkins, V. M., \& Williams, B. N. (2008). Black or blue: Racial profiling and representative bureaucracy. Public Administration Review, 68(4), 654-664. Retrieved from https://onlinelibrary.wiley.com/doi/abs/10.1111/j.15406210.2008.00905.x

Wooldridge, J. M. (2013). Introductory econometrics: A modern approach ( $\left.5^{\text {th }} \mathrm{ed}\right)$. Scarborough, ON, Canada: Nelson Education.

Xiao, W. S., Fu, G., Quinn, P. C., Qin, J., Tanaka, J. W., Pascalis, O., \& Lee, K. (2015). Individuation training with other-race faces reduces preschoolers' implicit racial bias: A link between perceptual and social representation of faces in children. Developmental Science, 18(4), 655-663. Retrieved from https://onlinelibrary.wiley.com/doi/abs/10.1111/desc.12241 
Appendix A

STATE AND FEDERAL PRISON POPULATION, 1925-2011

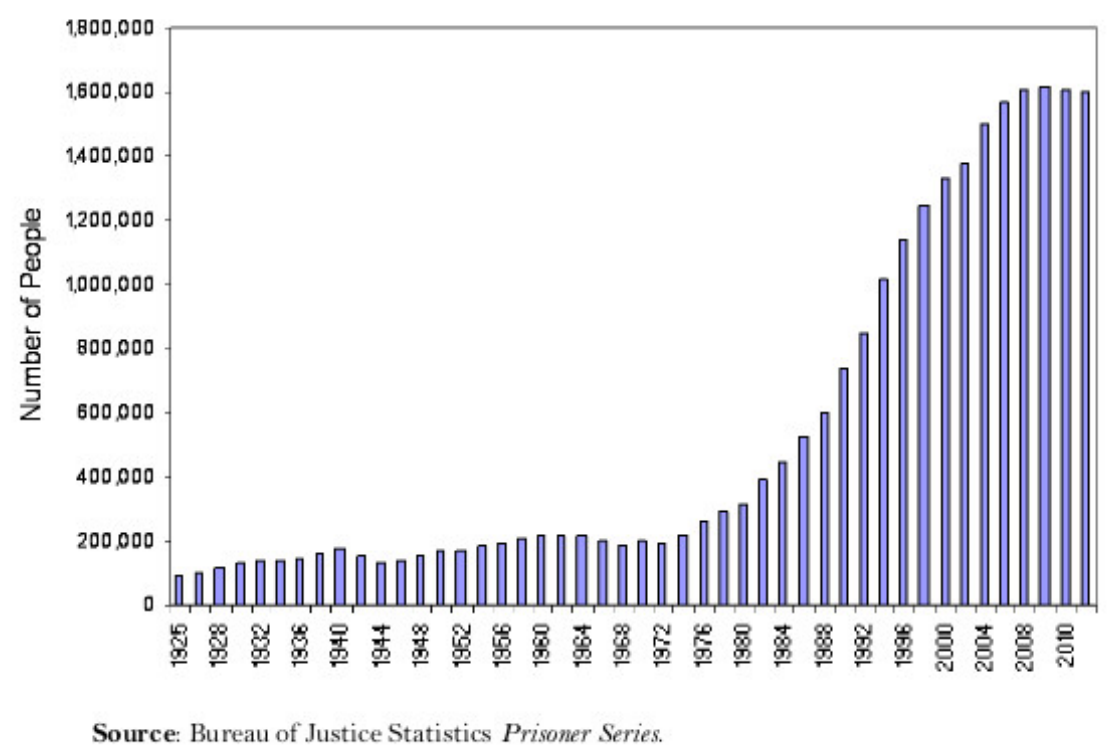




\section{Appendix B}

"The reasonableness of a particular use of force must be judged from the perspective of a reasonable officer on the scene, rather than with the 20/20 vision of hindsight. The calculus of reasonableness must embody allowance for the fact that police officers are often forced to make split-second judgments - in circumstances that are tense, uncertain and rapidly evolving - about the amount of force that is necessary in a particular situation. The test of reasonableness is not capable of precise definition or mechanical application" (Chief Justice William H. Rehnquist in Graham v. Connor, 1989). 


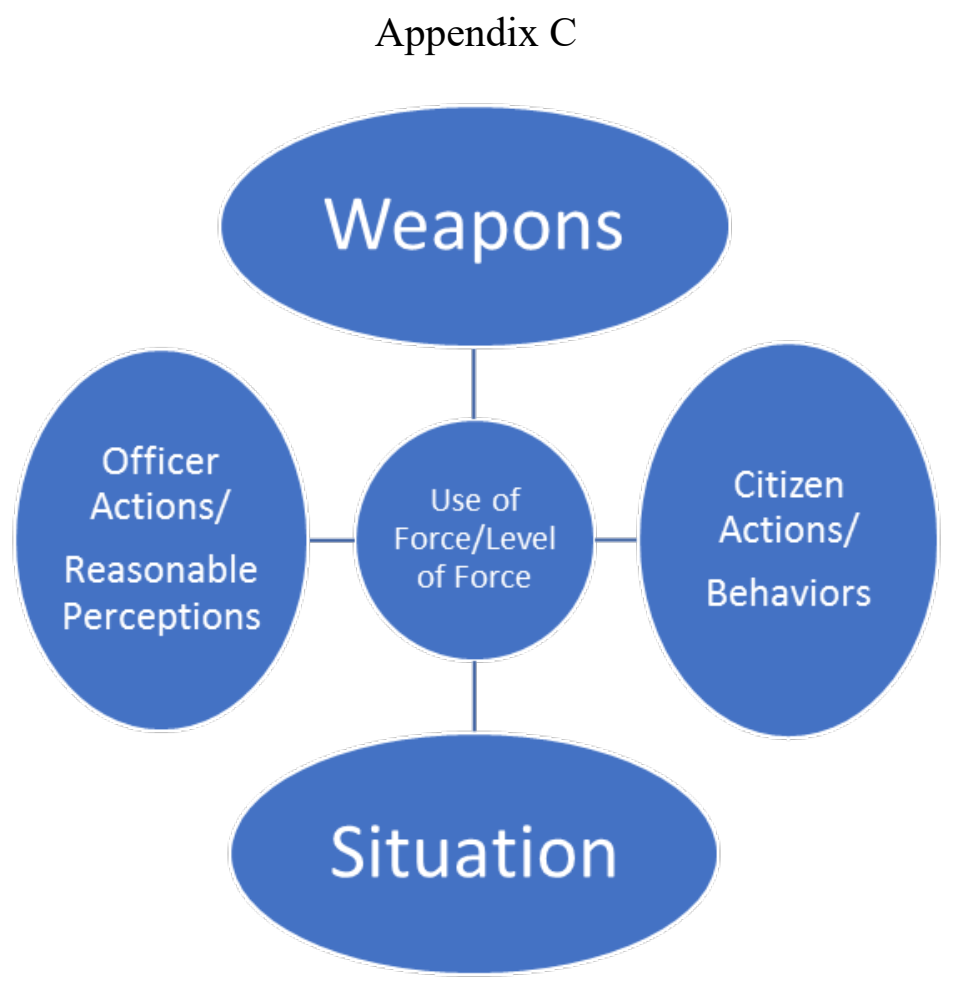

Appendix C. Situational perspective depicts the factors which should be considered when evaluating a law enforcement use of force or use of lethal force situation. Situational perspective depicts the relationship between law enforcement officers' actions and reasonable perceptions (Appendix D is a representation of officer perception and appropriate response recommendations), the presence of weapons, the context of the situation the officer and the citizen are involved in and the citizen's behaviors and actions both before and after the officer arrives on the scene. The Theoretical Model is an original concept from Michael Laughlin (2018) but takes into account information from the U.S. Supreme Court decisions on use of force and use of lethal force. [Copyright: Michael Laughlin, 2018]. 
Appendix D (National Use of Force Framework, 2016) Retrieved from:

https://www.ottawapolice.ca/en/news-and-community/Training-with-De-Escalation-

Component.aspx

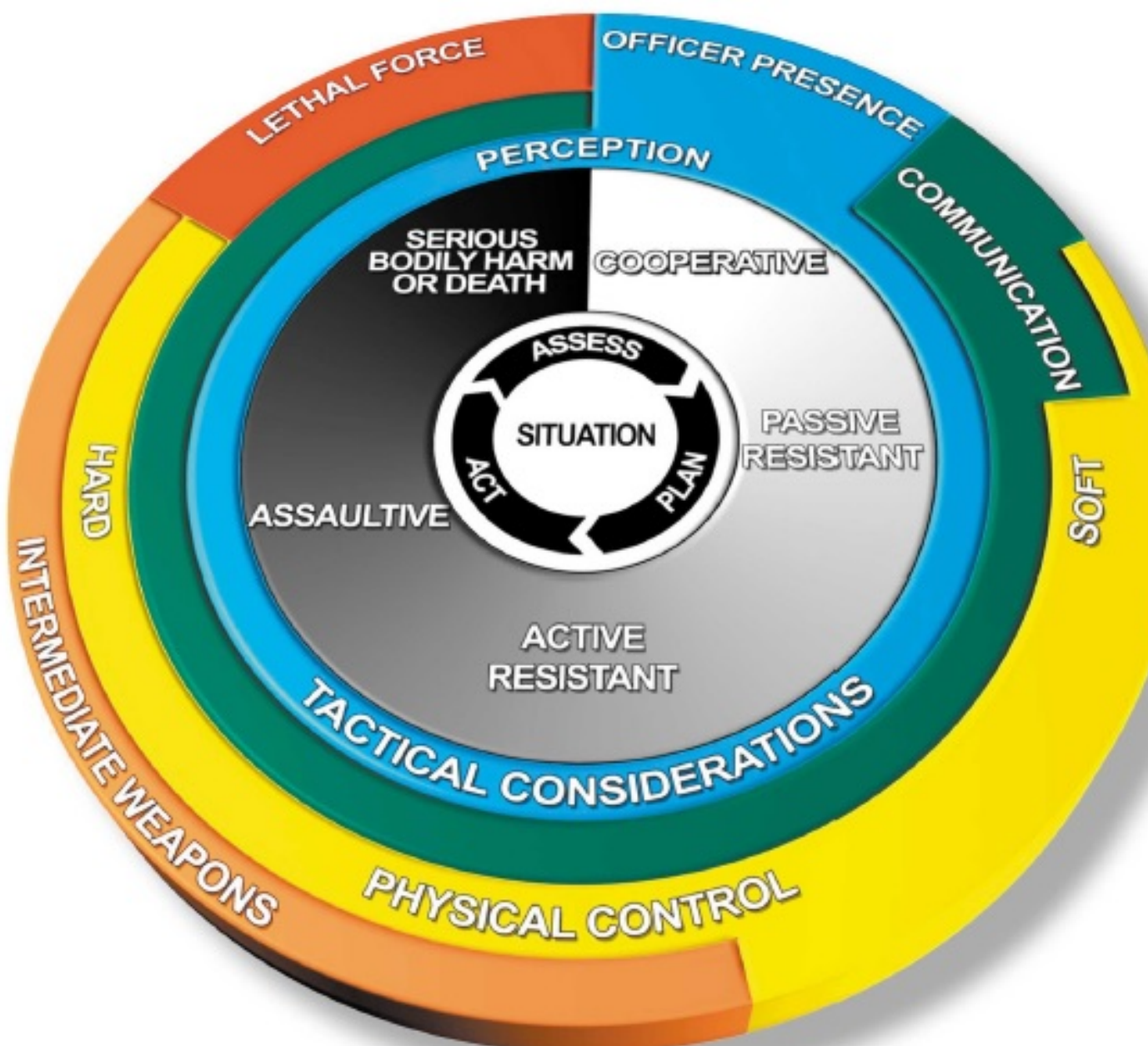


Appendix E (O.O.D.A. Loop (Boyd, 2018))

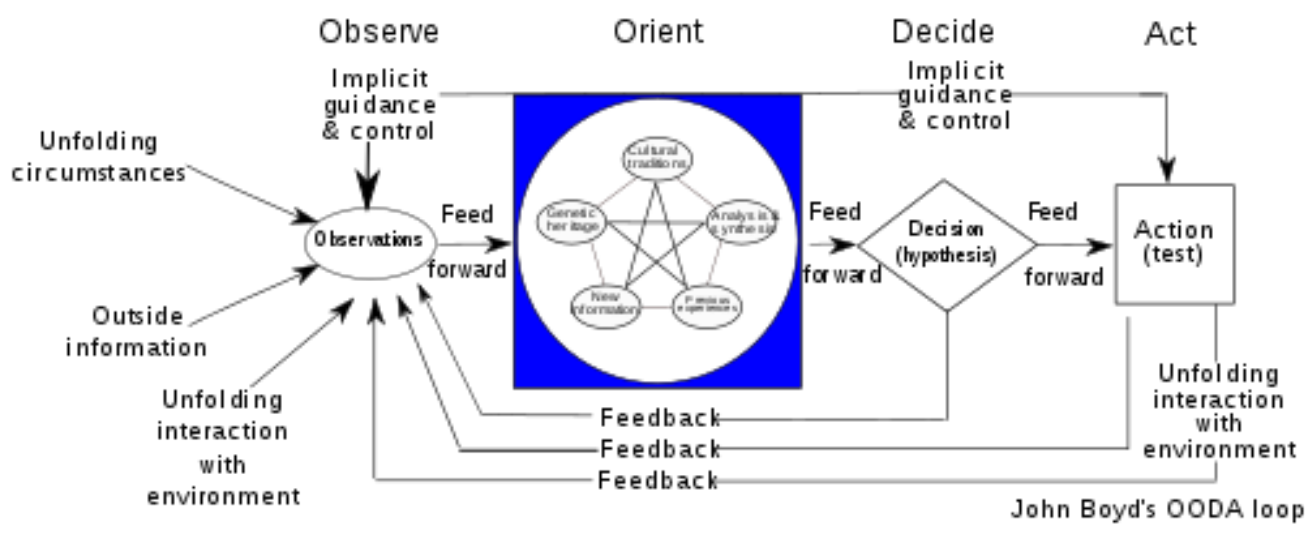


Appendix F ((Duhigg, 2014) Habit Loop)
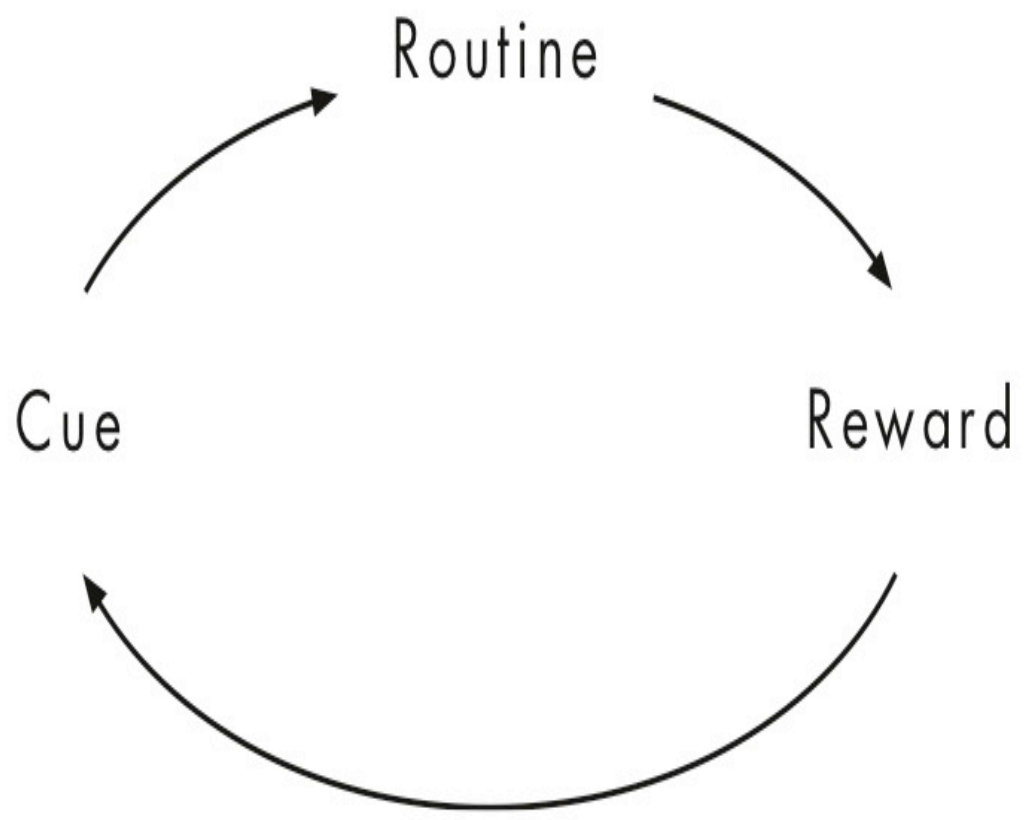
Michael Laughlin is interested in law enforcement, the criminal justice system, organizational analysis, public administration, ethical dilemmas, and ethical frameworks. Michael completed a B.A. in Philosophy and Religion at Greenville University in 1999 and a M.A. in Philosophy, with an emphasis in value theory and logic/philosophy of science, at the University of Missouri-St. Louis, in 2003. After graduating with his M.A., Michael was the supervisor of a G.E.D. program at a high school in Columbia, MO, and then worked as a police officer, detective, supervisor of a crime prevention unit, and officer-in-charge for a police department in Columbia, MO. While working for the police department, Michael helped organized trainings and presentations for co-workers and community members, and delivered over 200 presentations on varying topics during a two-year period. While working for the police department, Michael earned a M.P.A. at the Truman School of Public Affairs (University of Missouri-Columbia), with an emphasis in public administration in 2016 and began work on his PhD. Michael will graduate with a $\mathrm{PhD}$ in Public Affairs, with an emphasis in policing, upon the completion of this dissertation (December of 2019). 